\title{
WILEY-VCH
}

\section{Artificial Biosystems by Printing Biology}

\author{
Giuseppe Arrabito, ${ }^{1}$ Vittorio Ferrara, ${ }^{1,2}$ Aurelio Bonasera, ${ }^{1}$ Bruno Pignataro ${ }^{1} *$ \\ ${ }^{1}$ Dr. G. Arrabito, Mr. V. Ferrara, Dr. A. Bonasera, Prof. B. Pignataro \\ Department of Physics and Chemistry - Emilio Segrè, University of Palermo, viale delle \\ Scienze, blg. 17, Palermo, 90128, Italy. \\ E-mail: bruno.pignataro@unipa.it \\ ${ }^{2}$ Mr. Vittorio Ferrara \\ Department of Chemical Sciences, viale Andrea Doria, 6, University of Catania, Catania, \\ 95125, Italy
}

Keywords: artificial biosystems, aqueous compartments, life-like systems, molecular printing, Synthetic Biology

The continuous progress of printing technologies over the past 20 years has fueled the development of a wide plethora of applications in materials sciences, flexible electronics and biotechnologies. More recently, printing methodologies have started up to explore the world of Artificial Biology, offering new paradigms in the direct assembly of Artificial Biosystems (small condensates, compartments, networks, tissues and organs) by mimicking the result of the evolution of living systems and also by redesigning natural biological systems, taking inspiration from them. This recent progress is reported in terms of a new field here defined as Printing Biology, resulting from the intersection between the field of printing and the bottom up Synthetic Biology. Printing Biology explores new approaches for the reconfigurable assembly of designed life-like or life-inspired structures. This review presents this emerging field, highlighting its main features, i.e. printing methodologies (from $2 \mathrm{D}$ to $3 \mathrm{D}$ ), molecular ink properties, deposition mechanisms, and finally the applications and future challenges. Printing Biology is expected to show a growing impact on the development of biotechnology and lifeinspired fabrication. 


\section{WILEY-VCH}

\section{1. Introduction}

3 Printing technologies have been very important for the recent development of human mankind,

4 since from the invention of the printing press ( $15^{\text {th }}$ century), they allow producing and

5 distributing written texts among the masses. A fundamental milestone in this process was the

6 invention of lithography in 1796 by Alois Senefelder, that consisted in transferring images onto

7 paper by using lithographic limestone plate masks and inks. ${ }^{[1]}$ This approach was optimized

8 during the following centuries, permitting to pattern materials from polymer coated plates or,

9 by transferring the pattern onto flexible rubber blankets, as in the offset lithography. ${ }^{[2]}$ The

10 invention of soft lithography in 1993 marked another crucial step, since it defined the possibility

11 to use low-cost elastomeric stamps, allowing printing molecular inks onto large areas at high

12 resolution and low cost. ${ }^{[3]}$

13 Since the $21^{\text {th }}$ century, printing technologies gained a significant impact also in the context of

14 thin-film and plastic electronics by employing molecular inks onto flexible supports (such as

15 plastics), at low cost and low temperature in comparison to conventional silicon-based

16 electronics manufacturing. ${ }^{[4]}$ Molecular printing includes both $2 \mathrm{D}$ and $3 \mathrm{D}$ printing that can be

17 carried out according to contact and non-contact methodologies. ${ }^{[5]}$ In contrast to the non-

18 contact approaches (e.g., Inkjet Printing), the contact ones come in physical contact with the

19 substrate (e.g., Pin Printing, Microcontact Printing and Dip Pen Nanopatterning). In addition to

20 materials sciences, the development of printing methodologies has fueled also different bio-

21 related fields $\left(\right.$ genomics ${ }^{[6]}$ proteomics, ${ }^{[7]}$ biochips ${ }^{[8,9]}$ ) and more recently are intersecting the

22 field of Synthetic Biology by developing different artificial biosystems.

23 On this respect. Synthetic Biology originated from the $20^{\text {th }}$ century, with the studies on artificial

24 life assemblies made in the lab in the form of simple protocells. In particular, the term Synthetic

25 Biology was firstly employed by the Stéphane Leduc's publication of "Théorie physico- 


\section{WILEY-VCH}

1 chimique de la vie et générations spontanées" in 1910. ${ }^{[10]}$ In 1961, Jacob and Monod

2 investigated the cellular regulation by molecular networks from the lac operon in E. coli. ${ }^{[10]}$ In

3 1978, the term Synthetic Biology was used to describe the discovery of restriction enzymes. ${ }^{[11]}$

4 In 2010, the first bottom-up example of fabrication of a self-replicating synthetic bacterial cell

5 was demonstrated from DNA sequences of Mycoplasma myciodes delivered into a host

6 Mycoplasma capricolum cell ${ }^{[12]}$ and, as an example of a more recent breakthrough in this field,

7 Chin et al. realized a variant artificial form of E. coli in 2019. ${ }^{[13]}$ Thus, actually Synthetic

8 Biology is recognized as the emerging multidisciplinary field that employs engineering

9 approaches to build up artificial biosystems ${ }^{[14]}$ including biomimicking (life-like or life-

10 inspired) components and systems ${ }^{[15-17]}$. On this respect, Synthetic Biology employs two

11 different approaches, i.e. the so called top-down and bottom-up. ${ }^{[18]}$ The first refers to

12 experimental methods that derive from metabolic and genetic engineering for adding foreign

13 biomolecular elements or modules to living cells (typically DNA fragments or entire genes).

14 The bottom-up approach combines molecular or biomolecular building blocks in vitro to obtain

15 ordered and functional biosystems. The smallest artificial biosystems may be described by

16 nanoscopic condensates showing biological functions or membrane-free artificial

17 compartments. Typical examples include solid-supported dense DNA phases ${ }^{[19]}$ colloidal 18 systems from inorganic nanomaterials, ${ }^{[20]}$ clay-based systems, ${ }^{[21]}$ coacervates or soft colloidal 19 microgels capturing macromolecular systems (DNA, ${ }^{[22,23]}$ RNA, ${ }^{[24]}$ peptides, ${ }^{[25]}$ proteins $^{[26]}$ ).

20 These assemblies permit also to shed light on the role of the prebiotic organization of key

21 structural building blocks before the presence of membrane-separated systems; ${ }^{[27]}$ in particular,

22 it has been crucial the role of clays and layered double hydroxides ${ }^{[28-30]}$ in the molecular origin

23 of life on Earth, and also on the role of liquid/liquid phase separation in the complex

24 organization via the condensation of the molecular machineries inside eukaryotic cells leading

25 to membranelless organelles. ${ }^{[31-33]}$ 


\section{WILEY-VCH}

1 By increasing complexity, bottom-up synthetic biology develops artificial compartments

2 enclosed by nanoscopic membranes including assemblies enclosed by lipidic or polymeric

3 membranes (liposomes $^{[34]}$ and polymersomes ${ }^{[35]}$, respectively), oil-in-water ${ }^{[36-39]}$ and water-in-

4 oil $^{[40]}$ emulsions stabilized by amphiphilic membranes, inorganic nanoparticles

5 (colloidosomes $^{[41,42]}$ ) or protein-polymer capsules (proteinosomes ${ }^{[43,44]}$ ). The presence of a

6 permeable membrane may result in inter-compartments communication. ${ }^{[45]}$ Finally, bottom-up

$7 \quad$ Synthetic Biology provided insights in tissue engineering ${ }^{[46]}$ including 3D-patterned artificial networks responsive to environmental stimuli. ${ }^{[47]}$

9 Interestingly, the engineering of the above small condensates and artificial compartments may

10 be important also for understanding the abiogenesis processes (origin of life), the living systems

11 being believed to have evolved from primitive sub-micron sized protocells ${ }^{[48-50]}$ Indeed, as a result of this evolution, eukaryotic living cells experience volumes typically of picoliters ( $\mathrm{pL}$; tens of microns in diameters) and are characterized by a highly crowded molecular environment

14 within a confined space. ${ }^{[19]}$ This is possible since cellular systems have further localized the reaction components into femtoliter (fL; microns) scale compartments like membrane-bound organelles, as the nucleus storing the genetic instruction and the Golgi apparatus or the endoplasmic reticulum for protein trafficking. An important role into the cells is also played by membraneless organelles - i.e. protein and nucleic acid condensates rapidly assemble/disassemble in response to stimuli- such as the nucleoli (RNA-protein granules), the

Cajal bodies, $\mathrm{P}$ granules, ${ }^{[33,51]}{ }^{[52-54]}$ In some cases, biomolecular condensates can undergo

21 functional liquid-to-solid transitions as for the microtubule-mediated chromosome 22 segregation. ${ }^{[55]}$ Further downsizing to attoliters (aL; hundreds of nanometers) leads to the 23 production of systems devoted to cellular communication (synaptic vesicles, exosomes and 24 other ones). ${ }^{[56]}$ 


\section{WILEY-VCH}

1 By considering the fabrication of the above artificial biosystems, the printing approaches

experience their capability to generate biological complex assemblies over an extraordinary wide size range (from primitive organelles to tissues and organs) by software-defined programs. Thus, these approaches are very innovative and convenient with respect to those others currently reported in literature. On this respect, patterning approaches based on the microelectronics manufacturing techniques or the Electron Beam Lithography can operate only on solid substrates, are expensive and time consuming. Moreover, among the most conventional approaches the direct water-in-oil emulsification lacks in programmability and size control, ${ }^{[57]}$ DNA nanotechnology suffers from complex implementation and high cost, ${ }^{[58]}$ and microfluidic approaches $^{[59,60]}$ (T-junction, flow focusing and coflowing $)^{[61]}$ are not programmable and are limited in controlling droplet size and composition. ${ }^{[62]}$ As to microfluidics, Gañán-Calvo and collaborators have shown the possibility to produce attoliter droplets, by employing advanced platforms based on electrostatic or hydrodynamic flow focusing. ${ }^{[59]}$

In this scenario, the employment of printing approaches for the development of the bottomup Synthetic Biology is here referred to the new field of Printing Biology, defined as this research segment dealing with the direct assembly of life-like and life-inspired artificial biosystems from the nano- to the macro-scales by the additive delivery of molecular inks onto solids or into liquids. Differently from the well-known field of Bioprinting which leverages computer-aided printing processes for patterning and assembling living cells and other biomaterials with a predetermined $2 \mathrm{D}$ or $3 \mathrm{D}$ organization to realize cellularised structures, aiming to recapitulate natural tissue physiology for applications in cell biology, pharmacokinetics and regenerative medicine, ${ }^{[63]}$ Printing Biology aims to synthetize even new forms of life-like or life-inspired systems from the nano to the macro-scale which may show cutting-edge properties favoring the development of emerging applications in Biotechnology. In addition, Printing Biology employs inks of both natural and artificial origin, such as DNA, 


\section{WILEY-VCH}

1 proteins, lipids, carbohydrates and synthetic polymers, leading to the bottom-up assembling of nano- to macro-scale artificial biological systems.

This review highlights just the key features of Printing Biology specifically referring to the

engineering of those artificial biosystems inspired from the origin and the evolution of living systems by programming compartment sizes, compositions, physicochemical properties and, eventually, the collective behavior of assembles mimicking biological networks, tissues and organs (Figure 1).

In order to guide the reader, this Review is divided into different sections. After the introduction, the section 2 deals with the fundamentals of the physics of droplet formation and dispensing onto solid and liquid surfaces, along with the details of the most relevant molecular inks used in Printing Biology. In section 3, we describe the inks based on the most relevant molecular building blocks (nucleic acids, proteins, phospholipids, carbohydrates). Then, section 4 and 5 refers to the Printing Biology fabricated biosystems on solids and into liquids. Finally, in the conclusions the challenges and perspectives of the fields are provided.

\section{Printing Molecular Inks}

\subsection{Droplet formation: defining the operative parameters}

Since many printing approaches are involved in the fabrication of artificial biosystems, it is necessary to understand the physicochemical principles that regulate the droplet formation processes and the compatibility with solutions containing biomolecules, hereafter defined "molecular inks" and the receiving surface onto which the droplets are printed, considering its physical state (solid or liquid).

In general, the molecular ink droplet can be conveniently described by three dimensionless numbers, the Weber number We, the Ohnesorge number $O h$ and the Reynolds number $R e$, defined as follows: 


$$
W e=\left(\rho D V^{2}\right) / \sigma
$$

$$
O h=\mu /\left(\rho \sigma D^{1 / 2}\right)
$$

$$
R e=W e^{1 / 2} / O h
$$

4 where $\rho$ is the density $\left(\mathrm{kg} / \mathrm{m}^{3}\right)$ of the fluid, $D$ and $V$ are respectively, the diameter $(\mathrm{m})$ and the velocity $(\mathrm{m} / \mathrm{s})$ of the droplet, $\mu$ is the dynamic viscosity $(\mathrm{mPa} \cdot \mathrm{s})$ and $\sigma$ is the fluids surface tension $(\mathrm{mN} / \mathrm{m})$. The We number is defined as the ratio between the inertial and the surface tension forces, the $O h$ number relates the viscous force to the inertial and the surface tension

8 forces, and finally the $R e$ number is the ratio of inertial forces to viscous forces. These numbers are employed to quantify the droplets formation conditions and the droplet impact process onto the substrate of interest (see below).

11 As aforementioned, the printing technologies can be divided in contact and non-contact approaches, by considering if the printing device comes in physical contact with the receiving substrate (see Figure 2). The most relevant contact printing approaches relevant for Printing 14 Biology are those derived from Pin Printing, ${ }^{[64]}$ Microcontact Printing, ${ }^{[65]}$ Dip Pen 15 Nanolithography, ${ }^{[66]}$ Polymer Pens, ${ }^{[67]}$ Hard-Tip Soft-Spring Lithography; ${ }^{[68]}$ on the other hand, the non-contact approaches of interest for Printing Biology can be considered the following: Inkjet, ${ }^{[69]}$ Electrohydrodynamic ${ }^{[70]}$ and Pyro-Electrohydrodynamic Printing. ${ }^{[71]} 3 \mathrm{D}$ and $4 \mathrm{D}$ Printing techniques ${ }^{[72,73]}$ embrace a range of different specific approaches, spanning between contact (e.g. extrusion/fused deposition) and non-contact methods (e.g. jetting and inkjet printing), thereby it is fair to present the two separate ensembles of contact techniques and noncontact ones.

As far the contact approaches are concerned, the printing device can be considered not quite different from a pen. The molecular ink can be deposited from the pen to the receiving surface by molecular diffusion or by flowing to the surface. The first example of this strategy has been reported for high-resolution nanoscale patterning by Dip Pen Nanolithography (DPN). In 


\section{WILEY-VCH}

1 particular, for the DPN printing process it is fundamental to distinguish the printed fluids in diffusive inks and liquid inks. The former ones consist in molecules physically adsorbed on the tip surface, while the latter are actual liquid solutions containing the material to pattern. The two different kinds of inks are characterized by different mechanisms of material transport from the tip onto to the support. Concerning the diffusive inks deposition (Figure 3A), it can be described by a numerical/analytical model, which relies on a two-dimensional diffusion from a source (i.e. the tip). ${ }^{[74]}$ The model assumes that the molecular flux from the tip to the receiving surface creates a concentration gradient around the tip, triggering further molecules diffusion over the region already occupied by other ink molecules. The transport mechanism takes advantage of the water meniscus spontaneously condensed in between the tip and the receiving surface, resulting in a liquid bridge for the diffusion of molecules towards the solid surface. The lateral size of the deposited feature is at the nanoscale resolution. This analytical model enables to describe the radial deposition from the tip as a function of tip-surface dwell time, following this simple expression:

$$
R(t)^{2}=4 D t \cdot \ln \left[\frac{n}{4 D \pi \rho}\right]
$$

where $t$ (s) is the dwell time contact, $\rho$ the monolayer density $(1 / \AA), D\left(\mu \mathrm{m}^{2} / \mathrm{s}\right)$ is the coefficient of diffusion, $n(1 / \mathrm{s})$ is the number of ink molecules deposited per unit time. This model highlights the highly diffusional nature of self-assembly diffusion process which make this process dependent on the molecular size and the characteristics of the receiving surface.

The second case comprises the liquid inks, much more commonly used, that are kept in the liquid state over all the printing process (Figure 3B). The liquid ink deposition by DPN relies on a different mechanism with respect to the diffusive ones, because of the presence of solvent molecules in the droplet. Accordingly, the solvent can be described as a molecular carrier that allows molecules to be deposited to the receiving surface. In particular, the droplet deposition 
1 is triggered by the Laplace pressure gradient between the ink-tip $\left(\Delta \mathrm{P}_{\text {tip }}\right)$ and the ink-air $\left(\Delta \mathrm{P}_{\mathrm{m}}\right)$

2 menisci. The Laplace pressure is defined as the pressure difference the curved surface of a

3 liquid at the boundary between air and liquid and can be expressed by the Young-Laplace

4 equation:

$$
\Delta \mathrm{P}=\sigma\left(\frac{1}{R_{1}}+\frac{1}{R_{2}}\right)
$$

6 where $R_{1}$ and $R_{2}$ are the major curvature radii and $\sigma$ is the surface tension. In order to deposit 7 the droplet to the surface, the Laplace pressure at the tip/meniscus interface has to be larger 8 than that at the meniscus/substrate one. ${ }^{[75-77]}$ The difference between the Laplace pressures 9 arises from different curvatures of the liquid/air interface at the tip/meniscus interface as compared with that at the meniscus/substrate one. The size growth of the droplet continues until

11 a saturation is observed due to the variation with time of the droplet surface curvature at the meniscus/substrate and tip/meniscus. As reported by models, ${ }^{[78,79]}$ the ink viscosity depletes the driving deposition energy by the Laplace pressure gradient, slowing down the growth rate. When the ink-loaded pen approaches the surface, a liquid meniscus is formed, composed of the liquid ink itself in addition to water molecules from the atmosphere. When the tip is pulled away from the surface, it is subjected to an attractive capillary force, which goes to zero at a certain distance at which the water meniscus breaks, resulting in a droplet whose volume is usually at the micron scale. In the case of liquid ink deposition by soft polymeric based pens, such as in Microcontact Printing ( $\mu \mathrm{CP}$ ) or in Polymer Pen Lithography (PPL), it is again the difference between Laplace pressures at the tip and the surface that main factor that drives the 21 deposition on the receiving surface (Figure 3C). Along with this, the force exerted by the pens on the surface further permits to increase the lateral size of the deposited droplet up to the micron scale. ${ }^{[67]}$ 


\section{WILEY-VCH}

1 As far as the non-contact approaches are concerned, it is known that the droplet size is, in

2 principle, physically constrained by the size of the orifice/channel from which the droplet is

3 generated $^{[80]}$ and from the abovementioned physicochemical properties of the ink, especially

4 viscosity and surface tension. The possibility to print biomolecules-rich aqueous droplets at the

5 living cell scale (pL-scale) or even at the sub-cellular scale (fL-scale) becomes a crucial

6 parameter that can favorably permit the application of these techniques in Printing Biology.

7 Note that several reports have demonstrated the possibility to tune droplet formation dynamics

8 by using a set of different boundary conditions that involve hydrodynamic droplet dispensing

9 under electrical field guiding, ${ }^{[81]}$ droplets production within liquid environments, ${ }^{[82]}$ satellite

droplets printing, ${ }^{[83]}$ breaking up in a double-orifice system, ${ }^{[84]}$ reducing the impulse duration

11 time. ${ }^{[85]}$ Other approaches that can reach sub-cellular scale resolution include

12 electrohydrodynamic, ${ }^{[70]}$ or pyroelectrodynamic dispensing. ${ }^{[71]}$ One hurdle of these approaches

13 is that they are associated with significant shear/compression stresses that can ultimately lead

14 to the alteration of the biomolecular structures and functions.

In general, the rheological characteristics of molecular inks are usually tuned by the presence

16 of biocompatible additives, such as viscous high-boiling point co-solvents. Glycerol is among

17 the most used co-solvents in ink formulations, due to its capability to reduce potential aggregation phenomena in aqueous solutions, through its stabilizing effect on the biomolecule structures. ${ }^{[86-88]}$ For instance, the addition of glycerol (generally $10-30 \% \mathrm{v} / \mathrm{v}$ ) to a protein-rich

molecular inks generally permits to obtain high spot definition and resolution. ${ }^{[89]}$ Spots printed

21 without glycerol showed no regular shape and dimension along with misalignment and

22 numerous spread small features, due to the formation of satellites during the droplet ejection. ${ }^{\text {[8] }}$

23 Glycerol helps in raising viscosity in order to increase the stability of the liquid column ejected

24 from the nozzle finally avoiding the capillary waves that finally lead to droplet multiple 25 breakups. 


\section{WILEY-VCH}

1 In non-contact techniques, the produced droplets have to be ejected from the orifice where the

2 formation occurred, in order to be dispensed on the solid substrate. That implies the droplet

3 impact on the receiving surface. The scenario involved in the droplet impact is quite complex

4 and will be here briefly described according to the dynamic parameters characterizing the

5 system, that are dependent on the liquid droplet features along with the physical status of the

6 receiving surface (solid or liquid).

\subsubsection{Impact on solid surfaces}

In general, the impact of a micron-sized droplet onto a solid support can be described by a complex set of events that take into account bouncing, spreading and splashing. ${ }^{[90-92]}$ In the initial impact phase, the droplet hits the substrate along with air bubbles that can be blocked inside the droplet at the impact moment. In second phase, there is a rapid radial fluid flow in which a blob of fluid is formed near the contact line. In the third phase, the fluid comes to rest in a process of rebound followed by inertial oscillations, damped by viscous dissipation. A high amount of the initial energy in the droplet before spreading is dissipated by viscosity through the oscillations. After the fluid has reached its maximum radial extent, oscillations set in after a rebound in which the droplet remains intact as one volume. By considering an energy balance based on surface energy, kinetic energy $\frac{\mathbf{1}}{2} m U^{2}$ ( $m$ droplet mass, $U$ speed) and the viscous dissipation when impacting on the solid surface, ${ }^{[92]}$ it is also possible to estimate the size of the final radius by:

$$
\frac{2}{3} \pi R_{0}^{3} \rho U^{2}+4 \pi R_{0}^{2} \sigma_{l v}=\pi R_{f}^{2}\left(f_{s} \sigma_{l v}+\sigma_{l s}-\sigma_{s v}\right)+\Delta E_{u}
$$

where $R_{0}$ is the radius of the droplet before impact; $R_{f}$ is the final radius after impact has completed; $f s$ is the ratio of the fluid-vapor surface and the fluid-solid surface; $\Delta E_{u}$ is the dissipated energy in the impact by viscosity; $\sigma_{l v}, \sigma_{l s}$ and $\sigma_{s v}$ are the surface energies of the interfaces between the liquid droplet and the vapor, the liquid droplet and the solid surface and 


\section{WILEY-VCH}

1 the solid surface and the vapor, respectively. The interplay between these factors is reported in

2 Figure 3D. On this respect, it is important to discuss the role played by the droplet velocity.

3 When the droplet has low speed $(W e<1)$, the droplet deforms as a whole and flattens somewhat,

4 already during the first stage of impact - this behavior is explained by considering capillary

5 force as the important driving mechanism for spreading. In this case, the time scales for

6 capillary-driven spreading and deformation of the whole droplet are the same. The final radius

7 becomes larger for experiments with a larger $W e$ and is a function of the surface contact angle.

8 At high droplet velocities, i.e. at high $W e(>10)$, in the first stage of impact the upper part of

9 the droplet remains undisturbed. The time scale for spreading is significantly smaller than the

time scale for deformation of the droplet by surface tension, permitting the droplet to move

11 beyond its equilibrium advancing contact angle.

\section{2 \\ 2.2.2 Impact on liquid surfaces}

13 A more complex dynamics occurs for the impact of liquid droplets onto a liquid film; an excellent dealing with the involved physics is the one of Anderson. ${ }^{[93]}$ An important distinction has to be made by considering if the printed droplet is miscible or immiscible with the receiving liquid phase. In the case of miscible phases, the droplet impact strictly depends on its velocity. At low impact velocities $(0.01-1 \mathrm{~m} / \mathrm{s})$, no rim is obtained, and the droplet is simply deposited on the liquid film. At velocities of the order of $1-30 \mathrm{~m} / \mathrm{s}$, the motion initiated by the drop is virtually unconstrained and capable of pushing apart a significant liquid mass under the impact site. As a result, the droplet takes the shape of a liquid layer with a visible outer rim. At higher impact velocities (conditions of droplet splashing), the liquid layer takes the shape of crowns consisting of a thin liquid sheet with an unstable free rim at the top, from which numerous small secondary droplets are ejected. After the impact, the mixing between the droplet and the liquid surface occurs. This phenomenology depends upon the molecular diffusion in liquids and then, assuming a Brownian motion $\left(x^{2}=2 D \tau\right.$, where $x$ is the traveled distance, $D$ is the coefficient of diffusion, and is $\tau$ is the time), it depends on the droplet volume. ${ }^{[94]}$ 


\section{WILEY-VCH}

1 In the case of immiscible phases, which is greatly relevant for Printing Biology applications,

especially in compartments fabrication, the resulting fluid dynamics is definitely more complex, considering the possible spreading factor effects of the liquid droplet upon the impact liquid surface. The impact dynamics is governed by the spreading factor $S$ :

$$
S=\sigma_{\text {liquid surface-vapor }}-\left(\sigma_{\text {liquid ink-vapor }}+\sigma_{\text {liquid ink-liquid surface }}\right)
$$

In general, this factor is described as the resulting surfaces energy difference between the liquid surface-vapor ( $\left.\sigma_{\text {liquid surface-vapor }}\right)$, and the sum of liquid ink-vapor surface energy ( $\left.\sigma_{\text {liquid ink-vapor }}\right)$

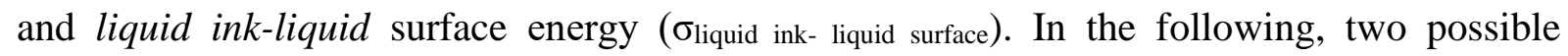
scenarios relevant for Printing Biology will be discussed. The first (reported in Figure 3E) consists in an aqueous ink impacting on an immiscible and lower density hydrophobic liquid $\left(\rho_{\mathrm{w}}>\rho_{\mathrm{o}}\right)$. The second one (reported in Figure 3F) consists in the impact of a hydrophobic ink droplet on an immiscible lower density aqueous liquid $\left(\rho_{\mathrm{o}},>\rho_{\mathrm{w}}\right)$. In the first case, the spreading factor can be expressed as $S=\sigma_{\mathrm{ov}}-\left(\sigma_{\mathrm{wv}}+\sigma_{\mathrm{ow}}\right)$, where $\sigma_{\mathrm{ov}}, \sigma_{\mathrm{wv}}, \sigma_{\mathrm{ow}}$ represent the oil-vapor, water-vapor and oil-water surface energies, respectively. This value is typically negative given the generally low values of $\sigma_{\mathrm{ov}}$ and the high values of the $\sigma_{\mathrm{wv}}$ and $\sigma_{\mathrm{ow}}$, resulting in a low tendency for the droplet to spread. The outcome is the immersion in the case the aqueous droplet ink has a sufficient velocity ( $>1 \mathrm{~m} / \mathrm{s}$ ) and a higher density with respect to the hydrophobic phase. ${ }^{[95]}$

Conversely, the second scenario, expressed as $S=\sigma_{\mathrm{wv}}-\left(\sigma_{\mathrm{o}^{\prime} \mathrm{v}}+\sigma_{\mathrm{o}^{\prime} \mathrm{w}}\right)$, is characterized by a positive spreading factor, since the $\sigma_{\mathrm{wv}}$ is significantly higher than $\sigma_{\mathrm{o}}{ }_{\mathrm{v}}$ and $\sigma_{\mathrm{o}}{ }^{\prime} \mathrm{w}$. This results in a driving force allowing the spread of the hydrophobic droplet on the aqueous droplet (see Figure 3F). The resulting film can be subjected to further Rayleigh-Plateau instabilities leading to fragmentation and immersion of smaller oil droplets due to the higher density of the oil droplet with respect to the aqueous phase. ${ }^{[96]}$

\section{Molecular Building Blocks for Printing Artificial Biosystems}




\section{WILEY-VCH}

1 In the context of Printing Biology, nucleic acids, proteins, phospholipids and carbohydrates

2 constitute the fundamental blocks to build-up biological modules. In addition to them, water

3 immiscible molecular systems (hydrophobic oils) and synthetic polymers are useful for

4 recreating artificial membraneless biosystems or building up artificial systems that can emulate

5 complex life-like behavior.

\section{$6 \quad 3.1$ Nucleic Acids}

$7 \quad$ Nucleic acids are the essential biopolymers for the biological systems. They include DNA 8 (deoxyribonucleic acid) and RNA (ribonucleic acid). The structure of DNA is constituted by 9 linear polymeric chains of nucleotides (adenine, cytosine, guanine, and thymine). Inside cells, DNA exist as a pair of strands that are held together by hydrogen bonding between 11 complementary pairing bases (adenine to thymine and guanine to cytosine), thus forming a right-handed double helix structure. ${ }^{[97]}$ RNA shows an analogous structure, except for the presence of uracil instead of thymine and is commonly found as single strand in living systems. The peculiar features for DNA and RNA reflect the different roles they assumed during the evolution of biological systems. Whereas DNA has been selected as a for genetic information storage, RNA is used for transporting the genetic information outside the cell nucleus, in the form of messenger RNA and to take part to the biochemical pathways involved in the gene expression. According to some theories about the origin of life, RNA molecules are thought to both store information for simpler biological systems, ${ }^{[98]}$ and act as a catalyst (for instance the ribosome is composed primarily of RNA). ${ }^{[99]-[100]}$

On the printing point of view, DNA is among the most suitable molecular systems for building up artificial nano- to microstructures featuring complexity and programmability, based upon the specific Watson-Crick base pairings, leading to the definition of the field of DNA nanotechnology. ${ }^{[97]}$ This was invented by Nadrian Seeman, as a method to order protein molecules in a crystalline lattice and later on evolved with the concepts of DNA tiles and the breakthrough of DNA origami by Rothemund, ${ }^{[101]}$ finally permitting to expand this technology 


\section{WILEY-VCH}

1 to complex nano- to microstructures with tailored geometry, possibility to drive nanodevices and engineering artificial DNA-based machines (such as bioinspired molecular computing and robots). ${ }^{[102]}$ Although the initial stages of DNA nanotechnology studies took place in aqueous solution, current research efforts have started to shift to solid surfaces for direct integration into devices and biointerfaces. However, the hurdle for applications is the high cost of DNA and the high error rate of self-assembly. This can be solved by developing large-scale, high-yield, and scalable synthetic strategies, which can leverage the handling of DNA synthesis by highthroughput processes by liquid dispensing the DNA-based inks. Despite of higher chemical instability of RNA with respect to DNA, some printing setups have been optimized to deposit RNA sequences. In particular, by means of microcontact printing, microarrays of RNA have been obtained by printing RNA oligosequences as polyplexes with polycationic polymers, for example poly(amidoamide) (PAMAM) dendrimers. ${ }^{[103]}$ A microintaglio printing method for RNA arraying has been optimized, by exploiting the complementarity of the DNA probes with the RNA sequences. ${ }^{[104]}$ Finally, more complex structures of RNA, in particular RNA aptamers, can be deposited on solid supports by inkjet printing, without any loss of functionality. ${ }^{[105]}$ However, the lower chemical stability of RNA oligonucleotides with respect to DNA, and the possibility to use equivalent complementary DNA (cDNA) sequences has limited the use of RNA in printing.

\subsection{Proteins}

Differently from nucleic acids, proteins are the biomolecules employed in natural systems to accomplish a plethora of biological functions, such as catalysis, biorecognition, molecular transport, and other ones. From the structural point of view, proteins are polymers of amino acids covalently bound through peptide bonds. The peptide chain intramolecular interactions and the interactions with the water molecules and ions in the surrounding medium induce the peptide chains rearrangement in the space leading to secondary and tertiary protein structures, that represent the proper protein folding. Many computational tools can indeed predict the 


\section{WILEY-VCH}

1 protein structure from the amino acid sequence. ${ }^{[106]}$ Interestingly, intrinsically disordered

2 proteins are able to form mimics of membraneless organelles via liquid-liquid phase separation,

3 as shown by model studies carried out with elastin-like polypeptides in a microfluidic-based

4 cytomimetic medium. ${ }^{[107]}$ Artificial protein-based nanostructures can be employed for different

5 applications ranging from drug delivery, scaffolds, biosensors, etc. ${ }^{[108]}$ Protein-based

6 nanostructures can be produced by top down approaches involving bacterial protein

7 microcompartments, engineering these structures to allow labeling of functional molecules and

8 particles or to tune their geometry. The alternative approaches based on bottom-up fabrication

9 employs non-covalent ${ }^{[109]}$ or quite recently also covalent ${ }^{[110]}$ protein-protein interactions, to assemble complex nanostructures which can be used as soft scaffolds for nanomaterials, multi-

11 step enzymatic reactions systems and nanocontainers. Notably, protein molecules are more 12 prone to degradation, and suffer from mechanical stresses during printing, ${ }^{[111]}$ which make it more challenging with respect to DNA processing into printed devices.

\section{$14 \quad 3.3$ Phospholipids and amphiphilic polymers}

Phospholipids represent a paradigmatic class of biomolecules usable for building up synthetic biosystems, since they represent the major component of all the cellular membranes. Generally, the phospholipids structures consist of two hydrophobic fatty acid tails and one hydrophilic head, resulting in well-known amphiphilic characteristic, permitting them to form lipid bilayers. Among them, a remarkable example of phospholipid-based systems is constituted by substratesupported phospholipid bilayers (SPBs), a versatile model of the biological membrane at the

21 solid surfaces. One key feature of SPBs is the possibility to generate micropatterned membranes, allowing for the creation of ordered microarrays that can find applications in drug screening, studies of molecular interactions and solid-supported biointerfaces under physicochemical conditions that mimic those of the native biological membrane. ${ }^{[112]}$

The most common vesicle system in life sciences is based on these biomolecules, namely liposomes, widely employed as drug carriers, cell membrane model systems and organelle 


\section{WILEY-VCH}

1 mimicking compartments. ${ }^{[13]}$ Liposomes can be prepared by the conventional film-hydration

2 method, which consists in the deposition of a phospholipid layer, followed by a film hydration

3 step ${ }^{[114]}$ or by more sophisticated microfluidic approaches. ${ }^{[115]}$ An artificial version of these

4 systems, defined as polymersomes, is constituted by amphiphilic polymers, which are able to

5 self-assemble into artificial vesicles enclosing an aqueous cavity. ${ }^{[116]}$ With respect to liposomes,

6 polymersomes are endowed with higher mechanical resistance and possibility to engineer their

7 membrane permeability, making them suitable candidates for artificial biosystems. ${ }^{[12]}$

8 Additionally, these systems can also be conjugated with biomolecules, as for example proteins,

9 with straightforward applications in all biological fields. ${ }^{[43]}$ In addition to amphiphilic

polymers, artificial biosystems can also be produced by employing functional polymeric

11 materials that can be 3D printed to produce smart interfaces with living cells or give rise to

12 water immiscible systems that can be used as membranelles organelles (see Introduction for 13 their definition) or synthetic capsules.

\section{$14 \quad 3.4$ Carbohydrates}

The most abundant biomolecules in Nature belong to the carbohydrates category, constituted by a wide variety of monosaccharides, and their relative oligomers and polymers, obtained by

17 linking saccharide units through glycosidic bonds. Carbohydrates are ubiquitously found in living organisms, being involved in several essential processes, such as energy production and storage, structural functions, as well as extracellular mechanisms of biorecognition. ${ }^{[117]}$ The intriguing features of carbohydrates have led to a remarkable interest in the use of this class of

21 biomolecules for printing. Focusing on polysaccharides, they have been used both in 2D and 3D printing processes in order to fabricate solid patterns and scaffolds for cell adhesion. To this aim, positively charged polysaccharides, e.g. chitosan, have emerged due to the favorable electrostatic interactions with most of eukaryotic cells, leading to ideal adhesion platforms. ${ }^{[118,119]} 2 \mathrm{D}$ inkjet-printed chitosan patterns have also been employed as structural layer for the fabrication of single-cell arrays. ${ }^{[120]} 3 \mathrm{D}$ printed chitosan scaffolds have also been 


\section{WILEY-VCH}

1 loaded with bioactive molecules, to develop an artificial printed architecture for cell adhesion

2 scaffold and surface-mediated drug delivery system. ${ }^{[121]}$ Also, negatively charged

3 polysaccharides have been exploited as structural matrix for artificial tissue constructs, as

4 reported for gels of alginate. ${ }^{[122]}$ On the other hand, some strongly hydrophilic non-charged

5 polysaccharides, e.g. agarose, have been used as biocompatible cell repellent coating, on which

6 bioadhesive materials can be printed to obtain well-resolved cell patterns. ${ }^{[123,124]}$ Furthermore,

7 polysaccharides are useful additives for formulation of printable inks for DPN. For instance,

8 agarose resulted to be a biocompatible carrier matrix for both DNA and proteins, since the

9 polysaccharide can modulate the inks deposition rates and the transfer of the biomolecules. ${ }^{[125]}$

10 Finally, it is noteworthy that very high-molecular weight polysaccharides $(>400 \mathrm{kDa}),{ }^{[126]}$

11 could pose some challenges for printing approaches, due to the high viscosity of the resulting

12 ink. This can be solved by increasing the relative humidity during printing deposition, or by

13 adding hygroscopic organic additives, e.g. tricine (a glycine derivative). ${ }^{[127]}$

\section{Nanoscale solid-supported Artificial Biosystems}

In this section, nanoscale resolution printing methodologies will be investigated, reporting on their major applications as solid-supported artificial biosystems (see Table 1). The methods herein described include contact printing methodologies, namely, DPN, PPL and Hard-Tip Softback Lithography (HSL). Importantly, all the reported methods allow preparing supported artificial biosystems at variable printing throughput, that can be of interest for the assembling of functional condensed molecular modules. In particular, by combining high-density molecular organization and reconfigurable submicrometric spatial organization, such condensates may be used for single cells manipulation and drug delivery, mimicking the plasma membrane compartmentalization. ${ }^{[128]}$

\subsection{Nanoscale Printing Methodologies}

\subsubsection{Dip Pen Nanolithography}




\section{WILEY-VCH}

1 Direct molecular printing approaches at nanoscale resolution have been developed by the

2 Scanning Probe Lithography (SPL) methods, which use either a sharp single tip, or multiple tip array, derived from the Atomic Force Microscope (AFM) system to deposit molecular systems onto solid surfaces, with lateral nanometer scale lateral resolution (i.e. 1-100 nm length scale). The seminal paper from the group of Mirkin ${ }^{[66]}$ has coined the term DPN for this approach. DPN permits to directly transfer an extraordinary variety of material "inks" (small molecules, polymers, DNA, proteins, peptides, colloidal nanoparticles, metal ions, sols, etc.) from microns down to sub-50 nm length scale. ${ }^{[129-132]}$ DPN allows for direct deposition of molecules from an ink-loaded tip onto a surface, following a diffusive or a liquid ink mechanism. In the diffusive case, the ink molecules coated on the tip are deposited through a water meniscus at the interface between the tip and the surface, leading to the deposition of a monolayer on solid surfaces with nanoscale lateral resolution. ${ }^{[132]}$ Such process is dependent on molecular diffusion rate and it is slower for high molecular weight molecules, e.g. proteins or DNA, whose diffusion coefficients are in the range of $10^{-12}-10^{-13} \mathrm{~m}^{2} / \mathrm{s}$. In the case of liquid inks, ink molecules remain homogeneously dissolved in the carrier solution. When the ink-loaded pen contacts the surface, a liquid meniscus is formed. By pulling the tip away from the surface, it is subjected to an attractive capillary force, which goes to zero at the distance at which the water meniscus breaks, releasing the droplet. ${ }^{[133]}$ In the liquid ink mechanism, the deposition process depends on the relative humidity (i.e. the amount of water vapor present in air expressed as a percentage of the amount needed for saturation at the same temperature), surface tension in between liquid and tip, liquid and surface as well as on the liquid carrier viscosity. The deposition process is not dependent upon the molecular weight of the deposited molecule, but mainly on the physicochemical properties of the liquid carried in which the biomolecule is dissolved.

\subsubsection{Polymer Pen Lithography and Hard-Tip Softback Lithography}

DPN-based techniques are typically hampered by the inherently low throughput in the 


\section{WILEY-VCH}

1 the conventional cantilevers with a polymeric soft film mounted on rigid substrates, permitting

2 to obtain a packed array of probes that can be actuated in parallel to deposit biomolecules onto

3 solid surfaces. ${ }^{[134]}$ The first approach demonstrating this significant evolution is constituted by

4 PPL. ${ }^{[78,135]}$ It can be defined as a patterning methodology in which pens made of a soft

5 elastomeric polymer (polydimethylsiloxane) deliver inks ${ }^{[136,137]}$ onto solid supports by

6 controlling the movement of the pen array with a scanning probe microscope on large areas (on

7 the order of several $\mathrm{cm}^{2}$ ) in a single print step. ${ }^{[138]}$ Elastomeric pens are also characterized by

8 an additional factor for controlling feature size since the pens themselves may deform, resulting

9 in a force-dependent pen-surface contact area. ${ }^{[139]}$ In particular, as the elastomeric pens are

located in close proximity of the solid support, a diffusive transport mechanism takes place,

11 mediated by the water meniscus. On the other hand, whether the pens are stamped onto the support, the mechanism of ink deposition is analogous to Microcontact Printing (see below in section 5). These mechanisms define extreme cases, then, depending on the elastomeric pens distance respect to the substrate the ink transfer may follow closer the characteristics of one or the other. ${ }^{[76]}$ A further evolution of PPL is constituted by HSL, ${ }^{[68]}$ in which hard silicon tips are mounted onto polymeric elastomeric backing. This approach is able to combine the high throughput ability of PPL (large area patterning over $\mathrm{cm}^{2}$ ) with the high lateral scale resolution (down to $50 \mathrm{~nm}$ ), of the DPN-based systems. However, HSL has not found so many bio-related applications, whereas PPL-based approaches have been widely employed given the higher simplicity and the remarkable compatibility with different biomolecular systems.

\subsection{DNA-based Artificial Biosystems}

\subsubsection{DPN of DNA-based biosystems}

DNA patterning by means of DPN was demonstrated by Demers et al. to generate covalently bonded patterns of oligonucleotides on gold and $\mathrm{SiO}_{\mathrm{x}}$ substrates. ${ }^{[140]}$ The surface of silicon promote a good adhesion of DNA ink molecules to the tip surface. Following similar 


\section{WILEY-VCH}

1 approaches, proteins can also be deposited by DPN, as well. ${ }^{[141,142]}$ In this field, our group described a strategy that employs DPN of oligonucleotide inks dissolved in polyethylene glycol (PEG) matrixes. ${ }^{[131]}$ Complementary sequences conjugated to a protein of interest were hybridized to the spotted DNA sequence via DNA directed immobilization (DDI). ${ }^{[143]}$ Optimal deposition parameters consisted in PEG 1000 molecular weight, relative humidity as high as $30 \%$, and a capture oligonucleotide concentration of $100 \mu \mathrm{M}$. Oligonucleotides complementary to the immobilized capture sequences were covalently linked to streptavidin, and the resulting conjugates were functionalized with fluorolabelled biotinylated antibodies. The streptavidinantibody complexes were bound to the immobilized capture-oligonucleotide arrays, resulting in a protein array, suitable for functionalization with the epidermal growth factor to recruit the complementary membrane receptor (EGFR) in the plasma membrane of MCF7 cells (Figure 4 A-B). The combination of DPN with DDI was used for the fabrication of arrays containing two capture oligonucleotides, resulting in two different protein patterns. ${ }^{[130]}$ The multiplexed microarray was applied to simultaneously measure the interaction of two bait-presenting artificial receptor constructs (PARCs) - i.e. the regulatory domain RII-b and the regulatory domain RI-a of protein kinase A (PKA) - with a prey protein construct constituted by the catalytic subunit mCherry-cat- $\alpha$ of PKA fused to the fluorescent protein mCherry inside single living cells. The two different PARCs were attached to the surface since in their extracellular region, they showed two different epitopes, respectively VSV-G bait and HA bait that are selectively captured by respective biotinylated antibodies linked to the ssDNA-streptavidin conjugate which is hybridized to the complementary ssDNA deposited by DPN. In Figure 4C, a single cell recruited on an anti-VSVG functionalized surface is shown. ${ }^{[130]}$

\subsubsection{PPL of DNA-based biosystems}

To improve the efficiency of multiplexed surface patterning in Printing Biology, Arrabito and collaborators developed a prototype of a robust custom plotter based on PPL, allowing rapid fabrication of microarrays at ambient conditions. ${ }^{[78]}$ Subsequent to optimization of ink viscosity 


\section{WILEY-VCH}

1 and surface tension by glycerol and polyoxyethylene (20) sorbitan monolaurate (respectively at concentrations equal to $5 \% \mathrm{v} / \mathrm{v}$ and $0.1 \% \mathrm{v} / \mathrm{v}$ ) addition, DNA arrays were plotted and used for DDI of EGF-bearing ssDNA-streptavidin conjugates. MCF7 cells expressing EGFP-EGFR were cultured on those functionalized surfaces. The microarrays showed the ability to recruit and activate EGF receptors in sub-cellular regions within human MCF7 cells, which were stained with antibodies against active EGFR, which is phosphorylated at tyrosine 1068 . The ratio between phosphorylated and total EGFR permitted to measure the activation state of this receptor, finding that a significantly higher fraction of EGF receptors was phosphorylated within cell regions that contacted EGF functionalized surfaces (see Figure 4D). In a recent paper, Angelin and coworkers ${ }^{[144]}$ demonstrated the site-directed sorting of protein-decorated DNA origami structures on DNA microarrays. The combination of bottom-up self-assembly of protein-DNA nanostructures and PPL allowed the realization of multiscale origami structures as biointerface, deriving from the 5438 nucleotides template $109 \mathrm{Z} 5$ having nine single-stranded DNA (ssDNA) binding tags, protruding from one side of the plane of the quasi-2D nanostructure. The nine binding sites were bound to their complementary surface-bound capture oligonucleotides. This technology permitted to investigate the activation of EGF receptors in living MCF7 cells through distinctive nanoscale arrangements of EGF ligands. Such approach led to the assembly of structures having the same size of biomolecular assemblies present in the membrane of living cells, that are composed of tens to thousands of molecules (sizes around 5$100 \mathrm{~nm}$ ) and that play a crucial role in the outcome of signaling events.

\subsection{Phospholipids-based artificial biosystems}

\subsubsection{DPN of phospholipid-based inks}

In the context of Printing Biology by DPN, a high relevant class of biomolecules is certainly represented by phospholipids, resulting in the L-DPN acronym to refer to lipid patterning via DPN. ${ }^{[129]}$ The importance of phospholipids patterning is related to their fundamental roles in biology as main components of cell and subcellular organelle membranes, as well as signaling 


\section{WILEY-VCH}

1 molecules. Remarkably, the phospholipid inks exhibit peculiar properties with respect to the

2 diffusive and liquid ones. In particular, phospholipid molecules loaded on the DPN tip undergo

3 a humidity-dependent hydration process to be released onto the substrate. When properly

4 hydrated, phospholipids diffuse from the tip towards the support through the water meniscus,

5 like in a diffusive ink. ${ }^{[76]}$ However, it has also been demonstrated that the ink flow can be

6 modified by controlling the relative humidity, and the deposited spots are domed-shaped, both

7 characteristics of liquid inks. ${ }^{[145]}$ Therefore, phospholipid inks feature a combination of both diffusive and liquid inks properties, offering the possibility to involve an alternative rheology in molecular printing. Another important aspect is the chemical structure of the phospholipid molecules, especially regarding the hydrophobic chains, whose chemical composition strongly affects the chain-ordered phase transition temperature. To achieve a proper direct-writing process, the temperature during printing has to be maintained above the transition temperature

13 in order to keep a suitable ink fluidity. ${ }^{[76]}$ Noteworthy, the L-DPN can also been performed in aqueous solution taking advantage of the lipid patterns insolubility and stability in water. ${ }^{[146]}$ As deposited by DPN, they can form multiple stacks of hydrated bilayers, ${ }^{[147]}$ that have opened up different applications. For instance, when employed as biointerfaces, phospholipid patterns can interact with cell membrane and induce the delivery of small molecule from the support into adherent cells. ${ }^{[148,149]}$ The fabrication of phospholipid-based surface-mediated delivery systems has been demonstrated by Kusi-Appiah et al., ${ }^{[148]}$ (see Figure 5A) that have shown the internalization of both valinomycin and docetaxel drugs by adherent cells. Interestingly, the bioactive molecules transferred from the subcellular phospholipid printed spots into the cells in a multilayer thickness-dependent fashion, with no cross-contamination between different functionalized areas.

In addition, phospholipids are traditionally assembled on solid supports to obtain SPBs to be employed as biological membrane models, ${ }^{[150]}$ whose thickness (2 to $100 \mathrm{~nm}$ ) and lateral resolution, as well as geometry and shape, can be finely controlled and modulated by DPN. ${ }^{[151]}$ 


\section{WILEY-VCH}

1 Such artificial membranes with high controlled dimensional features have found remarkable applications as optical biosensors as well. In fact, exploiting the high control on the spot height attainable by DPN, Lenhert and coworkers fabricated lipid multilayer gratings, whose response interaction with proteins intercalated in the multilayer structure, resulting in a label-free optical detection platform for lipid binding biomolecules. ${ }^{[152]}$

\subsubsection{PPL of phospholipid-based inks}

PLL has also been utilized to obtain phospholipid patterns as well, exploiting the highthroughput capability and multiplexing potentiality of a multi-probe system. ${ }^{[129]}$ As aforementioned, phospholipid deposition from a DPN tip occurs as a combination of diffusive and liquid ink transport mechanisms. ${ }^{[76]}$ This phospholipid ink deposition by PPL has been systematically investigated by Angelin and collaborators, (see Figure 5B) demonstrating a minor effect of dwell time and printing pressure in phospholipid PPL respect to other diffusive inks. ${ }^{[136]}$ In the same work, the authors demonstrated the application of the phospholipid patterns by PPL as cell recruitments platforms through an extracellular receptor binding mechanism at the printed surface. The principle has been demonstrated dispensing 1,2dipalmitoyl-sn-glycero-3-phosphoethanolamine bearing the model allergen dinitrophenol in an array fashion on a glass support. Mast cells RBL 2H3, sensitized with the fluorolabelled antidinitrophenol IgE, have shown a co-localization of the cell bound antibody with the allergen/lipid pattern. ${ }^{[136]}$ Moreover, PPL can be leveraged for an accurate biomolecular gradient fabrication by finely tuning the printing pressure, and consequently the relative distance between tips and substrate. ${ }^{[135]}$ To this aim, elastomeric pens holder has been tilted respect to the solid substrate, resulting in a gradient of printing pressure along the different tip lines. This procedure permitted to obtain in a single printing run different multi-stacking bilayers of phospholipids, whose height depends on the applied pressure. 


\section{WILEY-VCH}

1 5. Microscale and Macroscale Artificial Biosystems: from artificial compartments to

\section{synthetic tissues and bioinspired electronic networks}

In this section, the relevant methodologies of microscale printing and their main applications in developing artificial biosystems will be reported. The methods herein described include $\mu \mathrm{CP}$, Inkjet Printing (IJP) and 3D Printing (see Table 2 and Table 3). Differently from the previously reported nanoscale biosystems, the herein described microscale artificial biosystems have been assembled not only at solid surfaces but also into liquids, allowing obtaining a larger variety of artificial compartments and complex life-like assemblies at solid surfaces and into reconfigurable liquids environments. This section reports examples of further organization of the resulting artificial compartments to form complex 3D assemblies which are responsive to external triggers (such as light, osmolarity, electrical currents), finally leading to artificial tissues, scaffolds, organs and life-inspired electronics devices based on printed artificial neuronal networks.

\subsection{Microscale Printing Methodologies}

\subsubsection{Microcontact Printing}

The $\mu \mathrm{CP}$ method is among the most common patterning approaches for the deposition of organic molecules and biomolecules on large areas $\left(>\mathrm{cm}^{2}\right)$ and was developed by Kumar and Whitesides. ${ }^{[153]}$ Differently from other approaches, $\mu \mathrm{CP}$ is featured with simplicity, low cost, compatibility with different types of liquids, becoming a routine method to generate patterns at the microscale. ${ }^{[154]}$ The $\mu \mathrm{CP}$ method uses an elastomeric mold, realized from a negative master mold, on which a liquid prepolymer is poured. Once the polymerization is completed by a curing step, the mold is separated from the master and ready for use. Then, it is dipped in the solution containing the molecules to be deposited on the surface. After an incubation time (typically some minutes), it is dried and pressed on the substrate in order to favor the molecules transferring to the surface. Polydimethylsiloxane (PDMS) is the material of choice for $\mu \mathrm{CP}$, 


\section{WILEY-VCH}

1 because of its low-cost and suitability for conventional laboratories. Similarly to Scanning

2 Probe Lithography approaches, $\mu \mathrm{CP}$ allows for deposition of biomolecules onto solid supports

3 and has found many applications in the field of molecular dispensing on solid surfaces which

4 have recently been developed.

5

6

7

\subsubsection{Inkjet Printing}

The Inkjet Printing (IJP) method is among the most convenient printing approaches, allowing for the fabrication of wide variety of molecular arrays. ${ }^{[155,156]}$ Generally, the inkjetted droplets are in the volume range of $10^{-1}-10^{2} \mathrm{pL}$ and are dispensed through a mechanism based on the generation of a pressure pulse within the ink, causing the droplet ejection from a micrometric orifice, often referred as nozzle. ${ }^{[5]}$ The IJP technology has been implemented in many different forms that can be categorized into the Continuous Inkjet Printing (CIJ) and the Drop-onDemand Inkjet (DOD) printing methods. In the case of CIJ, the ink is subjected to a high pressure through the nozzle resulting in a jet that breaks up into a stream of droplets through the Rayleigh instability. ${ }^{[89]}$ In the DOD approach, the droplets are generated by the actuation of series of pressure pulses inducing the droplet formation in a controlled manner. ${ }^{[157]}$ The DOD approaches can be divided according to drop formation mechanism into thermal, piezoelectric, electrostatic, and acoustic, electrohydrodynamic and valve methods. ${ }^{[158]}$ The piezoelectricbased technology is currently the most commonly employed. In this case, the system employs a high-pressure pump with a piezoelectric crystal, such as lead zirconate titanate, that works as actuator to dispense droplets by a series of electrical pulses that induce shear and compression stresses on the liquid. Note that the structure of the most fragile biomolecules can be affected by the printing process as the droplets experience relative high shear stresses while flowing through the nozzle and impacting the substrate surface. ${ }^{[159]}$

The ink rheological properties play a fundamental role for the printing process. A convenient approach to illustrate the different regimes of inkjet printing is the Derby plot which reports the We number against the Re number, permitting to individuate regions which are compatible with 


\section{WILEY-VCH}

1 jettable fluids or with satellites production. ${ }^{[160]}$ In order to obtain sufficient ballistic accuracy of

2 a droplet, the We number should be higher than 1 . The Re number should be higher than 1 as

3 well, in order to prevent excessive viscous damping, while the need for some damping of the

4 fluid after droplet generation puts an upper bound on its value. ${ }^{[92]}$

\subsubsection{D printing}

Additive manufacturing technologies, commonly referred as three-dimensional (3D) printing, have emerged over the last years as a promising approach for the creation of customizable fabrication paradigms for life sciences. Differently to the previously discussed printing techniques, mainly involved in the fabrication of $2 \mathrm{D}$ artificial biosystems, the $3 \mathrm{D}$ printing approaches offer the possibility to build up 3D complex architectures mimicking the properties and structures of the biological systems, reaching the macro-scale. There are some recent reviews detailing the plethora of reported $3 \mathrm{D}$ printing techniques. ${ }^{[161,162]}$ This technology permits to draw reconfigurable objects by means of computer-aided design (CAD) software, offering the possibility to optimize the design and the 3D structure in a sequence of layers. 3D printing eliminates the photolithographic step and obviates the need for expensive siliconprocessing infrastructure.

The earliest form of 3D printing is Stereolithography (SL) ${ }^{[163]}$ based on the employment of a liquid photoresin, which undergoes photopolymerization under UV-light irradiation. The process goes on layer-by layer, until the structure is complete, following a draining of the unreacted resin and a final irradiation with stroboscopic UV-light in order to cross-link available sites, improve mechanical properties and uniform hardness. The possibility to recollect unreacted resin, to use limited amount of material and high resolution control given by light source resolution (in the range of micrometer to nanometer scale) ${ }^{[164]}$ makes it the protocol of choice for several researchers. Typical materials applied for SL comprise acrylates, ${ }^{[165,166]}$ hydroxyapatite combined with polymer matrices, ${ }^{[167]}$ poly(propylene fumarate)s, ${ }^{[168]}$ polycaprolactones, ${ }^{[169]}$ and poly(D,L-lactide) resins. ${ }^{[170]}$ Recently, the library has 


\section{WILEY-VCH}

1 been expanded by silicon-oxycarbide chemistry, which successfully ended up in the preparation

2 of $3 \mathrm{D}$ ceramic structures. ${ }^{[171]}$ Projection-based protocols are one of the most recent evolution

3 of SL protocols, allowing the definition of extremely sharp, fractal-like patterns, in closely

4 similar to natural circulatory systems of living beings. ${ }^{[172,173]}$ Another interesting surprise comes

5 from spider-inspired 3D printing technique, ${ }^{[174]}$ an extrusion-based 3D printing method with a

6 multi-barrel nozzle where the crucial role is played by the parallel printing of multiple components, forming a stable and biocompatible network after UV-initiated gelation of sodium alginate and acrylamide.

The achievements obtained through the 3D printing techniques represent a cornerstone for researchers targeting the understanding of basic mechanisms of life at cell-scale, and the

11 fabrication of complex artificial biological apparatuses. ${ }^{[175]}$ The realization of hollow tubular structures drives further investigations aiming at merging 3D printing with microfluidic circuits, disclosing the possibility to create 3D biological fluidic environments for advanced cell cultivation, with features closely resembling natural architectures. ${ }^{[176]}$ Microfluidic apparatuses realization by means of 3D printing necessarily calls for a wide-range investigation of new formulations and bioinks (a mixture of cells, biomaterials and bioactive molecules) allowing realizing biomimetic constructs. Bioinks formulations were limited in the early days of 3D printing, and this condition forced scientists to put several efforts in their investigation, culminating in the plethora of viable options that are described up to date. ${ }^{[177]}$ Among the highest achievements, an important goal has been the production of bioinks compatible with many cell phenotypes, ending up in the realization of functional 3D-printed biofilms and living

\subsection{Liquid Microscale Bio-Compartments Printed at Solid Surfaces}




\section{WILEY-VCH}

\subsubsection{DNA-rich microcompartments}

Nyamjav and Holz demonstrated the use of $\mu \mathrm{CP}$ as a robust, reliable and inexpensive method to produce high-density microarrays of DNA molecules directly on silicon oxide substrates.

The coupling of oligonucleotides to a silicon substrate was achieved by silanization of an acrylamide-terminated DNA, resulting in arrayed oligonucleotides with retained biological function. ${ }^{[180]}$ The $\mu \mathrm{CP}$ method was also used for the immobilization of lipidic vesicles containing amphiphilic $\beta$-cyclodextrin interconnected by biotin-streptavidin linker molecules. ${ }^{[181]}$ A very intriguing example of $\mu \mathrm{CP}$ versatility was provided by the group of prof. $\mathrm{He},{ }^{[182]}$ who demonstrated the fabrication of self-propelled chitosan/alginate polyelectrolyte multilayer (PEM) microsized films onto poly(vinylalcohol) (PVA) coated glass slides (Figure 6 A-C). These PEM systems have a spontaneous rolling behavior and ultimately give rise to microrockets when in presence of platinum nanoparticles, which can catalyze the decomposition of $\mathrm{H}_{2} \mathrm{O}_{2}$ into water and gaseous oxygen. The resulting microrockets can travel around straight trajectories, reaching speed of more than $50 \mu \mathrm{m} / \mathrm{s}^{[182]}$

The IJP method has been leveraged as a robust approach for the study of molecular interaction onto 2D solid-supports, following the application of protein microarray platforms. ${ }^{[183]} \mathrm{DNA}$ molecules are fully compatible with $\operatorname{IJP}^{[184]}$ allowing for the realization of microarrays usable as gene or cDNA probes. The IJP methodology can be a fundamental tool allowing printing chip-derived staple strands to assemble large DNA origami at low cost on 2D chips. The staple strands were individually synthesized on pillars and amplified off the chip surface by nickingstrand displacement amplification. The oligonucleotides were amplified via PCR and released as single stranded DNA to be used for folding a 51-kilobasepair origami from the $\lambda / \mathrm{M} 13$ hybrid scaffold. ${ }^{[185]}$ Similarly, 3D printing has been shown as suitable approach for assembling DNA molecules for molecular cloning, following the Golden Gate DNA assembly in 3D inkjetprinted fluidics. ${ }^{[186]}$ 


\section{WILEY-VCH}

1 Differently, proteins inkjet printing can be a more challenging task due to the possible

2 mechanical stresses that can compromise their structure during droplet formation and

3 impact. ${ }^{[159]}$ These issues can be solved by tuning the deposition process, obtaining a droplet

4 velocity enough for good directionality (i.e. around 5-6 m/s) without imposing excessive shear

5 and compression stresses. In particular, our group ${ }^{[69]}$ produced an all-printed $2 \mathrm{D}$ drug screening

6 platform in which pL-scale volume droplets containing a model enzymatic substrate/inhibitor

7 couple (D-glucose or a mixture of D-glucose/D-glucal) were inkjet-printed onto a glucose

8 oxidase monolayer immobilized on silicon oxide. Upon hitting the solid surface, the droplets

9 formed rounded spots with diameters of about 40-50 $\mu \mathrm{m}$. Figure 5D reports optical images of

10 alternated D-glucose rich (absence of D-glucal) and D-glucose/D-glucal (D-glucal molar

11 fraction equal to 0.88 ) rich spotted lines, as freshly printed and after 90 minutes of incubation

12 are shown, respectively. A colorimetric detection based on the horseradish peroxidase method $^{[159]}$ allowed to probe the interaction between the dispensed molecules and the enzymatic

14 target at the single spot in such 2D chip (Figure 6 D-E).

\subsubsection{Protein-rich microcompartments}

Protein immobilization by chemisorption on a solid surface is not mimicking the biological conditions, since the strong bond between the macromolecules and the solid support affects the structure and the biological activity of the biomolecules. A non-covalent printing approach compatible with solid surfaces would be highly desired. In this regard, Mugherli et al. leveraged surface-tension nL-scale 2D droplets microarrays stabilized within DMSO/glycerol (9:1) droplets, to investigate derivatives of phenylboronic acid and their profiling against the NS3/4A protease of the hepatitis C virus. ${ }^{[187]}$ A further innovation was demonstrated by our group ${ }^{[188]}$ in the form of a 3D layer-by-layer fabrication of the enzymatic array in which ink droplets remained stable both during the multilayer-assembling and the execution of the assay thanks to the high hygroscopicity of glycerol added to the ink at $30 \% \mathrm{v} / \mathrm{v}$, to maintain a constant water content in the printed droplets. ${ }^{[189]}$ The resulting CYP3A4-catalyzed reactions were conducted 


\section{WILEY-VCH}

1 in such pL-scale spots, and the enzymatic inhibition was verified at the single spot level by

2 luminometric detection. Notwithstanding the advantages of such non-covalent printing

3 approach, glycerol significantly affected the enzymatic kinetics. As an alternative to glycerol-

4 based inks, Mateen et al. developed printing approaches, based on a drop-on-demand syringe

5 solenoid printer. They used hydrogel inks onto nitrocellulose, protecting the biomolecules

6 against drying and denaturation. ${ }^{[190]}$ By using $\beta$-lac as a model protein, the enzyme-

7 immobilizing hydrogel can be employed for drug screening applications. Recently, Benz and

8 collaborators demonstrated that combinatorial synthesis and cellular screening can be applied

9 within biochips printed by a non-contact liquid dispenser, ${ }^{[191]}$ permitting the combination of

10 chemical synthesis with in vivo screening by recreating biologically native conditions in at the

$11 \mu$ L-scale droplets.

\section{2 \\ 5.2.3 Phospholipids-rich microcompartments}

13 A further step towards evolved artificial biosystems printing is constituted by the possibility to

14 define lipid vesicles that perform operations similar to those of cellular systems or smart bioinspired machines usable for drug delivery, artificial organelles or bioreactors. IJP allows for the realization of a 2D microarray of model biological membranes on solid substrates. ${ }^{[192]}$ Lipids were inkjet-printed onto a glass substrate that was functionalized with microsized membranes of phospholipid bilayers which were in turn realized by the lithographic photopolymerization of a diacetylene-containing phospholipid, 1,2-bis(10,12-tricosadiynoyl)sn-glycero-3-phosphocholine (DiynePC). IJP permitted the direct incorporation of the natural

21 lipid membranes into the polymer-free regions (corrals). Notably, an aqueous solution 22 containing agarose and trehalose was printed onto the corrals beforehand to stabilize the phospholipids bilayers and subsequently printed lipid suspensions. Fluorescence recovery after photobleaching (FRAP) measurements confirmed the fluidity of the phospholipids structures (Figure 6F-G). After removal of non-polymerized DiynePC with a detergent solution, the lipid 


\section{WILEY-VCH}

1 eject sub fL-volume droplets. To avoid rapid dehydration and destabilization, an aqueous

2 solution containing agarose and trehalose and subsequently lipid suspensions were printed onto

3 the corrals. After rinsing, stable lipid bilayer membranes were formed in the corrals. Lalone et

4 al. demonstrated the possibility to engineer single-cell-sized 2D micro-calibration standards by

5 IJP ink formulations containing high-density lipoprotein nanodiscs (HDLs) to dissolve

6 phospholipid in aqueous ink formulations. The inks were printed by a piezoelectric actuated

7 inkjet printer onto silicon surfaces and single cells adhered to them, allowing for quantitative

8 phenotypic characterization of cell populations on the basis of absolute biomolecular

9 composition, specifically measuring the total amounts of protein, lipid, nucleic acid and

10 carbohydrate present inside them. ${ }^{[193]}$

\section{$11 \quad 5.3$ Aqueous compartments into liquids}

\section{2 \\ 5.3.1 Printing protein-rich aqueous liquid microcompartments}

A further step towards native conditions is printing aqueous compartments that mimic the composition of cellular systems. This can be achieved by printing inks in the form of pL-scale aqueous droplets into mineral oil drops. ${ }^{[194]}$ The oil drop has a high boiling temperature, then is able to completely protects the printed aqueous droplets against fast evaporation. However, the molecular content inside the aqueous droplet is subjected to leakage into the oil phase. In this regard, the water/oil interface needs to be stabilized by non-ionic mild surfactants (polyoxyethylene 20 sorbitan monolaurate). The resulting aqueous environments constitute artificial compartments in which few molecular interactions can be quantitatively investigated. For example, the biotin/streptavidin model interaction has been investigated by Raster Image Correlation Spectroscopy (RICS), an advanced fluorescence technique enabling to follow molecular dynamic processes, in conditions similar to those of aqueous confined compartments (Figure 7 A-B). ${ }^{[95]}$

A transition to a crucially different molecular behavior is observed by downscaling the size of the printed droplet at fL scale, which actually corresponds to the size of subcellular 


\section{WILEY-VCH}

1 organelles. ${ }^{[31,33]}$ Differently from previously developed set-ups such as satellites printing or

2 droplet generation in liquid environments ${ }^{[2,83]}$ which have not been demonstrated to be suitable

3 for biomolecular systems, our group has recently designed a printing approach based on

4 piezoelectric IJP for the fabrication of artificial compartments at fL scale. ${ }^{[85]}$ In particular, by

5 following the theoretical model from Eggers and coworkers, ${ }^{[195]}$ in which the droplet size can

6 be finely tuned by minimizing the actuation time of the transducer, we were able to produce

7 stable fL-scale droplets, containing a mixture of non-ionic surfactants - the di-block copolymer

8 poly(ethylene glycol)-block-poly(propylene glycol)-block-poly(ethylene glycol) (PEG-PPG-

9 PEG) $(0.03 \% \mathrm{w} / \mathrm{v})$, and polyoxyethylene (20) sorbitan monolaurate $(0.05 \% \mathrm{v} / \mathrm{v})$. The droplets were printed into nL-scale oil drops, and the resulting water/oil interface was stabilized by the non-ionic surfactants. Note that the fL-droplets form an almost-regular circular pattern at the border of mineral oil drops due to Marangoni flows (see Figure 7C). In turn, the downscaling at the fL-size triggered the formation of molecularly crowded shells at the water/oil interface, with a typical thickness in the order of hundreds of nanometers, in accordance with models. ${ }^{[196]}$ This approach has been exploited to study two different biomolecular systems: first, a DNA hairpin in presence of a molecular triggers (i.e. a complementary sequence which leads to the formation of the double helix sequence), and second a CYP2E1-catalyzed enzymatic reaction in which 7-(ethoxymethoxy)-2-oxo-2H-1-benzopyran-3-carbonitrile (EOMCC) is converted to the fluorescent molecule 3-Cyano-7-hydroxycoumarin (CHC) (see Figure 7D). More specifically, molecular crowding effects were tested by using Fluorescence Lifetime Imaging Microscopy (FLIM), revealing different characteristic fluorescence lifetimes of environmental sensitive specific probes in the confined volumes with respect to bulk solutions, due to water molecules depletion effects. ${ }^{[197]}$

\subsubsection{Phospholipids-rich aqueous liquid microcompartments}

A completely different scenario occurs when phospholipid inks are printed into aqueous phases.

The pioneer investigations (not by printing methods) from Elani and collaborators leveraging 


\section{WILEY-VCH}

1 macroscale droplets produced by manual ${ }^{[198]}$ and microfluidic ${ }^{[199]}$ droplet formation, defined

2 the possibility to produce compartmentalized vesicles by transferring a set number of lipid-

3 coated water-in-oil nL-scale droplets from an oil to an aqueous solution (phase transfer). The

4 droplets were used to compartmentalize biochemical reactions, and for engineered signaling

5 cascade within an artificial cellular system. ${ }^{[198,199]}$ As far as IJP is concerned, Hauschild et

6 al. ${ }^{[200]}$ prepared inks from phosphatidylcholines and two block copolymers, poly(2-

7 vinylpyridine)-block-poly(ethyleneglycol) of different block lengths. In their experiments, they

8 used commercial piezoelectric inkjet printers to print $\mathrm{pL}$-scale droplets containing a solution of

9 a vesicle-forming amphiphile into an aqueous solution, where the amphiphiles are able to assemble into vesicles. They observed that inks with a solution of the vesicle-forming amphiphile (0.1-5 wt.\%) in ethanol gave rise to unilamellar vesicles in the 50-200 nm size ranges when printed in the aqueous solution. This result might appear unexpected since the droplet size is in the order of microns, but can be explained due to the fact that the vesicle formation proceeds via a nucleation and growth process. The author argued that the wellcontrolled distribution of monodisperse droplets by the printhead leads to a stable level of supersaturation, permitting a fine control of the number of nuclei and the resulting vesicle size. ${ }^{[200]}$ IJP has been also involved in the manufacturing of more complex phospholipid particles in order to build up cell-mimicking compartments, whose properties can be finely tuned through the printing process. In particular, Stachowiak and coworkers ${ }^{[201]}$ have reported an elegant piezoelectric inkjet setup, which allows to simultaneously form and load unilamellar

21 liposomes by directly injecting droplets of cargo-containing ink at the phospholipid solution 22 interface. By tuning the printing parameters, such as pulse number and pulse voltage, as well as ink viscosity by biocompatible additives, they demonstrated the possibility to assembly particles with diameters ranging from 10 to $400 \mu \mathrm{m}$, as well as the encapsulation of the actin, which is a fundamental constituent of the cell cytoskeleton, and the study of its intravesicle 


\section{WILEY-VCH}

1 (membrane and protein-based internal architecture), and promising features as artificial cell

2 (Figure 7E-F).

3

\subsubsection{Printing compartments networks: towards artificial tissues}

3D printing approaches have been applied for the fabrication of tissue-like biological architectures, allowing mimicking cellular networks. In a remarkable example from the group of Bayley, ${ }^{[202]}$ tens of thousands of pL-scale aqueous droplets were printed by a drop on demand by piezoelectric actuated 3D printer to become joined by single lipid bilayers, leading to a patterned, cohesive, tissue-like materials made up of cooperating artificial compartments. The staphylococcal $\alpha$-hemolysin ( $\alpha \mathrm{HL}$ ) protein was added to the phospholipids to create an ionically conductive droplet network (Figure 8A). The droplets pattern can be folded by the presence of osmosis triggers. The different osmolarity between adjacent droplets determine flow of water through the bilayer causing the droplets to swell or shrink (Figure 8B).

This printing approach has been proposed also as a powerful technology to be applied for selfassembling biomolecular memristors as synaptic mimics, ${ }^{[203]}$ where deposition has been performed following DOD approach governed by piezoelectric actuation. The same piezoelectric actuated 3D printing method can be applied for the realization of synthetic tissues that, under a light activated DNA promoter system, permit the expression of a model protein (the mVenus protein) inside the synthetic cells (Figure 8C-D). ${ }^{[204]}$ After light activation, optical investigation of the set of the artificial cells permits to visualize the cells where the yellow mVenus protein is expressed (Figure 8E).

3D printing also allows the assembly of water-in-water constructs. This process is challenging, due to the lack of a strong thermodynamic driving force, pivoting the phase separation phenomena. Nevertheless, some interesting reports describe how this goal can be achieved by synthesizing a membrane able to separate the inner space of the micro-constructs from the outer environment. Literature reports hollow tubular architectures, ${ }^{[205]}$ where separation is achieved 


\section{WILEY-VCH}

1 by means of a combination of dextran and PEG solutions. Those tubules demonstrated to induce

2 selective ion separation and accumulation, and selectively sequester, accumulate, and transfer

3 charged molecules. Similarly, globular capsules can be designed as 3D reactors for cell

4 culture. ${ }^{[206]}$ Here, sodium alginate sodium dodecyl sulphate were the main constituents of the

5 membrane layer, while the core space is constituted by an aqueous solution of hydroxy-ethyl

6 cellulose.

7 3D printing approaches have also been applied for the fabrication of organ-like constructs, a

8 cutting-edge aspect for the development of innovative tools in modern tissue engineering and

9 surgery practice. ${ }^{[207-209]}$ For instance, a new 3D printing approach, termed Freeform Reversible

10 Embedding of Suspended Hydrogels (FRESH), ${ }^{[210]}$ has shown great potentiality in the

11 fabrication of a plethora of artificial organs, thus representing a general purpose tool for

12 prosthesis architectures production. In particular, this strategy relies on the deposition of

13 biomaterial, such as alginate, collagen, and fibrin, containing ink into a sacrificial thermo-

14 responsive hydrogel of gelatin, which guarantees that the first fluid ink not to collapse. Once

15 the biomaterial has gained the sufficient mechanical stability, the sacrificial hydrogel limits can

16 be dissolved by simple heating a $37^{\circ} \mathrm{C}$. The FRESH methodology has been further exploited

17 to fabricate several proof-of-concept structures, such as artificial bones, branched coronary

18 arteries, embryonic and neonatal-scale human hearts. ${ }^{[210,211]}$ 3D Printing approaches can be

19 leveraged even to generate an artificial electric organ, as demonstrated by Schroeder and

20 coworkers $^{[212]}$ who reproduced the functionality of the electric organ of the knife fish

21 Electrophorus electricus (the electric eel). The authors printed thousands of compartmentalized

22 polyacrylamide hydrogel compartments by a 3D bioprinter bounded by a repeating sequence of

23 cation- and anion- selective hydrogel membranes, in order that the resulting materials generated

24 total open-circuit potential differences in excess of $100 \mathrm{~V}$ and power densities of $27 \mathrm{~mW} / \mathrm{m}^{2}$. 


\section{WILEY-VCH}

15.4 Towards autonomy: from primitive life-like entities towards artificial organs and neuromorphic systems

Self-propelling liquid compartments and autonomous vesicles can also be employed for building artificial systems that can find relevant technological applications, ranging from molecular encapsulation, stimuli-triggered devices, scaffolds, artificial tissues, neural networks and synapis-inspired computers towards living organisms.

\subsubsection{Primitive autonomous objects}

Liquid-liquid phase separation is an emerging topic, being clear the central role it assumes for the formation of autonomous biomolecular condensates or membranelless compartments within cellular environments. ${ }^{[33,51]}$ The research on this field is still at its infancy ${ }^{[213]}$ and many efforts are needed in order to properly understand the role of such condensates, acting as biological compartments and bioreactors, filters, and membranelless organelles in cells. This has motivated many researches to deeply understand the underlying physical principles and the specific properties of these systems to bring insights into a wide range of biological processes for healthy cells and their roles in contexts ranging from development to age-related diseases, finally providing some technologically relevant applications as bioreactors or liquid individual capsules for drug/molecular encapsulation in immiscible liquids. ${ }^{[214]}$

In principle, phase separation can trigger the formation of primitive autonomous objects, which can freely move within a continuous liquid phase. A model of liquid-liquid phase separation is constituted by the oil-in-water droplets emulsions, that can be used as primitive life-like systems given their ability to move in aqueous media in presence of chemical triggers (surfactant concentration gradient, solid-liquid interfacial tension and other ones). ${ }^{[36-38]}$ In this regard, IJP represents an ideal approach for producing oil droplets on demand, as firstly demonstrated by Zeng and collaborators ${ }^{[215]}$ who inkjet printed oil droplets at sizes comprised in the hundreds of microns $(210-290 \mu \mathrm{m})$. Their inkjet nozzles were immersed in the water phase, and the size of the droplets was tuned by varying the applied voltage and the pulse width exerted on the piezo 


\section{WILEY-VCH}

1 actuator. Our group has recently demonstrated the possibility to produce fL-scale oil-in-water

2 droplets by piezoelectric IJP after spontaneous interfacial droplet fragmentation. ${ }^{[216]}$ In

3 particular, pL-scale fluorinated oil drops were printed onto a surfactant-laden water surface at

4 moderately high We number $\left(\sim 10^{1}\right)$, then they spread, and fragment at the water/air interface.

5 The fragmentation at the interface is due to capillary instabilities, which lead to oil pL-drops

6 rupture into fL-droplets in accordance to the reported models for systems at macroscale (Figure

7 9A) ${ }^{[96]}$ A low concentration $(0.003 \% \mathrm{v} / \mathrm{v})$ of the biocompatible polyoxyethylene (80) sorbitan

8 monooleate surfactant (Tween 80 ) was added the receiving aqueous phase to lower the surface

9 tension. As a result, the fL-droplets are observed only if the surfactant concentration was equal

or higher than its critical micellar concentration, which corresponds to a complete saturation of

11 the interface with the surfactant molecules. This is a crucial difference with respect to

12 conventional studies on macroscale droplets, ${ }^{[217]}$ for which the immersion into water phase

13 depends mainly on the gravitational contribution and less on surface forces. The resulting fL-

14 scale droplets were characterized by impedance ${ }^{[216,218]}$ in which an AC voltage is applied to the

15 top electrodes within a microfluidic chip (Figure 9B). The resulting differential current

16 collected from the bottom electrodes is used to measure the size and the amount of the oil

17 droplets and compared with standard polystyrene beads (Figure 9C). The resulting oil droplet sizes and speed were in the range comprised between $2-4 \mu \mathrm{m}$ and $0.15-0.4 \mathrm{~m} / \mathrm{s}$, respectively.

Differently from the $6 \mu \mathrm{m}$ sized polystyrene beads, the small size of the droplets causes the lack of inertial focusing when flowing in the microchannels (Figure 9D).

\subsubsection{Biocompatible scaffolds}

22 Printing Biology approaches derived from 3D printing are employed for building up biocompatible scaffolds for living cells. The emulation of natural tissues is focused at recreating the natural "niche" in which cells proliferate. It is known how the natural extracellular matrix (ECM) tunes intrinsic cellular morphologies and functions, as in the case of stem cells; unfortunately, ECM complexity limited for long time the possibility for researchers to have a 


\section{WILEY-VCH}

1 valid support for biological studies including regenerative medicine and tissue engineering.

2 Within this exciting context, 3D printing is a key tool for researchers. The topic has been

3 recently reviewed by Heinrich et al. ${ }^{[219]}$ Starting from the initial concept of bone tissue

4 printing, ${ }^{[220]}$ it has been possible to expand this technology to more advanced systems, such as

5 synthetic cartilage, ${ }^{[221,222]}$ skin, ${ }^{[223]}$ heart valve, ${ }^{[224-226]}$ entire organs, ${ }^{[168,207,227,228]}$ neuronal ${ }^{[229]}$

6 and vascular ${ }^{[230,231]}$ networks and supports for medical surgery. ${ }^{[232,233]}$

7 The example reported by the team of Prof. McAlpine ${ }^{[234]}$ is an outstanding representation of an hybrid approach bridging Printing Biology and Bioprinting that leverages 3D printing for printing bionic objects from inks containing living cells and molecules that tune the ink physicochemical properties and support the biological systems during the printing process. The authors prepared a bionic ear by 3D printing a ink containing a cell-seeded alginate hydrogel. This work (see Figure 10A) has deeply inspired scientists (Surgeons, Chemists, Engineers) to push further the limits of 3D printing towards artificial organs. In general, the choice of the ink formulation for 3D printing depends on the viscosity of the printing solution/composite. In this regard, dichloromethane is a common choice due to the low boiling point and ease to be removed from the final material; ${ }^{[235]}$ higher boiling point solvents, such as $\mathrm{DMSO}^{[236]}$ or 1methyl-2-pyrrolidinone, ${ }^{[237]}$ are selected when expected deposition from hot solution or an annealing step has to be performed. Nonetheless, aqueous inks are needed for printing artificial biosystems, within narrow windows of $\mathrm{pH}$ and ionic strength. ${ }^{[238]}$ Additives offer the possibility to tune rheological properties and stabilization energy due to the interaction of different phases. Notably, the choice of the scaffold is driven by the final application. However, special focus has been addressed in recent years to the properties of the resulting scaffold and their correlation with the printing parameters, especially viscosity and temperature. For example, scaffolds designed for bone prostheses should possess a uniform pore structure, resembling natural bones in terms of weight, mechanical profile, and biodegradability. Piperazine-based polyurethaneurea air-driven extrusion 3D printed scaffolds have recently shown great potential, exhibiting 


\section{WILEY-VCH}

1 an interconnected porous structure of about $450 \mu \mathrm{m}$ in macropore size and about $75 \%$ in

2 porosity. ${ }^{[239]}$ Tuning the mechanical properties is also possible by adjusting piperazine relative

3 percentage, with the highest contents returning the highest compressive modulus $(155.9 \pm 5.7$

$4 \mathrm{MPa})$ and strength $(14.8 \pm 1.1 \mathrm{Mpa})$. Another route is proposed by De Giglio and coworkers,

5 whose work discloses the potential of used Filament Fabrication 3D printing. ${ }^{[240]}$ An intricate

6 compartmentalized bone scaffold has been designed and realized, combining poly $(\varepsilon-$

7 caprolactone) porous scaffold filled with a gellan gum-based hydrogel. Human-TERT

8 mesenchymal stem cells and human umbilical vein endothelial cells are therein encapsulated

9 within the gellan gum, revealing high degrees of osteogenic differentiation. Bioactive nanoparticle/poly( $\varepsilon$-caprolactone) scaffolds have been prepared with hierarchical porous

11 structures based on solvent evaporation of 3D printed water-in-oil high internal phase emulsion (HIPE) templates, containing hydrophobically modified hydroxyapatite and silica nanoparticles in the oil phase. ${ }^{[235]}$ Poly (E-caprolactone) shows versatility in the design of other human tissues undergoing mechanical stress; it has been employed as core material for the realization of an artificial meniscus. ${ }^{[241]}$ The realization of an artificial meniscus is challenging, due to its bizonal structure; the tissue presents a fibrous outer portion, with a cartilaginous counterpart in the inner region. The promising approach pursued by Bahcecioglu and co-workers consists in the preparation of poly( $\varepsilon$-caprolactone) scaffold, impregnated with agarose hydrogels in place of cartilage, and gelatin methacrylate as porous external layer. The realization of a core-shell design and the incorporation of fibrochondrocytes into the hydrogels protected the cells from

21 the mechanical damage. In a recent work from the group of McAlpine, polymer-based photodetectors were fully 3D printed by extrusion-based protocols in order to fabricate a bulk heterojunction formed by P3HT:PCBM photo active layers on a PET film. Such architecture evolved into an image sensing arrays with high sensitivity and wide field of view, by 3D 


\section{WILEY-VCH}

1 printing interconnected photodetectors directly on flexible substrates and hemispherical

2 surfaces, (Figure 10B) allowing for a prototype of a bionic eye. ${ }^{[242]}$

3 The effects of temperature and viscosity of the 3D printed ink are also of remarkable

4 importance. Shah and coworkers evidenced how temperature control during the process could

5 affect the quality of the liquid ink 3D printed scaffold prototype,${ }^{[243]}$ which consisted in versatile

6 hyperplastic bones, (Figure 10C) composed of hydroxyapatite and either polycaprolactone or

7 poly(lactic-co-glycolic acid). They observed that increasing the temperature leads some materials to lose elasticity and become brittle. In particular, elasticity of those synthetic bones evolves into plasticity depending on the print rate; that is a negative point for Shah's purposes, but could be desirable for other applications. If the previous example is a clear situation where

11 processability is limited by viscosity, the report offered by Chen and coworkers highlights the importance of the Young modulus, a quantification of materials stiffness. It is well known how cells evolves within the nature of the underlying supporting layer, ${ }^{[244]}$ and its stiffness is crucial for cell survival and proliferation. Chen correctly correlates Young modulus of his 3D printed blood vessels, iteratively optimizing printing conditions and UV-light exposure times of his resin, before obtaining the best material. ${ }^{[245]} 3 \mathrm{D}$ printing can be fruitfully used for the preparation of an artificial homolog of ECM considering the bioprinting of cell-laden constructs with novel decellularized extracellular matrix (dECM) bioink, which proved an optimized microenvironment conducive to the growth of three-dimensional structured tissues. ${ }^{[246]}$

\subsubsection{Bioinspired electronics}

21 Electroactive molecular inks represent an alternative strategy to achieve high control during the 22 ink deposition, and electrical properties fundamental for the fabrication of bioinspired electronic devices. Recently, sodium alginate-gated $\operatorname{In}_{2} \mathrm{O}_{3}$-gated transistor has been reported in the literature for the realization of artificial neuronal networks. ${ }^{[247]}$ These printed electronics were applied for image processing operations, implementing with success color filter algorithms. The working principle is based on the hydrogenation and hydroxylation of $\operatorname{In}_{2} \mathrm{O}_{3}$ 


\section{WILEY-VCH}

1 surface, which introduces profound hysteresis properties in the fabricated transistors; then, hysteresis provides short-term synaptic plasticity capabilities, which can be exploited to imitate synaptic functions (Figure 11A). An outstanding work has been presented by Lin and collaborators, ${ }^{[249]}$ who reported the implementation of an all-optical machine learning neural network based on passive diffractive layer components, patterned using 3D printing techniques. These layers contributed to the creation of a diffractive multiple-layer array, the key component, which allowed classifying images of handwritten digits (Figure 11B). A few reports arise in this cutting-edge area of research, but it is expectable to have an increasing number of research reports in the near future, along with the evolution of neural regenerative medicine, and the

possibility to develop artificial neural networks along with fully biocompatible matrices. ${ }^{[250,251]}$

11 On this respect, Printing Biology could push the development of array systems that have been actually prepared by unprinted approaches like those by Restrepo Schild and coworkers showing the preparation of a soft retina-like system comprising a $4 \times 4$ array of macroscale droplets $(200 \mathrm{~nL})$ containing bacteriorhodopsin, ${ }^{[248]}$ and envisaging the potential impact on neuronal pathways stimulation due to the integration of such bio-array into living tissues.

\section{Conclusions and Perspectives}

The realization of artificial biosystems is a topic of enormous interest in life sciences, since these platforms allow for fundamental understanding of biological processes in tailored celllike environments. These permit to shed lights on questions related to the origin of life on the Earth and finally constitute synthetic artificial modules of tunable size and composition that can be employed for the synthesis and the delivery of biomolecules and chemicals but also for the development of tissues and organs.

In this Review a critical comparison of the wide spectrum of printing methodologies applicable to realize artificial biosystems is given. The emerging field, here defined as Printing Biology, is proposed to result in a technological breakthrough for the field of Synthetic Biology, 


\section{WILEY-VCH}

1 permitting also a direct investigation and manipulation of life-like or life-inspired matter at tunable dimensional scales and under a plethora of different stimuli (optical, chemical, electrical and other ones). The Review summarizes the extraordinary progress of printing methodologies, considering them under a unified view, in order to ascertain the adaptability of these approaches to different scenarios that can span from those on solids to that into liquids. On solid surfaces, Printing Biology allows for the fabrication of technologically relevant condensed systems to be used for the high-throughput programming of biomolecular interaction studies under multiplexed platforms for applications in drug screening, molecular sensing, artificial biology, single cells manipulation. In the case of biosystems developed into liquids, Printing Biology effectively implements the fabrication of artificial compartments as separate cell-like entities of tunable size and composition, permitting the formation of reconfigurable assemblies that can be modulated by external triggers such as light, osmolarity, electrical currents.

It is important to note that Printing Biology is in its infancy and many different aspects still need to be optimized. Indeed, by considering the few main printing methods employed for the nano- (DPN, PPL, HSL), micro- (IJP, $\mu \mathrm{CP}$ ), and macro- (stereolithography, extrusion lithography) scale technologies, it is clear that the number of papers is growing over the last two decades (see Figure 12A). In particular, the nanoscale printing techniques show a quasiconstant number of published papers per year, as a result of the yet limited equipment and research laboratories. Differently, a constant increase is observed for microscale printing, due to the interest in drug screening, cell biology, biosensors. The case of macroscale printing is still different, since an almost exponential increase is observed from 2015. This because of an enormously growing interest for 3D printed devices in cellular scaffolds, tissue engineering, synthetic organs and bioelectronics, this growth being facilitated by the reduction of the equipment costs with a widespread diffusion in the research laboratories. 


\section{WILEY-VCH}

1 Notably, the development of Printing Biology is currently following three routes. First of all,

2 the implementation of the printing machine by the installation of printing hardware with

3 suitable software to finely control a high-resolution operation in the lab. The widespread

4 diffusion of high-resolution scanning probe related techniques has typically been limited by the

5 cost of the instrumentation. However, new setups based on microchannels built up on

6 cantilevers $^{[252]}$ or on 2D arrays of polymeric pens built up onto customized printing ${ }^{[78]}$ would

7 allow for the reduction of costs and more durable setups. Interestingly, the printers that are employed at the microscale are less expensive. In fact, the prices of the IJP and 3D printers has definitely lowered during the last decades, and it is now becoming affordable, also for low settings. As a second aspect, the optimization of the ink formulations is a crucial point. Here, a

11 brief overview of the most common materials is reported, especially focusing on DNA, proteins, 12 phospholipids and polymers-based biological modules. Importantly, each of them necessitates specific formulation inks suitable for printing which result from an optimization of their physicochemical properties. Among the considered materials, DNA shows high versatility and solubility in aqueous solutions. However, more and more studies focus on the employment of hydrophobic inks, based on phospholipids, proteins or oily substances to mimic cell-like membranes or primitive life modules. The future researches could possibly implement different materials within the same ink, in order to fully reconstitute the complex environment of biological systems. As a third aspect, the possibility to tune printed compartments assembly as a function of the external inputs can add a higher degree of complexity, paving the way to important applications in the field of artificial tissues and organs. The resulting artificial assemblies will need to be investigated also within their interactions with living tissues in order to fully characterize them as functional biointerfaces for applications in regenerative medicine and tissue engineering. 


\section{WILEY-VCH}

1 non-bio related fields (printed electronics, microfluidics devices, prototyping) are reported as a

2 function of the above defined nano-, micro-, and macro- scale technologies. As to the field of

3 Biotechnology, the nanoscale finds applications mainly in drug screening and drug delivery,

4 the microscale mainly in drug screening and tissue engineering, and finally the macroscale in

5 cellular scaffolds and tissue engineering. The number of papers in non-bio related fields is

6 higher with respect to those in the field of Biotechnology for all the different technological

7 scales. By further developing the field of Printing Biology, it is expected that in the next decade

8 the actual ratio showed in the Pie chart of Figure 12B between the bio-related applications and

9 the other non-bio related applications will be significantly increased for all the nano-, micro-

10 and macro- scale applications. As an example, Printing Biology assembled devices could find

11 important applications in the emerging field of Biocomputing, a discipline that employs

12 molecular biology modules like gene circuits as the hardware to implement bio-inspired

13 computer devices. ${ }^{[253]}$

14 Future researches efforts would fully exploit the potentialities of Printing Biology opening up the definition of new multiscale patterning protocols by coupling different printing techniques and ink formulations, along with the engineering of new artificial biosystems based on biological and non-biological materials which could be interfaced with living systems or could instead be designed as stand-alone systems with enhanced properties.

\section{Acknowledgements}

22 The research leading to this work was funded by MiUR (PRIN 2013 program, PRIN 2012CTAYSY_003, Pursuing new horizons for cancer therapy through the integration of innovative high-throughput drug-screening and rational drug-discovery). The Italian Ministry of University and Research (MURST, ex-MiUR) is acknowledged by A.B. for funding his 


\section{WILEY-VCH}

1 research activities (PON “AIM: Attrazione e Mobilità Internazionale”, call AIM1809078-2,

2 CUP B78D19000280001).

3

4

5

6

7

8

9

10

11

12

13

14

15

16

17

18

19

20

21

\section{References}

Received: ((will be filled in by the editorial staff))

Revised: ((will be filled in by the editorial staff)) Published online: ((will be filled in by the editorial staff))

[1] A. Senefelder, J. W. Muller, T. F. L. M. Company, The Invention of Lithography Scholar's Choice Edition, Creative Media Partners, LLC, 2015.

[2] B. Michel, A. Bernard, A. Bietsch, E. Delamarche, M. Geissler, D. Juncker, H. Kind, J.-. Renault, H. Rothuizen, H. Schmid, P. Schmidt-Winkel, R. Stutz, H. Wolf, IBM J. Res. Dev. 2001, 45, 697.

[3] A. Kumar, G. M. Whitesides, Appl. Phys. Lett. 1993, 4, 2002.

[4] J. M. Xu, Synth. Met. 2000, 115, 1.

[5] G. Arrabito, B. Pignataro, Anal. Chem. 2012, 84, 5450.

[6] R. Bumgarner, Curr. Protoc. Mol. Biol. 2013, 101, 22.1.1.

[7] B. Schweitzer, P. Predki, M. Snyder, Proteomics 2003, 3, 2190.

[8] H. Ben-Yoav, S. Melamed, A. Freeman, Y. Shacham-Diamand, S. Belkin, Crit. Rev. Biotechnol. 2011, 31, 337.

[9] A. B. Braunschweig, F. Huo, C. A. Mirkin, Nat. Chem. 2009, 1, 353.

[10] S. Leduc, Nature 1911, 86, 410.

[11] W. Szybalski, A. Skalka, Gene 1978, 4, 181.

[12] R. D. Sleator, Bioeng. Bugs 2010, 1, 231.

[13] M. Elowitz, S. Leibler, Nature 2000, 403, 335.

[14] O. G. Clark, R. Kok, Int. J. Intell. Syst. 1998, 13, 749. 


\section{WILEY-VCH}

1 [15] R. Wellhausen, K. A. Oye, in 2007 Atlanta Conf. Sci. Technol. Innov. Policy, ACSTIP, 2007.

[16] M. Sthijns, V. L. S. LaPointe, C. van Blitterswijk, Tissue Eng. Part A 2019, 1.

[17] European Commission, Opinion on Synthetic Biology I Definition, 2014.

[18] M. A. J. Roberts, R. M. Cranenburgh, M. P. Stevens, P. C. F. Oyston, Microbiol. 2013, 159,1219

[19] D. Bracha, E. Karzbrun, S. S. Daube, R. H. Bar-Ziv, Acc. Chem. Res. 2014, 47, 1912.

[20] L. Rodríguez-Arco, B. V. V. S. P. Kumar, M. Li, A. J. Patil, S. Mann, Angew. Chem. Int. Ed. 2019, 58, 6333.

[21] B. V. V. S. P. Kumar, A. J. Patil, S. Mann, Nat. Chem. 2018, 10, 1154.

[22] R. Merindol, S. Loescher, A. Samanta, A. Walther, Nat. Nanotechnol. 2018, 13, 730.

[23] A. Joesaar, S. Yang, B. Bögels, A. van der Linden, P. Pieters, B. V. V. S. P. Kumar, N. Dalchau, A. Phillips, S. Mann, T. F. A. de Greef, Nat. Nanotechnol. 2019, 14, 369.

[24] B. Drobot, J. M. Iglesias-Artola, K. Le Vay, V. Mayr, M. Kar, M. Kreysing, H. Mutschler, T. Y. D. Tang, Nat. Commun. 2018, 9, 1.

[25] S. Koga, D. S. Williams, A. W. Perriman, S. Mann, Nat. Chem. 2011, 3, 720.

[26] M. C. Huber, A. Schreiber, S. M. Schiller, ChemBioChem 2019, 2618.

[27] P. Walde, BioEssays 2010, 32, 296.

[28] V. Erastova, M. T. Degiacomi, D. G. Fraser, H. C. Greenwell, Nat. Commun. 2017, 8, 1.

[29] G. Arrabito, A. Bonasera, G. Prestopino, A. Orsini, A. Mattoccia, E. Martinelli, B. Pignataro, P. G. Medaglia, Crystals 2019, 9, 361.

[30] T. Zhou, E. D. McCarthy, C. Soutis, S. H. Cartmell, Appl. Clay Sci. 2018, 153, 246.

[31] C. D. Crowe, C. D. Keating, Interface Focus 2018, 8, 20180032.

[32] E. Gomes, J. Shorter, J. Biol. Chem. 2019, 294, 7115.

[33] S. F. Banani, H. O. Lee, A. A. Hyman, M. K. Rosen, Nat. Rev. Mol. Cell Biol. 2017, 


\section{WILEY-VCH}

18, 285.

[34] M. Weiss, J. P. Frohnmayer, L. T. Benk, B. Haller, J.-W. Janiesch, T. Heitkamp, M. Börsch, R. B. Lira, R. Dimova, R. Lipowsky, E. Bodenschatz, J.-C. Baret, T. Vidakovic-Koch, K. Sundmacher, I. Platzman, J. P. Spatz, Nat. Mater. 2017, 17, 89.

[35] B. M. Discher, Y. Y. Won, D. S. Ege, J. C.-M. Lee, F. S. Bates, D. E. Discher, D. A. Hammer, Science 1999, 284, 1143.

[36] T. Toyota, N. Maru, M. M. Hanczyc, T. Ikegami, T. Sugawara, J. Am. Chem. Soc. 2009, 131, 5012 .

[37] A. Hirono, T. Toyota, K. Asakura, T. Banno, Langmuir 2018, 34, 7821.

[38] T. Banno, S. Miura, R. Kuroha, T. Toyota, Langmuir 2013, 29, 7689.

[39] L. Wang, Y. Lin, Y. Zhou, H. Xie, J. Song, M. Li, Y. Huang, X. Huang, S. Mann, Angew. Chem. Int. Ed. 2019, 58, 1067.

[40] I. Platzman, J. W. Janiesch, J. P. Spatz, J. Am. Chem. Soc. 2013, 135, 3339.

[41] K. L. Thompson, M. Williams, S. P. Armes, J. Colloid Interface Sci. 2014, 447, 217.

[42] A. D. Dinsmore, M. F. Hsu, M. G. Nikolaides, M. Marquez, A. R. Bausch, D. A. Weitz, Science 2002, 298, 1006.

[43] X. Huang, M. Li, D. C. Green, D. S. Williams, A. J. Patil, S. Mann, Nat. Commun. 2013, 4,1 .

[44] P. Gobbo, A. J. Patil, M. Li, R. Harniman, W. H. Briscoe, S. Mann, Nat. Mater. 2018, $17,1145$.

[45] L. Aufinger, F. C. Simmel, Chem. Eur. J 2019, 25, 12659.

[46] M. B. Johnson, A. R. March, L. Morsut, Curr. Opin. Biomed. Eng. 2017, 4, 163.

[47] R. Langer, Mol. Front. J. 2017, 01, 92.

[48] S. Mann, Angew. Chem. Int. Ed. 2013, 52, 155.

[49] I. Ivanov, R. B. Lira, T. Y. D. Tang, T. Franzmann, A. Klosin, L. C. da Silva, A. Hyman, K. Landfester, R. Lipowsky, K. Sundmacher, R. Dimova, Adv. Biosyst. 2019, 


\section{WILEY-VCH}

1

3, 1 .

[50] P. L. Luisi, Chem. Biodivers. 2012, 9, 2635.

[51] Y. Shin, C. P. Brangwynne, Science 2017, 357, 1253.

[52] T. J. Nott, E. Petsalaki, P. Farber, D. Jervis, E. Fussner, A. Plochowietz, T. D. Craggs, D. P. Bazett-Jones, T. Pawson, J. D. Forman-Kay, A. J. Baldwin, Mol. Cell 2015, 57, 936.

[53] L. Guo, J. Shorter, Mol. Cell 2015, 60, 189.

[54] Y. F. Liu, M. H. Tsai, Y. F. Pai, W. S. Hwang, Appl. Phys. A Mater. Sci. Process. 2013, 111, 509 .

[55] M. J. Rale, R. S. Kadzik, S. Petry, Biochemistry 2018, 57, 30.

[56] N. Iraci, E. Gaude, T. Leonardi, A. S. H. Costa, C. Cossetti, L. Peruzzotti-Jametti, J. D. Bernstock, H. K. Saini, M. Gelati, A. L. Vescovi, C. Bastos, N. Faria, L. G. Occhipinti, A. J. Enright, C. Frezza, S. Pluchino, Nat. Chem. Biol. 2017, 13, 951.

[57] A. Gupta, H. B. Eral, T. A. Hatton, P. S. Doyle, Soft Matter 2016, 12, 2826.

[58] K. Göpfrich, I. Platzman, J. P. Spatz, Trends Biotechnol. 2018, 36, 938.

[59] A. M. Gañán-Calvo, R. González-Prieto, P. Riesco-Chueca, M. A. Herrada, M. FloresMosquera, Nat. Phys. 2007, 3, 737.

[60] Y. Ai, R. Xie, J. Xiong, Q. Liang, Small 2019, 1903940, 1.

[61] D. J. Collins, A. Neild, A. deMello, A.-Q. Liu, Y. Ai, Lab Chip 2015, 15, 3439.

[62] L. Shui, A. Van Den Berg, J. C. T. Eijkel, Microfluid. Nanofluidics 2011, 11, 87.

[63] J. Groll, T. Boland, T. Blunk, J. A. Burdick, D. W. Cho, P. D. Dalton, B. Derby, G. Forgacs, Q. Li, V. A. Mironov, L. Moroni, M. Nakamura, W. Shu, S. Takeuchi, G. Vozzi, T. B. F. Woodfield, T. Xu, J. J. Yoo, J. Malda, Biofabrication 2016, 8, 013001.

[64] G. MacBeath, S. L. Schreiber, Science 2000, 289, 1760.

[65] S. Alom Ruiz, C. S. Chen, Soft Matter 2007, 3, 168.

[66] R. D. Piner, J. Zhu, F. Xu, S. Hong, C. A. Mirkin, Science 1999, 283, 661. 


\section{WILEY-VCH}

1 [67] F. Huo, Z. Zheng, G. Zheng, L. R. Giam, H. Zhang, C. A. Mirkin, Science 2008, 321,

2

3

4

5 1658.

[68] W. Shim, A. B. Braunschweig, X. Liao, J. Chai, J. K. Lim, G. Zheng, C. A. Mirkin, Nature 2011, 469, 516.

[69] G. Arrabito, B. Pignataro, Anal. Chem. 2010, 82, 3104.

[70] J. U. Park, M. Hardy, S. J. Kang, K. Barton, K. Adair, D. kishore Mukhopadhyay, C. Y. Lee, M. S. Strano, A. G. Alleyne, J. G. Georgiadis, P. M. Ferreira, J. A. Rogers, Nat. Mater. 2007, 6, 782 .

[71] P. Ferraro, S. Coppola, S. Grilli, M. Paturzo, V. Vespini, Nat. Nanotechnol. 2010, 5, 429.

[72] C. de Marco, C. C. J. Alcântara, S. Kim, F. Briatico, A. Kadioglu, G. de Bernardis, X. Chen, C. Marano, B. J. Nelson, S. Pané, Adv. Mater. Technol. 2019, 4, 1.

[73] X. Kuang, D. J. Roach, J. Wu, C. M. Hamel, Z. Ding, T. Wang, M. L. Dunn, H. J. Qi, Adv. Funct. Mater. 2019, 29, 1.

[74] J. Jang, S. Hong, G. C. Schatz, M. A. Ratner, J. Chem. Phys. 2001, 115, 2721.

[75] G. Arrabito, V. Ferrara, A. Ottaviani, F. Cavaleri, S. Cubisino, P. Cancemi, Y. P. Ho, B. R. Knudsen, M. S. Hede, C. Pellerito, A. Desideri, S. Feo, B. Pignataro, Langmuir 2019, 35, 17156.

[76] A. Urtizberea, M. Hirtz, H. Fuchs, Nanofabrication 2016, 2, 43.

[77] C. D. O’Connell, M. J. Higgins, D. Marusic, S. E. Moulton, G. G. Wallace, Langmuir 2014, 30, 2712.

[78] G. Arrabito, H. Schroeder, K. Schröder, C. Filips, U. Marggraf, C. Dopp, M. Venkatachalapathy, L. Dehmelt, P. I. H. Bastiaens, A. Neyer, C. M. Niemeyer, Small 2014, 10, 2870.

[79] G. Liu, Y. Zhou, R. S. Banga, R. Boya, K. A. Brown, A. J. Chipre, S. T. Nguyen, C. A. Mirkin, Chem. Sci. 2013, 4, 2093. 


\section{WILEY-VCH}

1 [80] O. A. Basaran, H. Gao, P. P. Bhat, Annu. Rev. Fluid Mech. 2013, 45, 85.

2 [81] Y. Zhang, B. Zhu, Y. Liu, G. Wittstock, Nat. Commun. 2016, 7, 12424.

3 [82] Y. Zhang, D. Li, Y. Liu, G. Wittstock, Small 2018, 14, 1801212.

4 [83] Y. Zhang, D. Li, Y. Liu, G. Wittstock, Small 2018, 14, 1802583.

5 [84] Y. Zhang, B. Zhu, G. Wittstock, D. Li, Y. Liu, X. Zhang, Sensors Actuators B Chem.

6 2018, 255, 2011.

[85] G. Arrabito, F. Cavaleri, A. Porchetta, F. Ricci, V. Vetri, M. Leone, B. Pignataro, Adv. Biosyst. 2019, 3, 1900023.

[86] X. Chen, H. Zhang, Y. Hemar, N. Li, P. Zhou, Food Chem. 2020, 308, 125596.

[87] N. Chéron, M. Naepels, E. Pluhařová, D. Laage, J. Phys. Chem. B 2020, 124, 1424.

[88] K. Joshi, A. K. Bhuyan, Biophys. Chem. 2020, 257, 106274.

[89] G. D. Martin, S. D. Hoath, I. M. Hutchings, J. Phys. Conf. Ser. 2008, 105, 12001.

[90] T. Lim, S. Han, J. Chung, J. T. Chung, S. Ko, C. P. Grigoropoulos, Int. J. Heat Mass Transf. 2009, 52, 431.

[91] P. S. Brown, A. Berson, E. L. Talbot, T. J. Wood, W. C. E. Schofield, C. D. Bain, J. P. S. Badyal, Langmuir 2011, 27, 13897.

[92] C. Le Clerc, Phys. Fluids 2004, 16, 3403.

[93] D. M. Anderson, Phys. Fluids 2005, 17, 1.

[94] D. T. Chiu, R. M. Lorenz, G. D. M. Jeffries, Anal. Chem. 2009, 81, 5111.

[95] G. Arrabito, F. Cavaleri, V. V. Montalbano, V. Vetri, M. Leone, B. Pignataro, Lab Chip 2016, 16, 4666.

[96] H. Lhuissier, C. Sun, A. Prosperetti, D. Lohse, Phys. Rev. Lett. 2013, 110, 2.

[97] L. Wang, G. Arrabito, Analyst 2015, 140, 5821.

[98] M. A. Boerneke, J. E. Ehrhardt, K. M. Weeks, Annu. Rev. Virol. 2019, 6, 93.

[99] A. Pressman, C. Blanco, I. A. Chen, Curr. Biol. 2015, 25, R953.

[100] E. Janzen, C. Blanco, H. Peng, J. Kenchel, I. A. Chen, Chem. Rev. 2020, DOI 


\section{WILEY-VCH}

10.1021/acs.chemrev.9b00620.

[101] P. W. K. Rothemund, Nature 2006, 440, 297.

[102] W. Wang, S. Yu, S. Huang, S. Bi, H. Han, J. R. Zhang, Y. Lu, J. J. Zhu, Chem. Soc. Rev. 2019, 48, 4892.

[103] D. I. Rozkiewicz, W. Brugman, R. M. Kerkhoven, B. J. Ravoo, D. N. Reinhoudt, J. Am. Chem. Soc. 2007, 129, 11593.

[104] R. Kobayashi, M. Biyani, S. Ueno, S. R. Kumal, H. Kuramochi, T. Ichiki, Biosens. Bioelectron. 2015, 67, 115.

[105] J. Jaeger, F. Groher, J. Stamm, D. Spiehl, J. Braun, E. Dörsam, B. Suess, Biosensors 2019, 9, 7 .

[106] B. Kuhlman, P. Bradley, Nat. Rev. Mol. Cell Biol. 2019, 20, 681.

[107] H. Zhao, V. Ibrahimova, E. Garanger, S. Lecommandoux, Angew. Chem. Int. Ed. 2020.

[108] A. Ljubetič, F. Lapenta, H. Gradišar, I. Drobnak, J. Aupič, Ž. Strmšek, D. Lainšček, I. Hafner-Bratkovič, A. Majerle, N. Krivec, M. Benčina, T. Pisanski, T. Ć. Veličković, A. Round, J. M. Carazo, R. Melero, R. Jerala, Nat. Biotechnol. 2017, 35, 1094.

[109] S. Gonen, F. DiMaio, T. Gonen, D. Baker, Science 2015, 348, 1365.

[110] W. Bai, C. J. Sargent, J. M. Choi, R. V. Pappu, F. Zhang, Nat. Commun. 2019, 10, 3317.

[111] G. M. Nishioka, A. A. Markey, C. K. Holloway, J. Am. Chem. Soc. 2004, 126, 16320.

[112] E. Rideau, R. Dimova, P. Schwille, F. R. Wurm, K. Landfester, Chem. Soc. Rev. 2018, $47,8572$.

[113] H. Xing, K. Hwang, Y. Lu, Theranostics 2016, 6, 1336.

[114] A. Jesorka, O. Orwar, Annu. Rev. Anal. Chem. 2008, 1, 801.

[115] V. M. Shah, D. X. Nguyen, P. Patel, B. Cote, A. Al-Fatease, Y. Pham, M. G. Huynh, Y. Woo, A. W. Alani, Nanomedicine 2019, 18, 146.

[116] Y. Zhu, B. Yang, S. Chen, J. Du, Prog. Polym. Sci. 2017, 64, 1. 


\section{WILEY-VCH}

1 [117] L. L. Kiessling, R. A. Splain, Annu. Rev. Biochem. 2010, 79, 619.

2 [118] Y. Gu, W. Zhang, H. Wang, W. Y. Lee, Colloids Surf. B 2014, 117, 42.

3 [119] Y. Shen, H. Tang, X. Huang, R. Hang, X. Zhang, Y. Wang, X. Yao, Carbohydr. Polym. 2020, 235, 115970.

[120] V. Ferrara, G. Zito, G. Arrabito, S. Cataldo, M. Scopelliti, C. Giordano, V. Vetri, B. Pignataro, ACS Biomater. Sci. Eng. 2020, DOI 10.1021/acsbiomaterials.9b01871.

[121] G. U. Preethi, J. Sreekutty, B. S. Unnikrishnan, M. G. Archana, H. P. Syama, M. Deepa, R. Shiji, K. S. Anusree, T. T. Sreelekha, Mater. Sci. Eng. C 2020, 107, 110332.

[122] H. Gudapati, M. Dey, I. Ozbolat, Biomaterials 2016, 102, 20.

[123] E. A. Roth, T. Xu, M. Das, C. Gregory, J. J. Hickman, T. Boland, Biomaterials 2004, $25,3707$.

[124] G. Tourniaire, J. Collins, S. Campbell, H. Mizomoto, S. Ogawa, J. F. Thaburet, M. Bradley, Chem. Commun. 2006, 2, 2118.

[125] A. J. Senesi, D. I. Rozkiewicz, D. N. Reinhoudt, C. A. Mirkin, ACS Nano 2009, 3,

[127] K. A. Brown, D. J. Eichelsdoerfer, X. Liao, S. He, C. A. Mirkin, Front. Phys. 2014, 9, 385.

[128] Z. Kalay, T. K. Fujiwara, A. Kusumi, PLoS One 2012, 7, e32948.

[129] G. Liu, M. Hirtz, H. Fuchs, Z. Zheng, Small 2019, 15, 1900564.

[130] S. Gandor, S. Reisewitz, M. Venkatachalapathy, G. Arrabito, M. Reibner, H. Schröder, K. Ruf, C. M. Niemeyer, P. I. H. Bastiaens, L. Dehmelt, Angew. Chem. Int. Ed. 2013, $52,4790$.

[131] G. Arrabito, S. Reisewitz, L. Dehmelt, P. I. Bastiaens, B. Pignataro, H. Schroeder, C. M. Niemeyer, Small 2013, 9, 4243. 


\section{WILEY-VCH}

1 [133] L. Fabié, H. Durou, T. Ondarçuhu, Langmuir 2010, 26, 1870.

2 [134] K. A. Brown, J. L. Hedrick, D. J. Eichelsdoerfer, C. A. Mirkin, ACS Nano 2019, 13, 8.

3 [135] R. Kumar, A. Urtizberea, S. Ghosh, U. Bog, Q. Rainer, S. Lenhert, H. Fuchs, M. Hirtz, Langmuir 2017, 33, 8739.

[136] A. Angelin, U. Bog, R. Kumar, C. M. Niemeyer, M. Hirtz, Polymers 2019, 11, 891.

[137] E. Rani, S. A. Mohshim, M. Z. Ahmad, R. Goodacre, S. A. A. Ahmad, L. S. Wong, Polymers 2019, 11, 561.

[138] X. Liu, C. Carbonell, A. B. Braunschweig, Chem. Soc. Rev. 2016, 45, 6289.

[139] S. Liu, M. Olvera de la Cruz, J. Polym. Sci. Part B Polym. Phys. 2018, 56, 731.

[140] L. M. Demers, D. S. Ginger, S. J. Park, Z. Li, S. W. Chung, C. A. Mirkin, Science 2002, 296, 1836.

[141] K.-B. Lee, S.-J. Park, C. A. Mirkin, J. C. Smith, M. Mrksich, Science 2002, 295, 1702.

[142] K.-B. B. Lee, J.-H. H. Lim, C. A. A. Mirkin, J. Am. Chem. Soc. 2003, 125, 5588.

[143] R. Meyer, S. Giselbrecht, B. E. Rapp, M. Hirtz, C. M. Niemeyer, Curr. Opin. Chem. Biol. 2014, 18, 8 .

[144] A. Angelin, S. Weigel, R. Garrecht, R. Meyer, J. Bauer, R. K. Kumar, M. Hirtz, C. M. Niemeyer, Angew. Chem. Int. Ed. 2015, 54, 15813.

[145] K. A. Brown, D. J. Eichelsdoerfer, X. Liao, S. He, C. A. Mirkin, Front. Phys. 2014, 9, 385.

[146] S. Lenhert, C. A. Mirkin, H. Fuchs, Scanning 2010, 32, 15.

[147] S. Lenhert, P. Sun, Y. Wang, H. Fuchs, C. A. Mirkin, Small 2007, 3, 71.

[148] A. E. Kusi-Appiah, N. Vafai, P. J. Cranfill, M. W. Davidson, S. Lenhert, Biomaterials 2012, 33, 4187.

[149] A. E. Kusi-Appiah, T. W. Lowry, E. M. Darrow, K. A. Wilson, B. P. Chadwick, M. W. Davidson, S. Lenhert, Lab Chip 2015, 15, 3397.

[150] O. A. Nafday, T. W. Lowry, S. Lenhert, Small 2012, 8, 1021. 


\section{WILEY-VCH}

1 [151] O. A. Nafday, S. Lenhert, Nanotechnology 2011, 22, 22.

2 [152] S. Lenhert, F. Brinkmann, T. Laue, S. Walheim, C. Vannahme, S. Klinkhammer, M. Xu, S. Sekula, T. Mappes, T. Schimmel, H. Fuchs, Nat. Nanotechnol. 2010, 5, 275.

4 [153] A. Kumar, G. M. Whitesides, Appl. Phys. Lett. 1993, 63, 2002.

5 [154] T. Kaufmann, B. J. Ravoo, Polym. Chem. 2010, 1, 371.

6 [155] W. Feng, E. Ueda, P. A. Levkin, Adv. Mater. 2018, 30, 1.

7 [156] M. Nakamura, A. Kobayashi, F. Takagi, A. Watanabe, Y. Hiruma, K. Ohuchi, Y. Iwasaki, M. Horie, I. Morita, S. Takatani, Tissue Eng. 2005, 11, 1658.

[157] B. Derby, J. Mater. Chem. 2008, 18, 5717.

[158] J. Li, F. Rossignol, J. Macdonald, Lab Chip 2015, 15, 2538.

11 [159] G. Arrabito, C. Musumeci, V. Aiello, S. Libertino, G. Compagnini, B. Pignataro, Langmuir 2009, 25, 6312.

[160] B. Derby, Annu. Rev. Mater. Res. 2010, 40, 395.

[161] H. N. Chia, B. M. Wu, J. Biol. Eng. 2015, 9, 4.

[162] L. Zhang, G. Yang, B. N. Johnson, X. Jia, Acta Biomater. 2019, 84, 16.

[163] F. P. W. Melchels, J. Feijen, D. W. Grijpma, Biomaterials 2010, 31, 6121.

[164] K. M. Choi, J. A. Rogers, J. Am. Chem. Soc. 2003, 125, 4060.

[165] Z. Wang, R. Abdulla, B. Parker, R. Samanipour, S. Ghosh, K. Kim, Biofabrication 2015, 7, 45009 .

[166] Z. Zhang, R. Liu, H. Zepeda, L. Zeng, J. Qiu, S. Wang, ACS Appl. Polym. Mater. 2019, $1,2023$.

[167] F. Scalera, C. E. Corcione, F. Montagna, A. Sannino, A. Maffezzoli, Ceram. Int. 2014, $40,15455$.

[168] K.-W. Lee, S. Wang, B. C. Fox, E. L. Ritman, M. J. Yaszemski, L. Lu, Biomacromolecules 2007, 8, 1077.

[169] S. A. Skoog, P. L. Goering, R. J. Narayan, J. Mater. Sci. Mater. Med. 2014, 25, 845. 


\section{WILEY-VCH}

1 [170] T. M. Seck, F. P. W. Melchels, J. Feijen, D. W. Grijpma, J. Control. Release 2010, 148, 34 .

[171] E. Zanchetta, M. Cattaldo, G. Franchin, M. Schwentenwein, J. Homa, G. Brusatin, P. Colombo, Adv. Mater. 2016, 28, 370.

[172] D. Xue, Y. Wang, J. Zhang, D. Mei, Y. Wang, S. Chen, ACS Appl. Mater. Interfaces 2018, 10, 19428.

[173] B. Grigoryan, S. J. Paulsen, D. C. Corbett, D. W. Sazer, C. L. Fortin, A. J. Zaita, P. T. Greenfield, N. J. Calafat, J. P. Gounley, A. H. Ta, F. Johansson, A. Randles, J. E. Rosenkrantz, J. D. Louis-Rosenberg, P. A. Galie, K. R. Stevens, J. S. Miller, Science 2019, 364, 458 .

[174] Y. Zhou, S. Liao, X. Tao, X.-Q. Xu, Q. Hong, D. Wu, Y. Wang, ACS Appl. Bio Mater. 2018, $1,502$.

[175] D. B. Kolesky, K. A. Homan, M. A. Skylar-Scott, J. A. Lewis, Proc. Natl. Acad. Sci. 2016, 113, 3179 .

[176] A. Schober, U. Fernekorn, S. Singh, G. Schlingloff, M. Gebinoga, J. Hampl, A. Williamson, Eng. Life Sci. 2013, 13, 352.

[177] S. Correia Carreira, R. Begum, A. W. Perriman, Adv. Healthc. Mater. 2019, n/a, 1900554

[178] S. Balasubramanian, M.-E. Aubin-Tam, A. S. Meyer, ACS Synth. Biol. 2019, 8, 1564.

[179] I. Donderwinkel, J. C. M. M. van Hest, N. R. Cameron, Polym. Chem. 2017, 8, 4451.

[180] D. Nyamjav, R. C. Holz, Langmuir 2010, 26, 18300.

[181] O. Roling, C. Wendeln, U. Kauscher, P. Seelheim, H. J. Galla, B. J. Ravoo, Langmuir 2013, 29, 10174.

[182] N. Hu, M. Sun, X. Lin, C. Gao, B. Zhang, C. Zheng, H. Xie, Q. He, Adv. Funct. Mater. 2018, 28,1 .

[183] C.-S. Chen, H. Zhu, Biotechniques 2006, 40, 423. 


\section{WILEY-VCH}

1 [184] T. Goldmann, J. S. Gonzalez, J. Biochem. Biophys. Methods 2000, 42, 105.

2 [185] A. N. Marchi, I. Saaem, B. N. Vogen, S. Brown, T. H. LaBean, Nano Lett. 2014, 14,

3

4 5740.

[186] W. G. Patrick, A. A. K. Nielsen, S. J. Keating, T. J. Levy, C. W. Wang, J. J. Rivera, O. Mondragón-Palomino, P. A. Carr, C. A. Voigt, N. Oxman, D. S. Kong, PLoS One $2015,10,1$.

[187] L. Mugherli, O. N. Burchak, L. A. Balakireva, A. Thomas, F. Chatelain, M. Y. Balakirev, Angew. Chem. Int. Ed. 2009, 48, 7639.

[188] G. Arrabito, C. Galati, S. Castellano, B. Pignataro, Lab Chip 2013, 13, 68.

[189] R. A. Clark, P. B. Hietpas, A. G. Ewing, Anal. Chem. 1997, 69, 259.

[190] R. Mateen, M. M. Ali, T. Hoare, Nat. Commun. 2018, 9, 602.

[191] M. Benz, M. R. Molla, A. Böser, A. Rosenfeld, P. A. Levkin, Nat. Commun. 2019, 10, 1.

[192] M. Yamada, H. Imaishi, K. Morigaki, Langmuir 2013, 29, 6404.

[193] V. Lalone, M. V. Fawaz, J. Morales-Mercado, M. A. Mourão, C. S. Snyder, S. Y. Kim, A. P. Lieberman, A. Tuteja, G. Mehta, T. J. Standiford, K. Raghavendran, K. Shedden, A. Schwendeman, K. A. Stringer, G. R. Rosania, Analyst 2019, 144, 3790.

[194] Y. Sun, X. Chen, X. Zhou, J. Zhu, Y. Yu, Lab Chip 2015, 15, 2429.

[195] J. Eggers, Phys. Rev. Lett. 1993, 71, 3458.

[196] M. Staszak, J. Surfactants Deterg. 2016, 19, 297.

[197] C. Stringari, A. Cinquin, O. Cinquin, M. A. Digman, P. J. Donovan, E. Gratton, Proc. Natl. Acad. Sci. U.S.A. 2011, 108, 13582.

[198] Y. Elani, R. V Law, O. Ces, Nat. Commun. 2014, 5, 5305.

[199] Y. Elani, T. Trantidou, D. Wylie, L. Dekker, K. Polizzi, R. V. Law, O. Ces, Sci. Rep. 2018, 8,1 .

[200] S. Hauschild, U. Lipprandt, A. Rumplecker, U. Borchert, A. Rank, R. Schubert, S. 


\section{WILEY-VCH}

Förster, Small 2005, 1, 1177.

[201] J. C. Stachowiak, D. L. Richmond, T. H. Li, F. Brochard-Wyart, D. A. Fletcher, Lab Chip 2009, 9, 2003.

[202] G. Villar, A. D. Graham, H. Bayley, Science 2013, 340, 48.

[203] J. S. Najem, G. J. Taylor, R. J. Weiss, M. S. Hasan, G. Rose, C. D. Schuman, A. Belianinov, C. P. Collier, S. A. Sarles, ACS Nano 2018, 12, 4702.

[204] M. J. Booth, V. R. Schild, A. D. Graham, S. N. Olof, H. Bayley, Sci. Adv. 2016, 2, 1.

[205] G. Xie, J. Forth, Y. Chai, P. D. Ashby, B. A. Helms, T. P. Russell, Chem 2019, 5, 2678.

[206] H. Doméjean, M. De La Motte Saint Pierre, A. Funfak, N. Atrux-Tallau, K. Alessandri, P. Nassoy, J. Bibette, N. Bremond, Lab Chip 2017, 17, 110.

[207] S. V Murphy, A. Atala, Nat. Biotechnol. 2014, 32, 773.

[208] H.-W. Kang, S. J. Lee, I. K. Ko, C. Kengla, J. J. Yoo, A. Atala, Nat. Biotechnol. 2016, 34,312 .

[209] M. A. Skylar-Scott, S. G. M. Uzel, L. L. Nam, J. H. Ahrens, R. L. Truby, S. Damaraju, J. A. Lewis, $S c i$. Adv. 2019, 5, 1.

[210] T. J. Hinton, Q. Jallerat, R. N. Palchesko, J. H. Park, M. S. Grodzicki, H.-J. Shue, M. H. Ramadan, A. R. Hudson, A. W. Feinberg, Sci. Adv. 2015, 1, 1.

[211] A. Lee, A. R. Hudson, D. J. Shiwarski, J. W. Tashman, T. J. Hinton, S. Yerneni, J. M. Bliley, P. G. Campbell, A. W. Feinberg, Science 2019, 365, 482.

[212] T. B. H. Schroeder, A. Guha, A. Lamoureux, G. Vanrenterghem, D. Sept, M. Shtein, J. Yang, M. Mayer, Nature 2017, 552, 214.

[213] W. T. Snead, A. S. Gladfelter, Mol. Cell 2019, 76, 295.

[214] D. Kumar, J. D. Paulsen, T. P. Russell, N. Menon, Science 2018, 359, 775.

[215] H. Zeng, J. Yang, D. Katagiri, Y. Rang, S. Xue, H. Nakajima, K. Uchiyama, Sensors Actuators B Chem. 2015, 220, 958. 


\section{WILEY-VCH}

1 [216] G. Arrabito, V. Errico, A. De Ninno, F. Cavaleri, V. Ferrara, B. Pignataro, F. Caselli, Langmuir 2019, 35, 4936.

[217] Z. Che, O. K. Matar, Langmuir 2017, 33, 12140.

[218] D. Spencer, F. Caselli, P. Bisegna, H. Morgan, Lab Chip 2016, 16, 2467.

[219] M. A. Heinrich, W. Liu, A. Jimenez, J. Yang, A. Akpek, X. Liu, Q. Pi, X. Mu, N. Hu, R. M. Schiffelers, J. Prakash, J. Xie, Y. S. Zhang, Small 2019, 15, 1805510.

[220] K. Rezwan, Q. Z. Chen, J. J. Blaker, A. R. Boccaccini, Biomaterials 2006, 27, 3413.

[221] K. Markstedt, A. Mantas, I. Tournier, H. Martínez Ávila, D. Hägg, P. Gatenholm, Biomacromolecules 2015, 16, 1489.

[222] D. H. Rosenzweig, E. Carelli, T. Steffen, P. Jarzem, L. Haglund, Int. J. Mol. Sci. 2015, $16,15118$.

[223] W. L. Ng, S. Wang, W. Y. Yeong, M. W. Naing, Trends Biotechnol. 2016, 34, 689.

[224] L. A. Hockaday, K. H. Kang, N. W. Colangelo, P. Y. C. Cheung, B. Duan, E. Malone, J. Wu, L. N. Girardi, L. J. Bonassar, H. Lipson, C. C. Chu, J. T. Butcher, Biofabrication 2012, 4, 35005 .

[225] S. Jana, B. J. Tefft, D. B. Spoon, R. D. Simari, Acta Biomater. 2014, 10, 2877.

[226] E. Gasparotti, E. Vignali, P. Losi, M. Scatto, B. M. Fanni, G. Soldani, L. Landini, V. Positano, S. Celi, Int. J. Polym. Mater. Polym. Biomater. 2019, 68, 1.

[227] V. Mironov, V. Kasyanov, R. R. Markwald, Curr. Opin. Biotechnol. 2011, 22, 667.

[228] I. T. Ozbolat, Y. Yu, IEEE Trans. Biomed. Eng. 2013, 60, 691.

[229] E. Abelseth, L. Abelseth, L. De la Vega, S. T. Beyer, S. J. Wadsworth, S. M. Willerth, ACS Biomater. Sci. Eng. 2019, 5, 234.

[230] V. K. Lee, A. M. Lanzi, H. Ngo, S.-S. Yoo, P. A. Vincent, G. Dai, Cell. Mol. Bioeng. 2014, 7, 460 .

[231] V. K. Lee, D. Y. Kim, H. Ngo, Y. Lee, L. Seo, S.-S. Yoo, P. A. Vincent, G. Dai, Biomaterials 2014, 35, 8092. 


\section{WILEY-VCH}

1 [232] A. Marro, T. Bandukwala, W. Mak, Curr. Probl. Diagn. Radiol. 2016, 45, 2.

2 [233] N. Martelli, C. Serrano, H. van den Brink, J. Pineau, P. Prognon, I. Borget, S. El Batti, Surgery 2016, 159, 1485.

[234] M. S. Mannoor, Z. Jiang, T. James, Y. L. Kong, K. A. Malatesta, W. O. Soboyejo, N. Verma, D. H. Gracias, M. C. McAlpine, Nano Lett. 2013, 13, 2634.

[235] Y. Hu, J. Wang, X. Li, X. Hu, W. Zhou, X. Dong, C. Wang, Z. Yang, B. P. Binks, J. Colloid Interface Sci. 2019, 545, 104.

[236] S. Zhao, M. Zhu, J. Zhang, Y. Zhang, Z. Liu, Y. Zhu, C. Zhang, J. Mater. Chem. B 2014, 2, 6106.

[237] R. Herbert, S. Mishra, H.-R. Lim, H. Yoo, W.-H. Yeo, Adv. Sci. 2019, 6, 1901034.

[238] L. Valot, J. Martinez, A. Mehdi, G. Subra, Chem. Soc. Rev. 2019, 48, 4049.

[239] Y. Ma, N. Hu, J. Liu, X. Zhai, M. Wu, C. Hu, L. Li, Y. Lai, H. Pan, W. W. Lu, X. Zhang, Y. Luo, C. Ruan, ACS Appl. Mater. Interfaces 2019, 11, 9415.

[240] E. De Giglio, M. A. Bonifacio, A. M. Ferreira, S. Cometa, Z. Y. Ti, A. Stanzione, K. Dalgarno, P. Gentile, Sci. Rep. 2018, 8, 15130.

[241] G. Bahcecioglu, N. Hasirci, B. Bilgen, V. Hasirci, Biofabrication 2019, 11, 25002.

[242] S. H. Park, R. Su, J. Jeong, S.-Z. Guo, K. Qiu, D. Joung, F. Meng, M. C. McAlpine, Adv. Mater. 2018, 30, 1803980.

[243] A. E. Jakus, A. L. Rutz, S. W. Jordan, A. Kannan, S. M. Mitchell, C. Yun, K. D. Koube, S. C. Yoo, H. E. Whiteley, C. P. Richter, R. D. Galiano, W. K. Hsu, S. R. Stock, E. L. Hsu, R. N. Shah, Sci. Transl. Med. 2016, 8, 358ra127.

[244] S.-Y. Tee, J. Fu, C. S. Chen, P. A. Janmey, Biophys. J. 2011, 100, L25.

[245] Y.-C. Chiu, Y.-F. Shen, A. K.-X. Lee, S.-H. Lin, Y.-C. Wu, Y.-W. Chen, Polymers 2019, 11, 1394.

[246] F. Pati, J. Jang, D.-H. Ha, S. Won Kim, J.-W. Rhie, J.-H. Shim, D.-H. Kim, D.-W. Cho, Nat. Commun. 2014, 5, 3935. 


\section{WILEY-VCH}

1 [247] J. Yong, Y. Liang, Y. Yu, B. Hassan, M. S. Hossain, K. Ganesan, R. R. Unnithan, R. Evans, G. Egan, G. Chana, B. Nasr, E. Skafidas, ACS Appl. Mater. Interfaces 2019, 11, 17521.

[248] V. Restrepo Schild, M. J. Booth, S. J. Box, S. N. Olof, K. R. Mahendran, H. Bayley, Sci. Rep. 2017, 7, 46585.

[249] X. Lin, Y. Rivenson, N. T. Yardimci, M. Veli, Y. Luo, M. Jarrahi, A. Ozcan, Science 2018, 361, 1004.

[250] Q. Gu, E. Tomaskovic-Crook, R. Lozano, Y. Chen, R. M. Kapsa, Q. Zhou, G. G. Wallace, J. M. Crook, Adv. Healthc. Mater. 2016, 5, 1429.

[251] D. Joung, N. S. Lavoie, S. Guo, S. H. Park, A. M. Parr, M. C. McAlpine, Adv. Funct. Mater. 2020, 30, 1906237.

[252] J. Xu, M. Lynch, J. L. Huff, C. Mosher, S. Vengasandra, G. Ding, E. Henderson, Biomed. Microdevices 2004, 6, 117.

[253] A. Goñi-Moreno, P. I. Nikel, Front. Bioeng. Biotechnol. 2019, 7, 1.

[254] R. Suriano, S. Biella, F. Cesura, M. Levi, S. Turri, Appl. Surf. Sci. 2013, 273, 717.

[255] A. K. Schneider, P. M. Nikolov, S. Giselbrecht, C. M. Niemeyer, Small 2017, 13, 1.

[256] S. Reisewitz, H. Schroeder, N. Tort, K. A. Edwards, A. J. Baeumner, C. M. Niemeyer, Small 2010, 6, 2162.

[257] S. Laing, R. Suriano, D. A. Lamprou, C. A. Smith, M. J. Dalby, S. Mabbott, K. Faulds, D. Graham, ACS Appl. Mater. Interfaces 2016, 8, 24844.

[258] C. Carbonell, K. C. Stylianou, J. Hernando, E. Evangelio, S. A. Barnett, S. Nettikadan, I. Imaz, D. Maspoch, Nat. Commun. 2013, 4, 1.

[259] M. Hirtz, W. Feng, H. Fuchs, P. A. Levkin, Adv. Mater. Interfaces 2016, 3, 1.

[260] J. M. Collins, R. T. S. Lam, Z. Yang, B. Semsarieh, A. B. Smetana, S. Nettikadan, Lab Chip 2012, 12, 2643.

[261] J.-W. W. Jang, J. M. M. Collins, S. Nettikadan, Adv. Funct. Mater. 2013, 23, 5840. 


\section{WILEY-VCH}

1 [262] M. Hirtz, J. Brglez, H. Fuchs, C. M. Niemeyer, Small 2015, 11, 5752.

2 [263] M.-S. Yang, C. Song, J. Choi, J.-S. Jo, J.-H. Choi, B. K. Moon, H. Noh, J.-W. Jang, 3 Nanoscale 2019, 11, 2326.

4 [264] J.-W. Jang, B. Park, S. Nettikadan, Nanoscale 2014, 6, 7912.

5 [265] N. Cubo, M. Garcia, J. F. del Cañizo, D. Velasco, J. L. Jorcano, Biofabrication 2016, 9 , 615006.

7

8

9

10

11

12

13

14

15 


\section{WILEY-VCH}

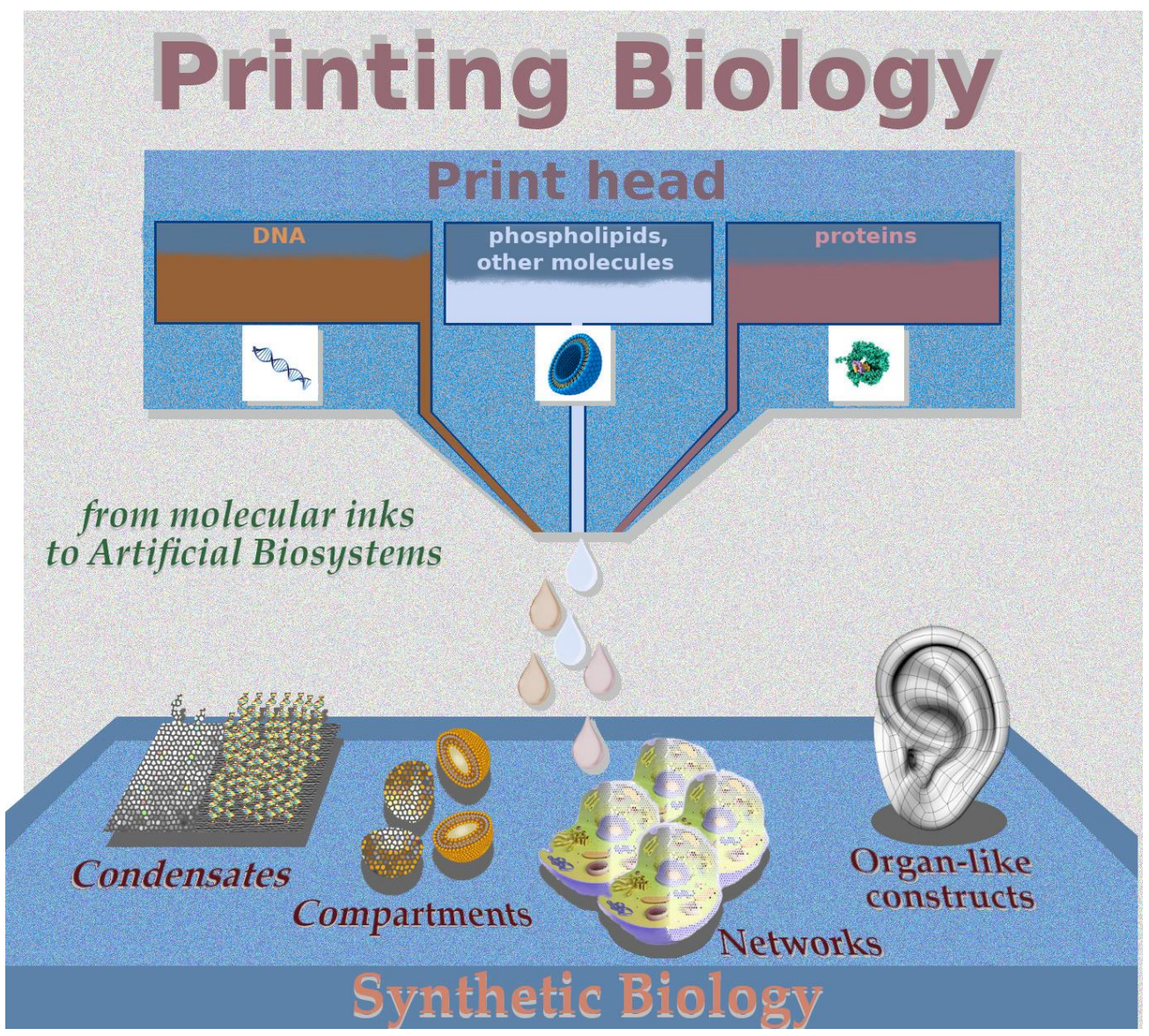

2 Figure 1. A schematic picture showing the key feature of Printing Biology consisting of highresolution printing heads, employing engineered molecular inks (e.g. DNA, phospholipids, proteins) to build up artificial biosystems (on-solids, into-liquids), including all those life-like or life-inspired structures showing a biological behavior, from small condensates, up to compartments, networks, tissues and organ-like constructs. In this way, Printing Biology intersects the field of the bottom-up Synthetic Biology.
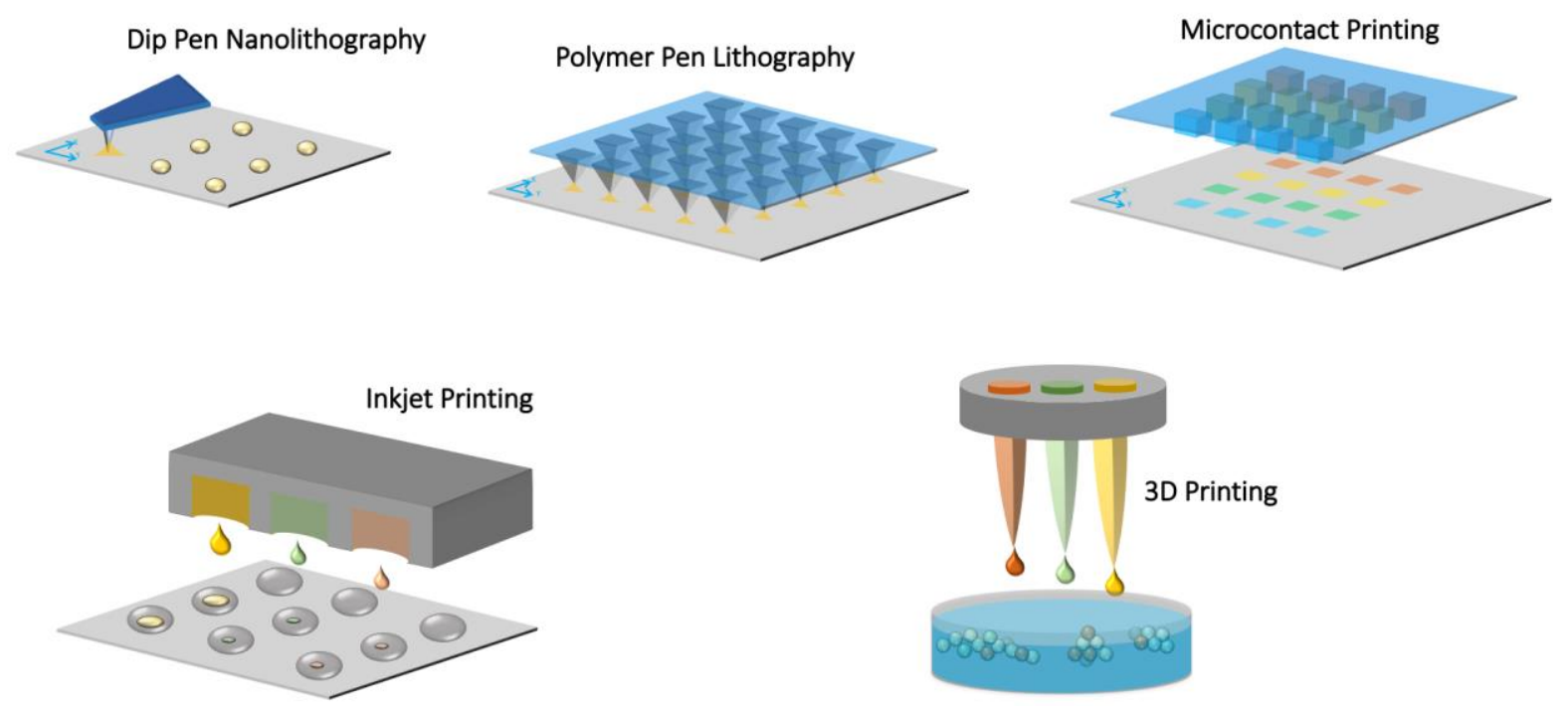

Figure 2. Main printing methods allowing delivering size tunable molecular inks onto solids or into liquids. 


\section{CONTACT METHODS}

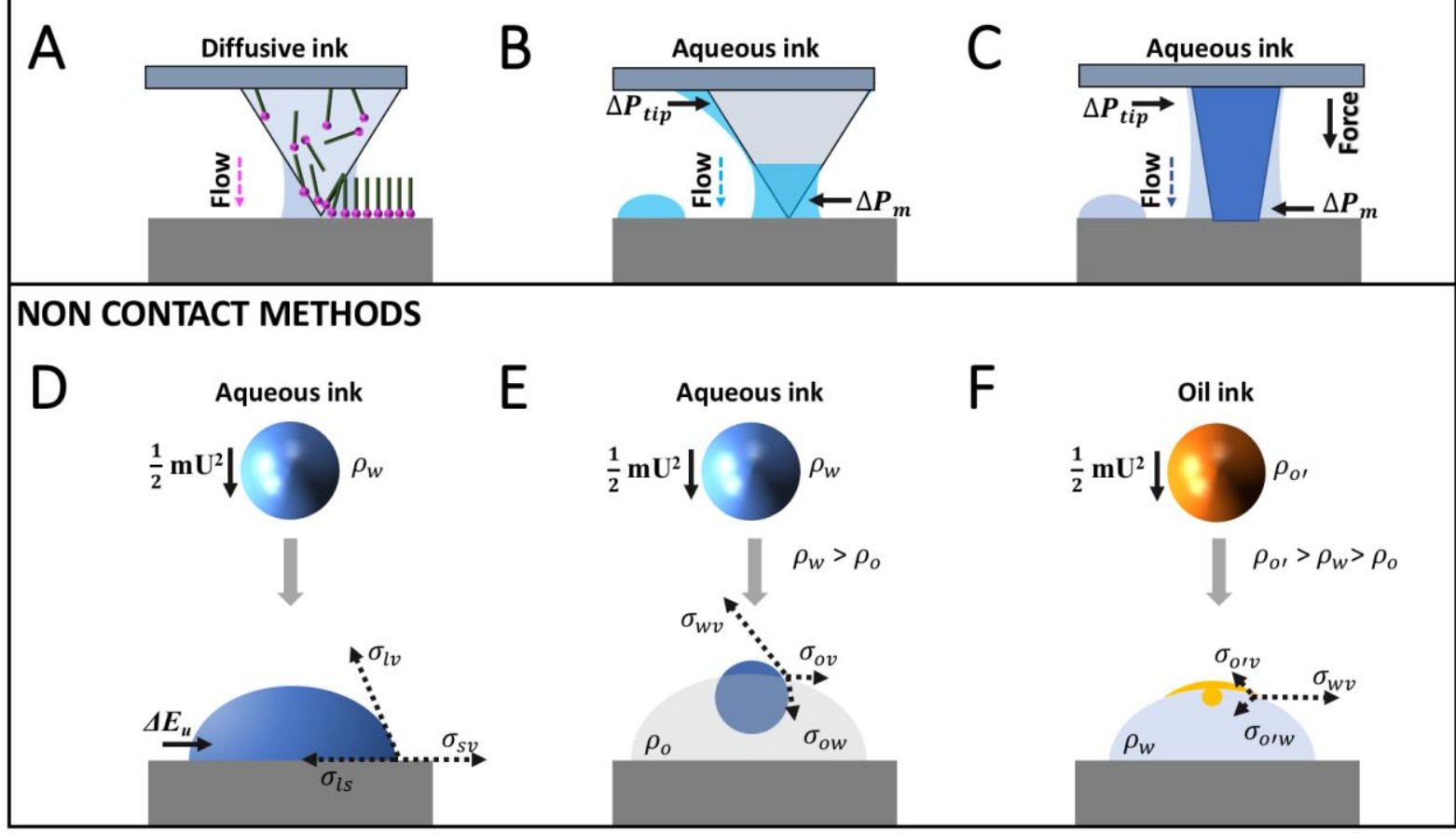

Figure 3. Physical mechanisms of inks deposition. (A) Diffusive molecular ink deposition by Dip Pen Lithography onto solid surfaces. (B) Liquid ink deposition by Dip Pen Lithography onto solid surfaces. (C) Liquid ink deposition by Polymer Lithography onto solid surfaces. Notably, $\Delta \mathrm{P}_{\text {tip }}$ and $\Delta \mathrm{P}_{\mathrm{m}}$ identify the Laplace gradient between the ink-tip and the ink-air menisci, respectively. (D) Microscale ink droplet deposition onto solid supports. The parameters $\mathrm{m}$ and $\mathrm{U}$ identify the mass and the velocity of the impacting droplet. $\Delta \mathrm{E}_{\mathrm{u}}$ is the dissipated energy by viscosity during the droplet impact; $\sigma_{\mathrm{lv}}, \sigma_{\mathrm{ls}}$ and $\sigma_{\mathrm{sv}}$ identify the liquidvapor, liquid-solid and solid-vapor surface energies, respectively. (E) Microscale aqueous ink droplet deposition onto immiscible oil-droplet; $\sigma_{\mathrm{ov}}, \sigma_{\mathrm{wv}}$ and $\sigma_{\mathrm{ow}}$ represent the oil-vapor, water-vapor and oil-water surface energies, respectively. (F) Microscale oil ink droplet deposition onto immiscible aqueous droplet; $\sigma_{\mathrm{o} / \mathrm{v}}, \sigma_{\mathrm{wv}}, \sigma_{\mathrm{o} / \mathrm{w}}$ represent the oil-vapor, watervapor and oil-water surface energies, respectively. The terms $\rho_{\mathrm{w}}, \rho_{\mathrm{o}}$ and $\rho_{\mathrm{o}}$, identify the densities of the aqueous ink and of the two different oils, respectively. 


\section{WILEY-VCH}

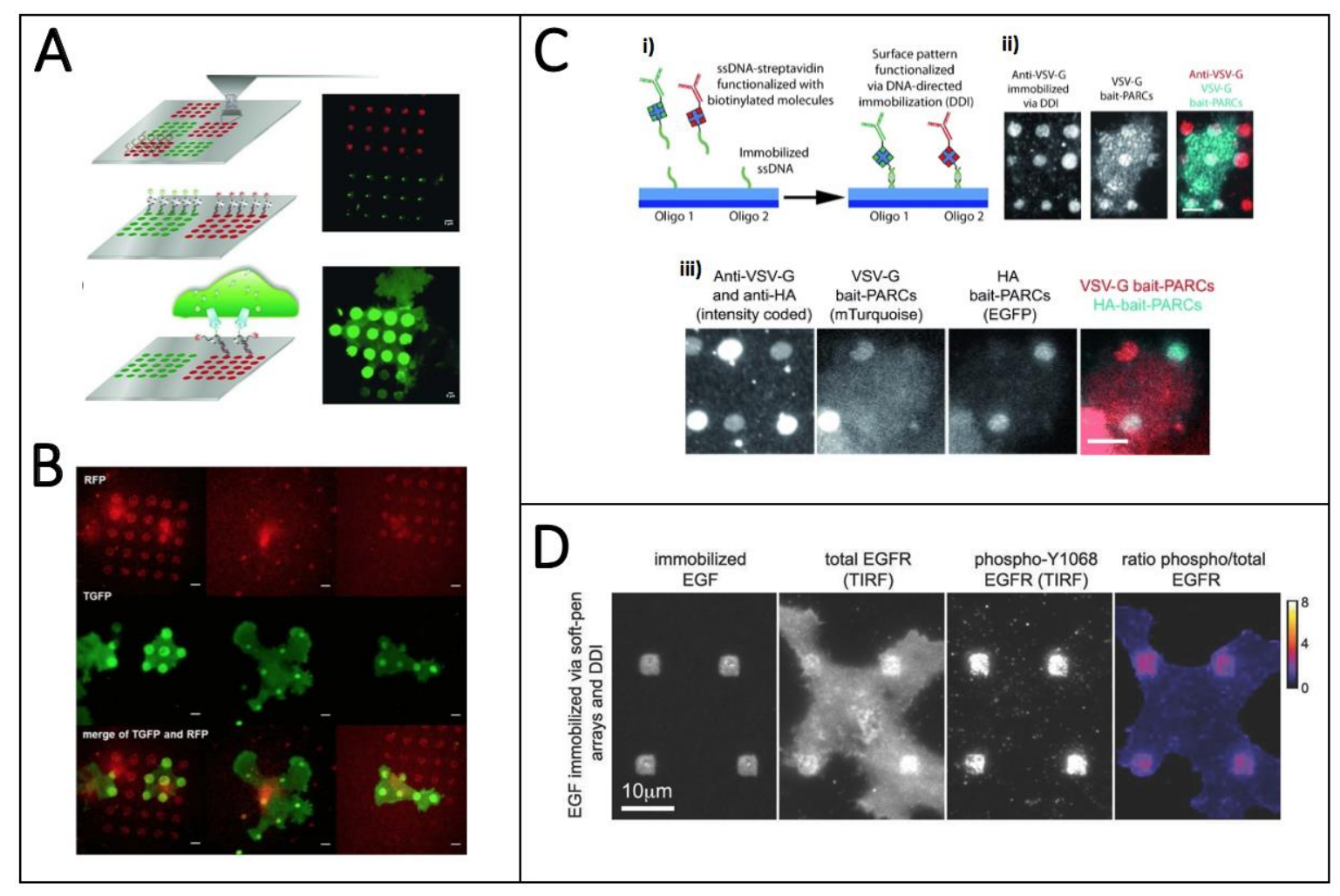

2 Figure 4. Printed DNA-rich condensates on solids. (A-B) DPN coupled with DDI allows the generation of live-cell arrays for the recruitment of transmembrane EGFR receptors on MCF 7 cells. Scale bar is equal to $5 \mu \mathrm{m}$. Reproduced with permission from Ref. ${ }^{[131]}$ Copyright (C) 2013 WILEY-VCH. (C) i) Multiplexed antibodies microarrays by coupling DPN and DDI. ii) COS7 cells expressing bait-PARCs, which display VSV-G epitope tags, are recruited to anti-VSV-G functionalized microarray. iii) COS7 cells expressing two bait-PARCs, which display the corresponding peptide epitope tags (HA and VSV-G) in their extracellular region onto antiVSV-G and anti-HA. Scale bar is equal to $5 \mu \mathrm{m}$ in ii) and equal to $10 \mathrm{microns}$ in iii). Reproduced with permission from Ref. ${ }^{[130]}$ Copyright (C) 2014 WILEY-VCH. (D) EGFR activation on MCF7 cells by EGF ligands is detected by the increased phosphorylation of EGFR at Tyrosine residue 1068 in subcellular regions at interface with EGF-rich microspots. Reproduced with permission from Ref. ${ }^{[78]}$ Copyright $@ 2014$ WILEY-VCH. 


\section{WILEY-VCH}

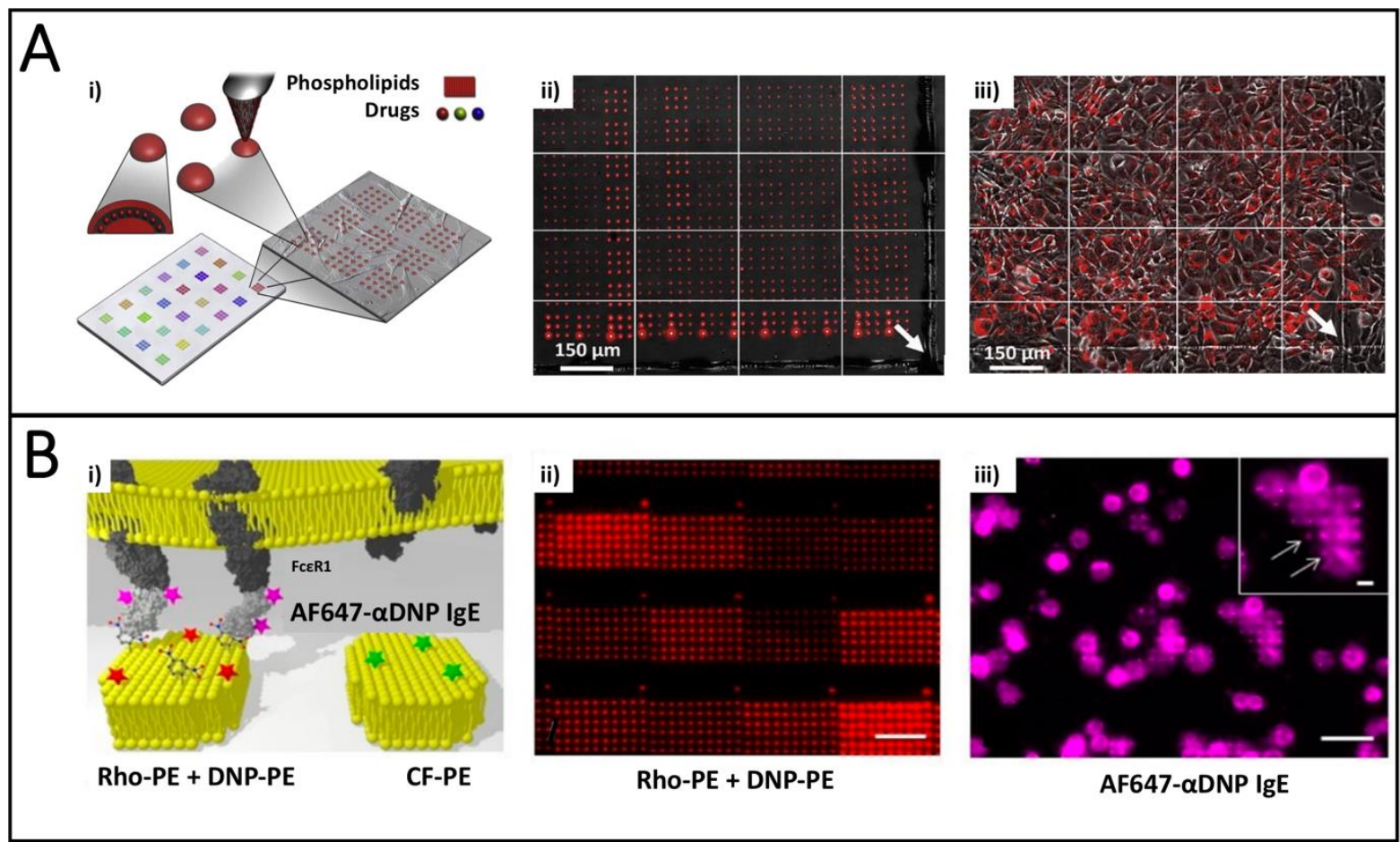

Figure 5. Printed phospholipid-rich condensates on solids. (A) Scheme of phospholipid complex microarrays deposited by DPN: (i) patterns of different color represent drugs loaded at the phospholipid interface, and the relative zoom shows the microarrays constituting each pattern; (ii) phase contrast and fluorescence images overlay of a rhodamine-DOPE/DOTAP pattern, and (iii) its application as surface-mediated delivery system at NIH 3T3 cells interface. The white arrows indicate the printed area borders and evidence the absence of solutionmediated drug delivery. Reprinted from Ref. ${ }^{[148]}$ Copyright (2012), with permission from Elsevier. (B) L-DPN-based platform for extracellular receptor recruitment: (i) scheme of the binding assay, (ii) array of rhodamine-PE and DNP-PE mixture, and (iii) mast cells RBL 2H3 showing co-localization of the cell bound Alexa Fluor 647-labelled anti-dinitrophenol IgE AB (AF647- $\alpha$ DPN IgE) with the allergen/lipid pattern. Scale bars $50 \mu \mathrm{m}$. Reproduced from Ref. ${ }^{[136]}$ under the terms of the Creative Commons Attribution Non-Commercial License. 


\section{WILEY-VCH}

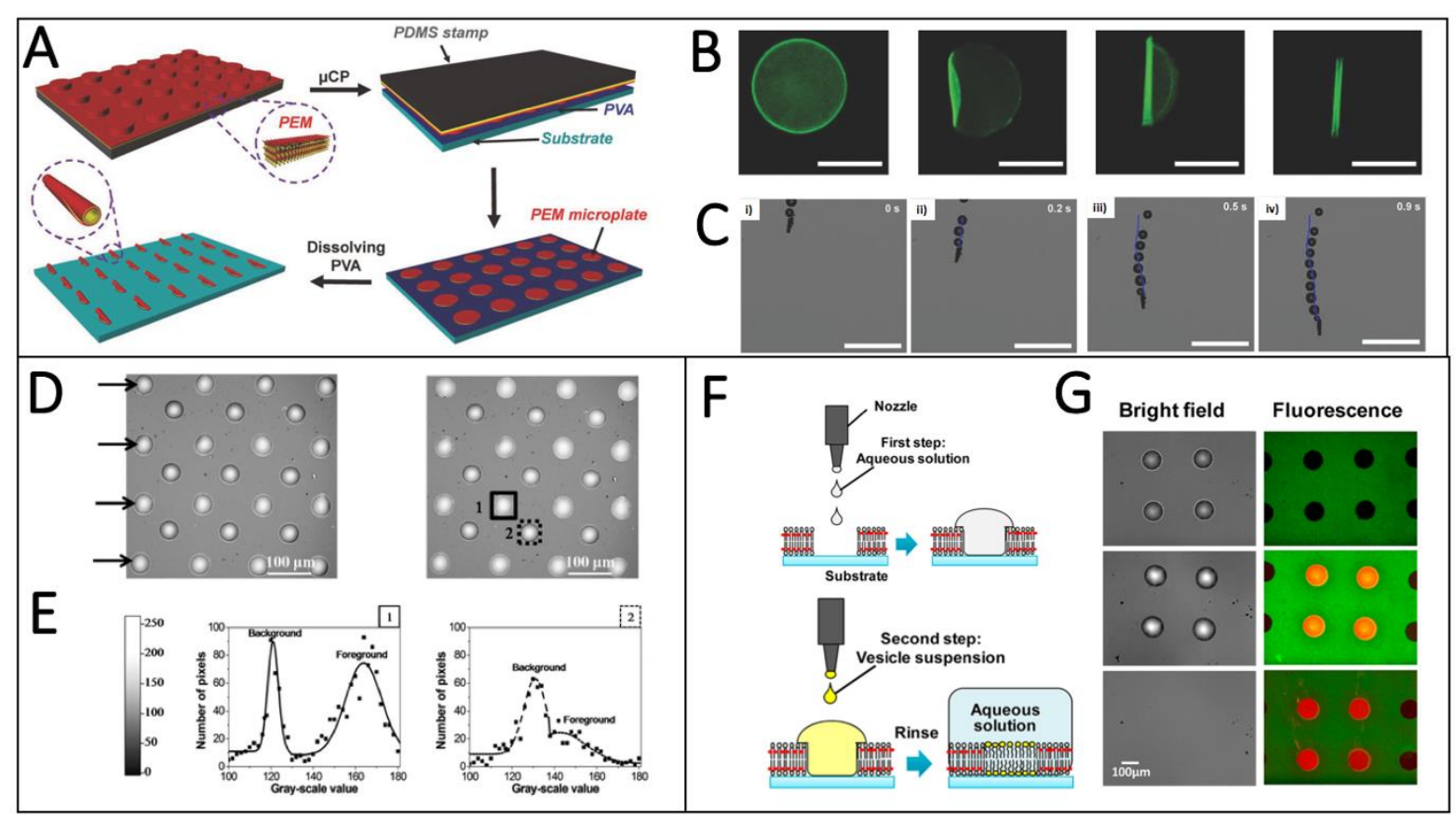

2 Figure 6. Printed microscale aqueous compartments on solids. (A) Fabrication of 3 polyelectrolyte multilayer (PEM) based on $\mu \mathrm{CP}$. (B) PEM microplates can be rolled up to intermediate rolling stages from to microtubes resulting microrockets $(\mathbf{C})$ can travel around straight trajectories upon propulsion, as reported in the (i)-(iv), reaching speed higher than 50 $\mu \mathrm{m} / \mathrm{s}$. Scale bars: $20 \mu \mathrm{m}$. Reproduced with permission from Ref. ${ }^{[182]}$ Copyright $@ 2018$ by John Wiley and Sons, Inc. Reprinted with permission from John Wiley and Sons, Inc. (D) IJP-based drug screening platform based on colorimetric detection of surface immobilized glucose oxidase with glucose at solid/liquid interface. Reaction occurs in spot 1 , whereas it is inhibited in spot 2, due to the presence of the inhibitor D-glucal in the printed droplet. (E) Colorimetric signal extraction from single spots. Reprinted with permission from Ref. ${ }^{[69]}$ Copyright 2010 American Chemical Society. (F) IJP-based fabrication of a microarray containing model biological membranes onto solid substrates. (G) Brightfield and fluorescence images of the printed droplets of the printed phospholipids. Reprinted with permission from Ref. ${ }^{[192]}$ Copyright 2013 American Chemical Society. 
WILEY-VCH

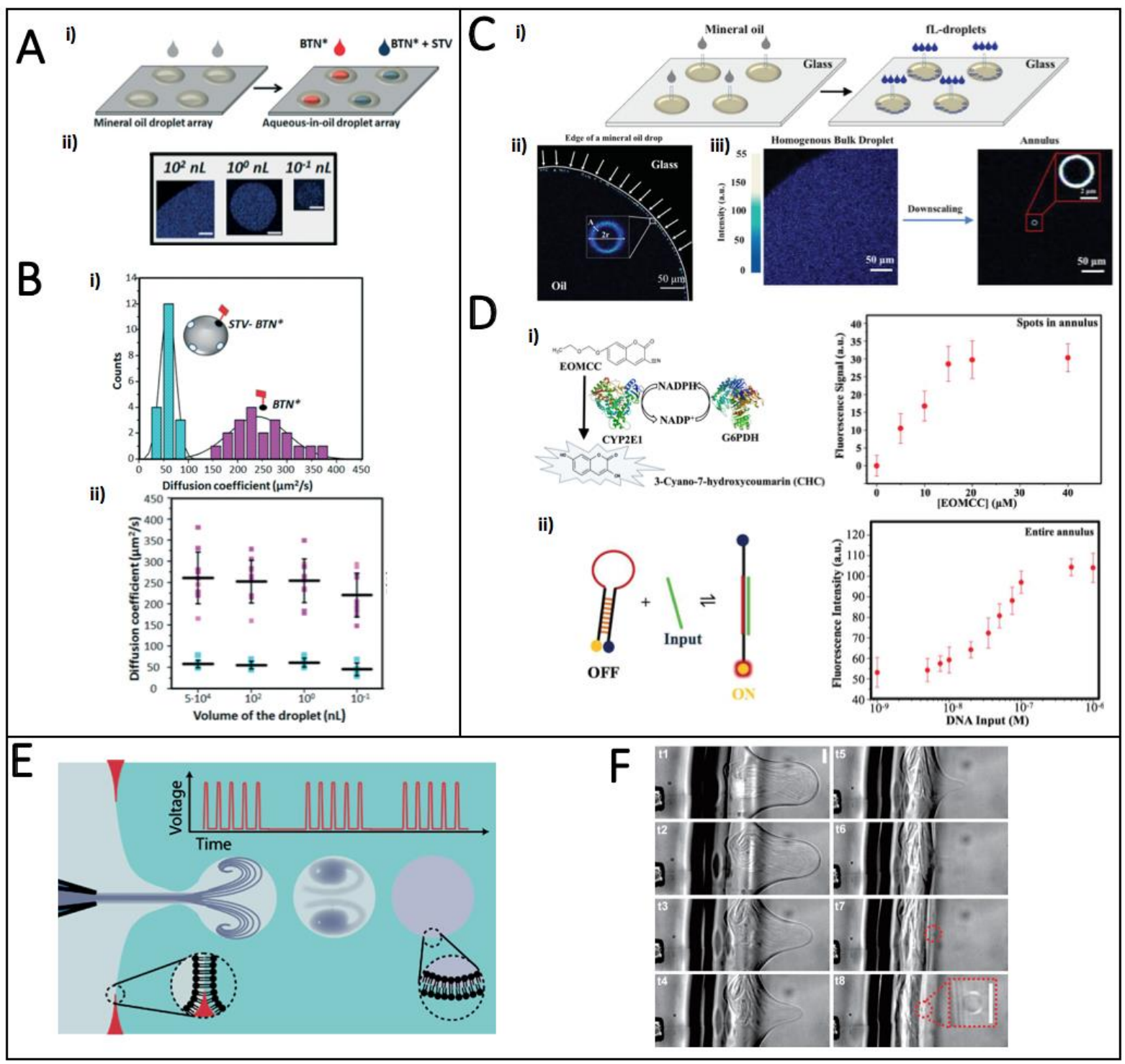

Figure 7. Printed microscale aqueous compartments into liquids. (A) (i) IJP protein-rich aqueous compartments containing mixtures of streptavidin (STV) - fluorolabeled biotin $\left(\mathrm{BTN}^{*}\right)$ at nL-scale. (ii) IJP allows tuning the aqueous compartment volume from $10^{2}$ to $10^{-1}$ nL. (B) The model STV-BTN* binding interaction is investigated in the compartments by RICS, permitting to obtain the differences on the diffusion coefficient between the free BTN* and the STV-BTN* complex (i) and the effect of the droplet volume (ii). Republished with permission from the Royal Society of Chemistry, from Ref. ${ }^{[95]}$; permission conveyed through Copyright Clearance Center, Inc. (C) IJP fL-scale compartments printed inside mineral oil droplets (i) with crowding effects at water/oil interfaces (ii); the droplets are assembled at the water/oil interface and (iii) autonomous molecular adsorption at the water/oil interface is observed. (D) Model mitochondrial reaction (i) consisting in the EOMCC conversion to form CHC and (ii) DNA hairpin conformational change to double strand DNA can be successfully carried out within the compartments. Reproduced from Ref. ${ }^{[85]}$ (E) IJP-based formation of single lipid vesicles at liquid/liquid interfaces. The pauses between pulses determine the frequency of vesicle formation. (F) The formation of pL-sized phospholipid vesicles is possible by tuning the shear rates during the membrane collapse by increasing the viscosity of the solution in which the phospholipid membranes are formed. Scale bar is equal to $50 \mu \mathrm{m}$. Reproduced with permission from the Royal Society of Chemistry, from Ref. ${ }^{[201]}$; permission conveyed through Copyright Clearance Center, Inc. 


\section{WILEY-VCH}

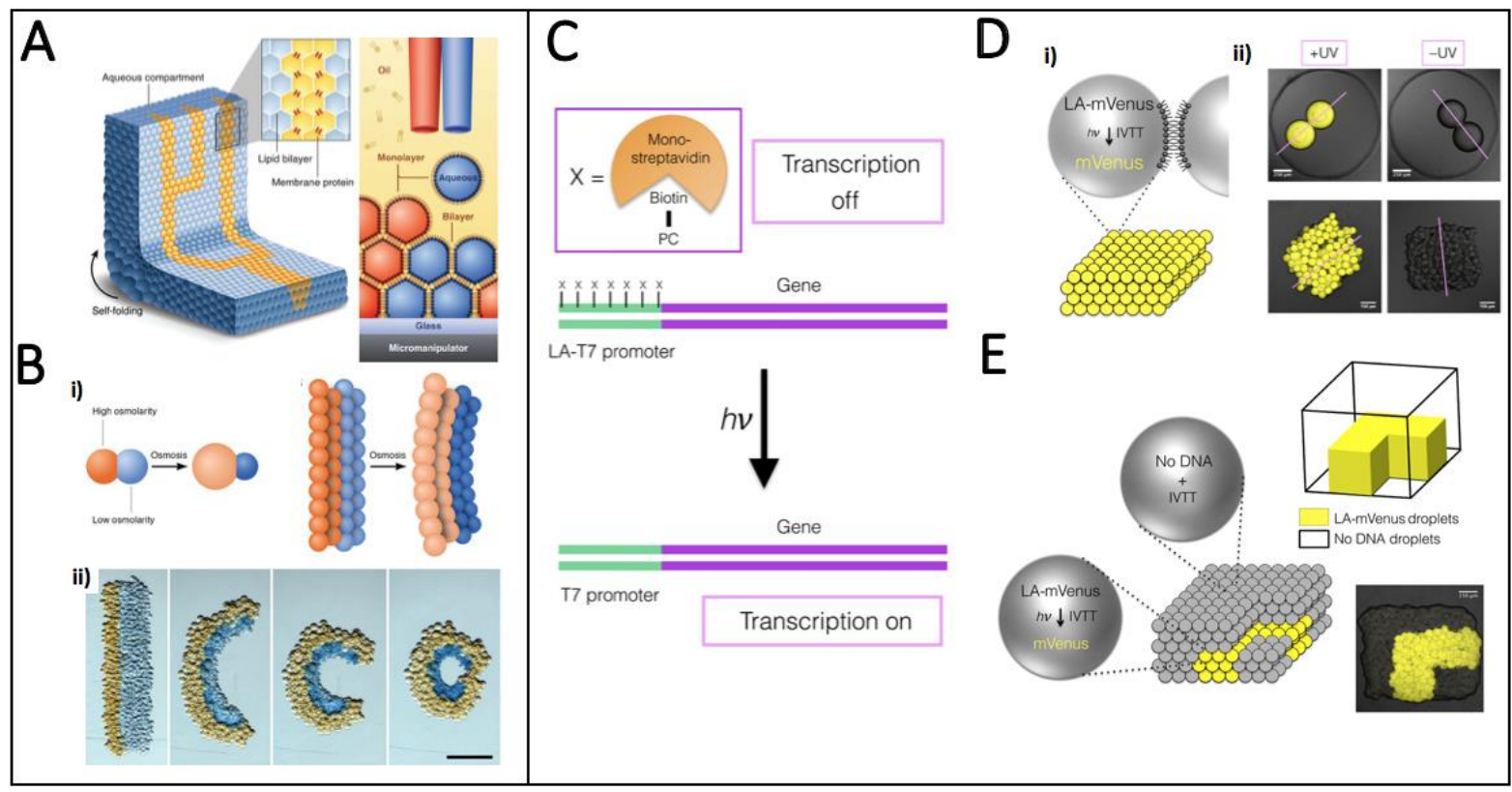

Figure 8. Printed aqueous compartments networks: towards synthetic tissues. (A) Fabrication of tissue-like soft materials by printing aqueous droplets of about $\sim 65 \mathrm{pL}$ volume into a solution of lipids in oil. The staphylococcal $\alpha$-hemolysin $(\alpha H L)$ was added to favor electrical conductivity between the droplets. (B) When droplets at different osmolarities (i) are joined by a lipid bilayer, the resulting flow of water through the bilayer causes swelling or shrinking of the droplets (ii). The orange and blue droplets contained $250 \mathrm{mM} \mathrm{KCl}$ and $16 \mathrm{mM}$ $\mathrm{KCl}$, respectively. Scale bar, $250 \mu \mathrm{m}$. Figures reproduced from Ref. ${ }^{[202]}$ Reprinted with permission from AAAS. (C) UV-triggered protein expression system. UV light allows the cleavage of the photocleavable biotin linkers that bind streptavidin to DNA, permitting the T7 RNA polymerase to bind the LA-T7 promoter, allowing the gene transcription. (D) Scheme (i) and optical images (ii) of the light-activated expression of LA-mVenus in synthetic cells and synthetic tissues. (E) Patterned control of the protein expression in synthetic tissues (i). Optical image of the synthetic compartments expressing mVenus. Figure reproduced from Ref. ${ }^{[204]}$ under the terms of the Creative Commons Attribution Non-Commercial License.

A

B
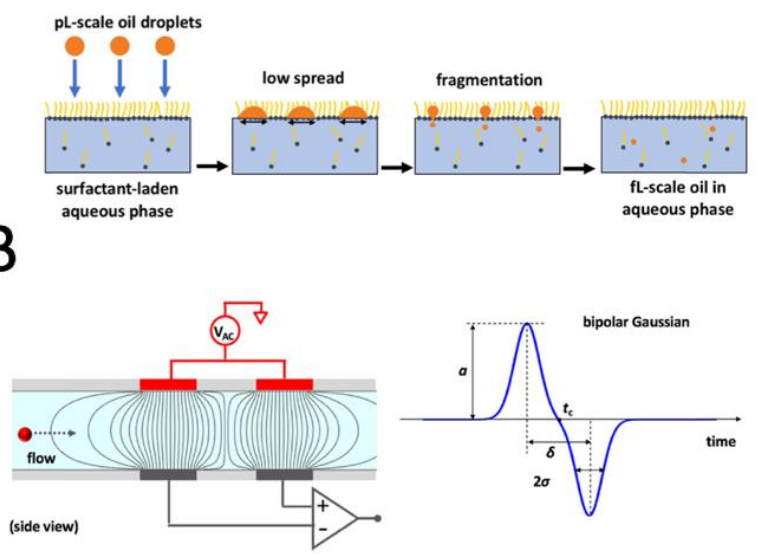

C

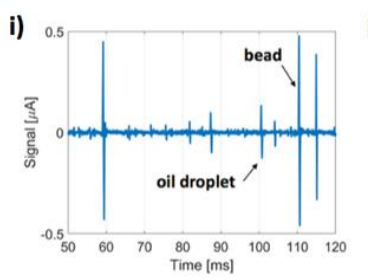

D

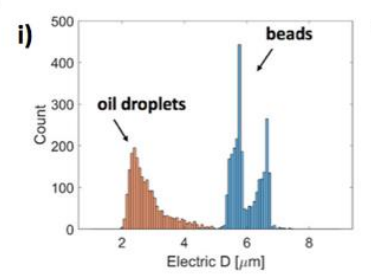

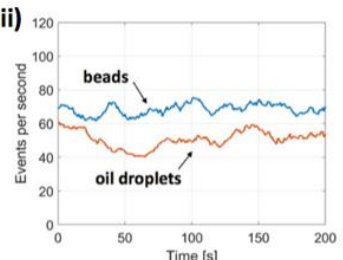

i)

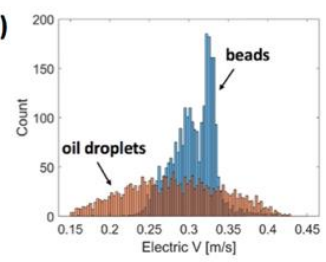




\section{WILEY-VCH}

1 Figure 9. Printed primitive microscale compartments. (A) IJP water-immiscible pL-scale

2 oil droplets into a surfactant laden water phase leads to the spontaneous fragmentation leading 3 to the formation of fL-scale oil droplets dispersed in the aqueous phase. (B) Electrical detection 4 of single oil droplets by a microfluidic impedance chip. (C) Single oil droplets are detected in 5 a microfluidic chip by observing the electrical impedance variations in the flowing aqueous 6 phase. (D) (i) Size and (ii) velocity profile of the droplets lead to the emergence of a scenario 7 in which the oil droplets lack from field focusing effects, due to their small sub-cellular scale. 8 Reprinted with permission from Ref. ${ }^{[216]}$ Copyright (2019) American Chemical Society. 


\section{WILEY-VCH}

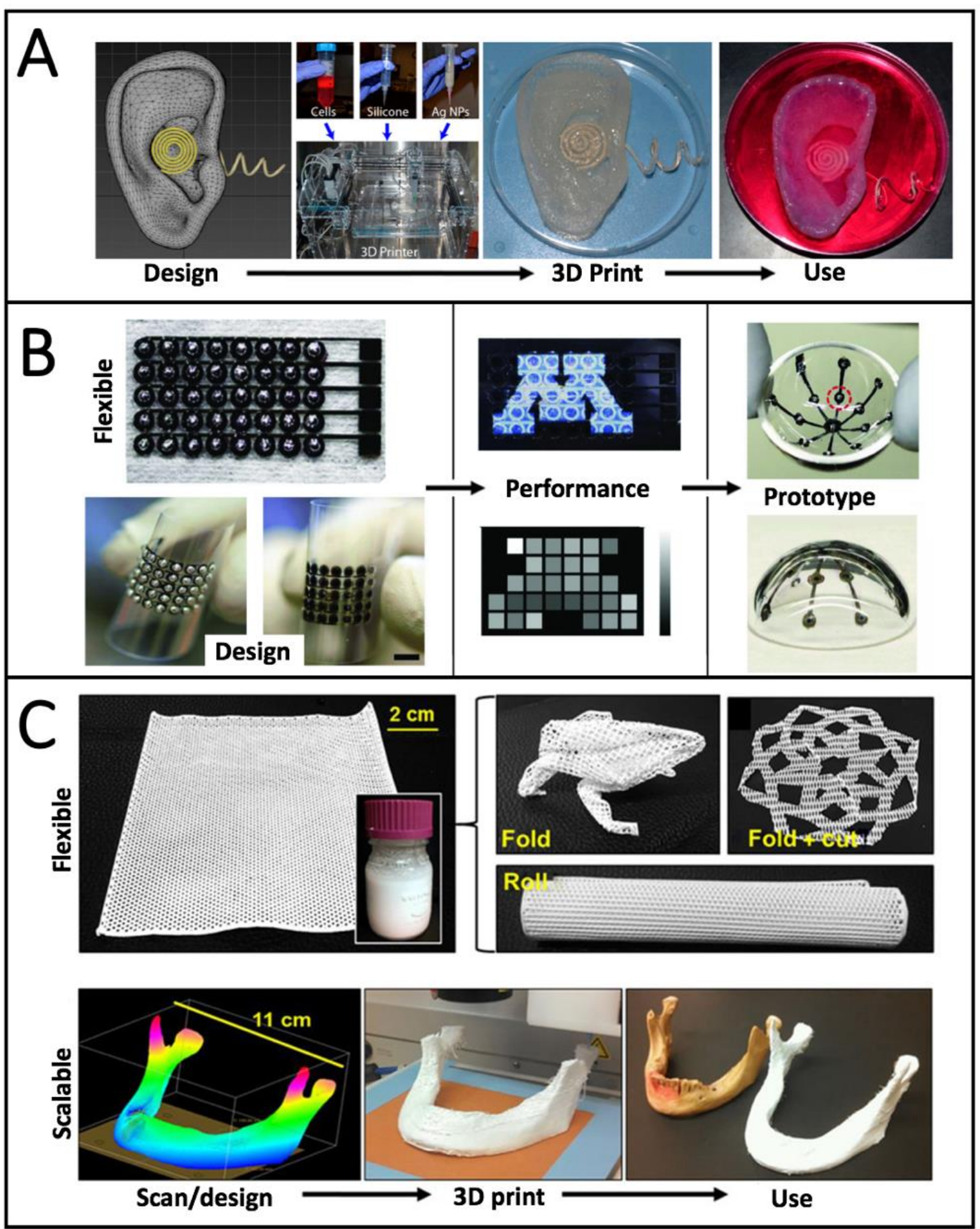

Figure 10. Progress towards 3D printed tissues and organs. (A) Manufacturing steps to generate a bionic ear. From left to right, (i) CAD drawing of the bionic ear, (ii) panoramic view of the printed functional materials and the 3D printed employed for the printing process, (iii) the 3D printed bionic ear immediately after printing, iv) the 3D printed bionic ear during in vitro culture. Reproduced with permission from Ref. ${ }^{[234]}$ Copyright 2013, American Chemical Society. (B) 3D-printed photodetector arrays printed on planar and spherical surfaces. From left to right, (i) photodetector array printed on PET films, (ii) letter "M" optical patterns projected onto the photodetector array and the reconstructed image, (iii) photographs of the concentric 11 photodetector array printed onto the inner surface of a hemispherical glass dome. Reproduced 


\section{WILEY-VCH}

with permission from Ref. ${ }^{[242]}$ Copyright 2018, WILEY-VCH. (C). 3D printed hyperplastic bones, composed of hydroxyapatite and either polycaprolactone or poly(lactic-co-glycolic acid). Several possible designs are presented, and the hypothetical route from CAS drawing until the pre-surgical prototype. Reproduced with permission from Ref. ${ }^{[243]}$ Copyright 2016, AAAS.

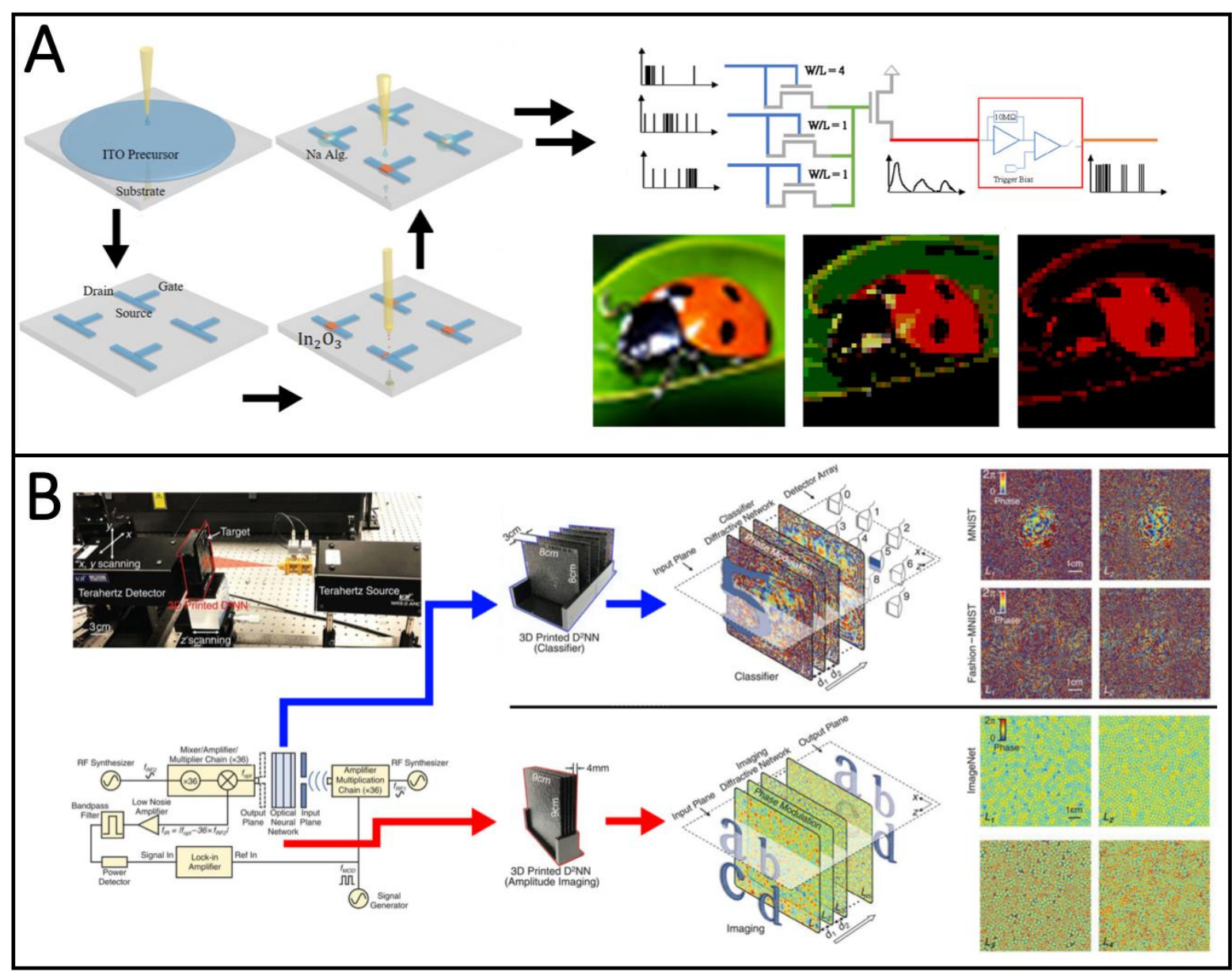

Figure 11. Printed artificial neural networks. (A) Schematic representation of the fully solution-processed synaptic network using metal salt combustion precursors and the transistor morphology. An example of implemented color filtering algorithm is herein shown for a photogram depicting a ladybug on a leaf. Reproduced with permission from Ref. ${ }^{[247]}$ Copyright 2019, American Chemical Society. (B) Diffractive deep neural networks (D2NNs) comprising multiple transmissive (or reflective) layers, where each point on a given layer acts as a neuron, with a complex-valued transmission (or reflection) coefficient. In details, the experimental design for the machine learning apparatus, a representative image of the classifier D2NN (for handwritten digits and fashion products) and the amplitude imaging D2NN. Reproduced with permission from Ref. ${ }^{[249]}$ Copyright 2018, AAAS. 

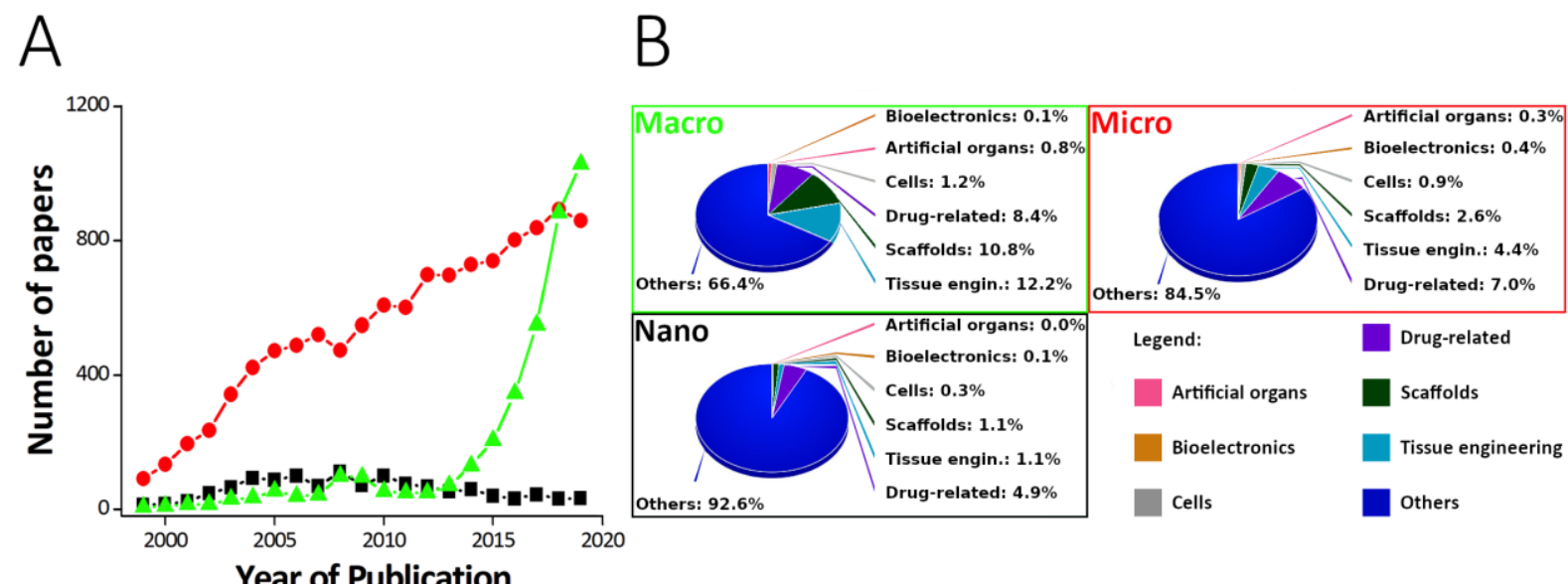

Figure 12. Applications of Printing Technologies. (A) Number of published papers from 1999 to 2019 on nanoscale printing (black squares), microscale printing (red dots) and macroscale printing (green triangles). (B) Pie chart of the major applications of printing technologies for six target bio-related applications (artificial organs, bioelectronics, cells, drugs, scaffolds, tissue engineering) and other technological relevant sectors (printed electronics, microfluidics devices, prototyping technology). Data extracted from the Scopus database. 


\section{WILEY-VCH}

1 Table 1. Major contact nanoscale printing methodologies, molecular ink features 2 (molecules/biomolecules, additives, sizes) and some bio-related applications onto solid 3 surfaces. *DDI stands for DNA directed immobilization, a technique which employs surface4 bound capture oligonucleotides for selectively binding biomolecules tagged with 5 complementary oligomeric sequences. ${ }^{[143]}$

\begin{tabular}{|c|c|c|c|c|c|}
\hline $\begin{array}{c}\text { Printing } \\
\text { Methodology }\end{array}$ & $\begin{array}{c}\text { Printed } \\
\text { Molecules/Biomolecules }\end{array}$ & Added Additives & Droplet Size & Main Features & Ref. \\
\hline \multirow[t]{12}{*}{$\begin{array}{l}\text { Dip Pen } \\
\text { Lithography }\end{array}$} & Oligonucleotides & PEG & $10^{\circ} \mu \mathrm{m}$ & $\begin{array}{l}\text { Protein immobilization } \\
\text { by } \mathrm{DDI}^{*}\end{array}$ & [131] \\
\hline & Oligonucleotides & - & $10^{2} \mu \mathrm{m}$ & $\begin{array}{l}\text { DNA sequences } \\
\text { immobilization } \\
\text { on thermoplastic polymers }\end{array}$ & [254] \\
\hline & Oligonucleotides & Trehalose & $10^{2} \mu \mathrm{m}$ & $\begin{array}{c}\text { Protein immobilization } \\
\text { by DDI }\end{array}$ & [255] \\
\hline & Oligonucleotides & - & $10^{2} \mu \mathrm{m}$ & $\begin{array}{c}\text { Protein immobilization } \\
\text { by DDI }\end{array}$ & [256] \\
\hline & Oligonucleotides & $\begin{array}{l}\text { Glycerol } \\
\text { PEG }\end{array}$ & $10^{1} \mu \mathrm{m}$ & $\begin{array}{c}\text { Protein immobilization } \\
\text { by DDI }\end{array}$ & [130] \\
\hline & $\begin{array}{c}\text { Thermoresponsive } \\
\text { Polymers }\end{array}$ & - & $10^{1} \mu \mathrm{m}$ & $\begin{array}{c}\text { Thermosensitive cell } \\
\text { support }\end{array}$ & [257] \\
\hline & Phospholipids & - & $10^{0}-10^{1} \mu \mathrm{m}$ & $\begin{array}{c}\text { Supported Phospholipid } \\
\text { Patterns }\end{array}$ & [147] \\
\hline & Phospholipids & - & $10^{-1}-10^{0} \mu \mathrm{m}$ & Combination with $\mu \mathrm{CP}$ & [150] \\
\hline & $\begin{array}{l}\text { Phospholipids } \\
\text { Drug }\end{array}$ & - & $10^{1}-10^{2} \mu \mathrm{m}$ & $\begin{array}{l}\text { Surface-mediated } \\
\text { drug delivery }\end{array}$ & [148] \\
\hline & $\begin{array}{c}\text { Fluorescent Dyes } \\
\text { Mineral Acids and Bases } \\
\text { Transition Metal Salts } \\
\text { Enzymes }\end{array}$ & $\begin{array}{c}\text { Glycerol } \\
\text { Diethyleneglycol }\end{array}$ & $10^{1} \mu \mathrm{m}$ & $\begin{array}{l}\text { Chemical reactions } \\
\text { at the fL-scale }\end{array}$ & [258] \\
\hline & Organic Azides & Glycerol & $5 \mu \mathrm{m}$ & $\begin{array}{l}\text { Protein immobilization } \\
\text { by click-chemistry }\end{array}$ & [259] \\
\hline & $\begin{array}{l}\text { ECM Proteins } \\
\text { Fluorescent Dyes }\end{array}$ & Printing Buffer & $10^{1} \mu \mathrm{m}$ & $\begin{array}{l}\text { Surface-mediated dye } \\
\text { delivery into arrays of cells }\end{array}$ & [260] \\
\hline \multirow[t]{3}{*}{$\begin{array}{l}\text { Multiple } \\
\text { Probe } \\
\text { Lithographies }\end{array}$} & Oligonucleotides & $\begin{array}{l}\text { Glycerol } \\
\text { Tween-20 }\end{array}$ & $10^{1} \mu \mathrm{m}$ & $\begin{array}{l}\text { Protein immobilization by } \\
\text { DDI }\end{array}$ & [78] \\
\hline & Oligonucleotides & Trehalose & & $\begin{array}{l}\text { Detection of fungal } \\
\text { pathogen }\end{array}$ & [137] \\
\hline & PEG derivatives & - & $10^{\circ} \mu \mathrm{m}$ & $\begin{array}{c}\text { ECM protein } \\
\text { immobilization } \\
\text { by chemisorption }\end{array}$ & [261] \\
\hline
\end{tabular}




\section{WILEY-VCH}

\begin{tabular}{ccccc}
\hline Phospholipids & - & $10^{0}-10^{1} \mu \mathrm{m}$ & $\begin{array}{c}\text { Phospholipid pattern } \\
\text { functionalization with DNA } \\
\text { Origami }\end{array}$ & [262] \\
\hline Phospholipids & - & $10^{0}-10^{1} \mu \mathrm{m}$ & $\begin{array}{c}\text { Gradient patterns of } \\
\text { phospholipids }\end{array}$ & ${ }^{[135]}$ \\
\hline Phospholipids & - & $10^{1} \mu \mathrm{m}$ & $\begin{array}{c}\text { Cells recruiting } \\
\text { by immobilized protein }\end{array}$ & [136] \\
\hline Thiols & - & $10^{-1}-10^{0} \mu \mathrm{m}$ & $\begin{array}{c}\text { Diffraction Gratings } \\
\text { Fabrication }\end{array}$ & [263] \\
\hline Thiols & - & $10^{0} \mu \mathrm{m}$ & $\begin{array}{c}\text { Patterning on gold } \\
\text { surfaces }\end{array}$ & [264] \\
\hline
\end{tabular}

1 


\section{WILEY-VCH}

1 Table 2. Major non-contact printing methodologies, molecular ink features 2 (molecules/biomolecules, additives, sizes) and some relevant bio-related applications onto 3 solids or into liquids.

\begin{tabular}{|c|c|c|c|c|c|}
\hline $\begin{array}{l}\text { Printing } \\
\text { Methodology }\end{array}$ & $\begin{array}{c}\text { Printed } \\
\text { Molecules/Biomolecules }\end{array}$ & Added Additives & Droplet Size & Applications & Ref. \\
\hline \multirow[t]{2}{*}{$\begin{array}{l}\text { Microcontact } \\
\text { Printing }\end{array}$} & Oligonucleotides & $\begin{array}{c}30 \mathrm{mM} \text { sodium } \\
\text { acetate buffer; } 10 \% \\
\text { DMSO }\end{array}$ & $10^{1} \mu \mathrm{m}$ & $\begin{array}{l}\text { DNA directly patterned } \\
\text { on glass surfaces }\end{array}$ & [180] \\
\hline & $\begin{array}{c}\text { biotin thiol, mannose thiol, } \\
\text { and tetraethylene glycol } \\
\text { thiol }\end{array}$ & $\begin{array}{l}\alpha, \alpha \text {-dimethoxy- } \alpha- \\
\text { phenylacetophenone }\end{array}$ & $10^{1} \mu \mathrm{m}$ & $\begin{array}{c}\text { Lipidic vesicles } \\
\text { containing amphiphilic } \beta \text { - } \\
\text { cyclodextrin }\end{array}$ & [181] \\
\hline
\end{tabular}

\begin{tabular}{|c|c|c|c|c|c|}
\hline & $\begin{array}{l}\text { Chitosan/alginate } \\
\text { polyelectrolyte multilayer } \\
\text { microsized films }\end{array}$ & l & $10^{1} \mu \mathrm{m}$ & $\begin{array}{l}\text { Fabrication of polymer } \\
\text { multilayer plate } \\
\text { micromotors }\end{array}$ & [182] \\
\hline \multirow[t]{3}{*}{$\begin{array}{l}\text { Inkjet } \\
\text { Printing }\end{array}$} & Oligonucleotides & $\begin{array}{l}\text { 2-Hydroxyethyl } \\
\text { methacrylate; } \\
\text { Phosphoramidite }\end{array}$ & $10^{1} \mu \mathrm{m}$ & $\begin{array}{l}\text { Coupling of of DNA } \\
\text { oligonucleotide synthesis } \\
\text { with DNA origami } \\
\text { technology }\end{array}$ & [185][131] \\
\hline & Proteins & $10-50 \%$ w/v glycerol & $10^{1} \mu \mathrm{m}$ & $\begin{array}{l}\text { Glucose oxidase } \\
\text { monolayer at silicon } \\
\text { dioxide surface }\end{array}$ & [69] \\
\hline & Proteins & DMSO/glycerol (9:1) & $10^{2} \mu \mathrm{m}$ & $\begin{array}{l}\text { DMSO-rich liquid } \\
\text { compartments }\end{array}$ & [187] \\
\hline
\end{tabular}

\begin{tabular}{|c|c|c|c|c|}
\hline Proteins & $30 \% \mathrm{w} / \mathrm{v}$ glycerol & $10^{2} \mu \mathrm{m}$ & $\begin{array}{l}\text { Glycerol-rich liquid } \\
\text { compartments }\end{array}$ & [188] \\
\hline $\begin{array}{c}\text { Lipids } \\
\text { 2-bis(10,12- } \\
\text { tricosadiynoyl)-sn-glycero- } \\
\text { 3-phosphocholine } \\
\text { (DiynePC) }\end{array}$ & $\begin{array}{ll}\text { Fluorophore } & (0.1 \\
\mathrm{mM}), \text { and } 5 \% \quad(\mathrm{v} / \mathrm{v}) \\
\text { glycerine. }\end{array}$ & $10^{1} \mu \mathrm{m}$ & $\begin{array}{l}\text { Phospholipid bilayers at } \\
\text { solid/liquid interface }\end{array}$ & [192] \\
\hline $\begin{array}{l}\text { Lipids } \\
\text { 1,2-dipalmitoyl-sn-glycero- } \\
\text { 3-phosphocholine; }\end{array}$ & \multirow[t]{2}{*}{$\begin{array}{l}\text { Polysorbate } 20 \\
\text { cholesterol }\end{array}$} & $10^{1} \mu \mathrm{m}$ & \multirow[t]{2}{*}{$\begin{array}{l}\text { Single-cell Raman } \\
\text { calibration standard }\end{array}$} & \multirow[t]{2}{*}{ [193] } \\
\hline $\begin{array}{l}\text { 1,2-dioleoyl-sn-glycero-3- } \\
\text { phosphocholine }\end{array}$ & & & & \\
\hline Proteins & $\begin{array}{c}\text { polyoxyethylene }(20) \\
\text { sorbitan } \\
\text { monolaurate }\end{array}$ & $10^{1}-10^{2} \mu \mathrm{m}$ & $\begin{array}{l}\text { pL- to } \mathrm{nL} \text { - scale } \\
\text { aquoeus compartments } \\
\text { by inkjet printing }\end{array}$ & [95] \\
\hline DNA hairpin, Proteins & $\begin{array}{l}\text { polyoxyethylene (20) } \\
\text { sorbitan } \\
\text { monolaurate and } \\
\text { poly(ethylene } \\
\text { glycol)-block- } \\
\text { poly(propylene } \\
\text { glycol)-block- } \\
\text { poly(ethylene glycol) }\end{array}$ & $10^{0}-10^{1} \mu \mathrm{m}$ & $\begin{array}{c}\mathrm{fL} \text {-scale aquoeus } \\
\text { compartments by inkjet } \\
\text { printing }\end{array}$ & [85] \\
\hline $\begin{array}{c}\text { Egg phosphatidylcholine } \\
\text { and poly(2-vinyl- pyridine- } \\
b \text {-ethyleneglycol) }\end{array}$ & Ethanol & $10^{-1} \mu \mathrm{m}$ & $\begin{array}{l}\text { Direct formation of lipid } \\
\text { and polymer vesicles }\end{array}$ & [200]. \\
\hline
\end{tabular}




\section{WILEY-VCH}

\begin{tabular}{ccccc}
\hline $\begin{array}{c}\text { Phospholipids in aqueous } \\
\text { phase }\end{array}$ & $\begin{array}{c}7.5 \mathrm{w} / \mathrm{v} \% \text { ficoll } 400 ; \\
300 \mathrm{mM} \text { glucose } \\
\text { solution }\end{array}$ & $10^{2-3} \mu \mathrm{m}$ & $\begin{array}{l}\text { Unilamellar lipid vesicles } \\
\text { by inkjet printing }\end{array}$ & [201] \\
\hline $\begin{array}{c}\text { Alkaline phosphatase, } \\
\text { Urease, } \beta \text {-lactamase }\end{array}$ & $\begin{array}{c}\text { Glycerol }(5 \mathrm{w} / \mathrm{w} \%) \text { in } \\
10 \mathrm{mM} \text { PBS }\end{array}$ & $10^{2} \mu \mathrm{m}$ & $\begin{array}{c}\text { Protein immobilization } \\
\text { in printed hydrogels }\end{array}$ & [190] \\
\hline Lipidoids & $\begin{array}{c}\text { Aqueous sodium } \\
\text { acetate buffer }\end{array}$ & $10^{2-3} \mu \mathrm{m}$ & $\begin{array}{c}\text { Surface-mediated } \\
\text { molecular delivery into }\end{array}$ & [191]
\end{tabular}

arrays of cells

2

3

4

5

6

7

8

9

10

11

12

13

14

15

16

17

18

19

20

21

22

23

24

25

26

27

28

29

30

31

32 


\section{WILEY-VCH}

Table 3. Major 3D Printing reported examples for the realization of molecular ink features (molecules/biomolecules, solvent(s), additives, printing rate) and some relevant bio-related applications (artificial organs, scaffolds, tissue engineering). The abbreviation n.r. stands for not reported.

\begin{tabular}{|c|c|c|c|c|c|c|}
\hline Application field(s) & Environment & Solvent(s) & $\begin{array}{c}\text { Printed } \\
\text { Molecule(s)/ Biomolecule(s)/ matrix(es) }\end{array}$ & Added Additive(s) & Printing rate & Ref. \\
\hline Artificial electric organs & Aqueous & $\mathrm{H}_{2} \mathrm{O}$ & Acrylamides w/ and w/o glycerol. & Photoinitiator & n.r. & [212] \\
\hline Biocompatible scaffolds & Aqueous & $\mathrm{H}_{2} \mathrm{O} / \mathrm{DMSO}$ & Poly(ethylene glycol)/ poly(D,L-lactide) & $\begin{array}{l}\text { Cross-linking inhibitor, dye, } \\
\text { photoinitiator }\end{array}$ & Stereolithography & [170] \\
\hline Biocompatible scaffolds & Aqueous & $\mathrm{H}_{2} \mathrm{O}$ & Poly(ethylene glycol)/diacrylate hydrogel & Photoinitiator & Stereolithography & [172] \\
\hline Biocompatible scaffolds & Aqueous & $\begin{array}{l}\text { Phosphate buffer solution } \\
\text { / DMSO }\end{array}$ & $\begin{array}{l}\text { Gelatin methacrylate hydrogel/ poly(ethylene glycol)- } \\
\text { diacrylate }\end{array}$ & $\begin{array}{l}\text { 4-Dimethylaminopyridine, photo- } \\
\text { iniziator, 1-Vinyl-2-pyrrolidinone }\end{array}$ & Stereolithography & [165] \\
\hline $\begin{array}{l}\text { Biocompatible scaffolds } \\
\quad \text { (hollow tubules) }\end{array}$ & Aqueous & $\begin{array}{l}-\mathrm{H}_{2} \mathrm{O} \\
-\mathrm{H}_{2} \mathrm{O}\end{array}$ & $\begin{array}{l}\text { - Sodium alginate } \\
\text { - Alginate / gelatin / glutaraldehyde / polyacrylamide } \\
\text { binary combinationshydrogels }\end{array}$ & $\begin{array}{l}\text { - Cross-linking agent } \\
-/\end{array}$ & $\begin{array}{l}-20 \mu \mathrm{L} / \mathrm{min} \\
-5 \div 20 \mu \mathrm{L} / \mathrm{min}\end{array}$ & [174] \\
\hline $\begin{array}{l}\text { Compartmentalized } \\
\text { reactive systems }\end{array}$ & Aqueous & $\begin{array}{l}\text { - Dextran } \\
\text { - PEG }\end{array}$ & $\begin{array}{l}\text { - Poly(diallyldimethylammonium chloride) } \\
\text { - Poly(sodium 4-styrenesulfonate) }\end{array}$ & 1 & $100 \div 4 \mathrm{kmm} / \mathrm{min}$ & [205] \\
\hline Tissue engineering & Aqueous & Phosphate buffer solution & $\begin{array}{l}\text { Poly( } \varepsilon \text {-caprolactone) / adipose, cartilage or heart } \\
\text { decellularized extracellular matrices }\end{array}$ & I & n.r. & [246] \\
\hline $\begin{array}{c}\text { Tissue engineering } \\
\text { (bone, vascular network) }\end{array}$ & Aqueous & Phosphate buffer solution & $\begin{array}{l}\text { - Collagen } \\
\text { - FITC-alginate } \\
\text { - Fibrinogen }\end{array}$ & Hyaluronic acid, albumin & n.r. & [210] \\
\hline $\begin{array}{l}\text { Tissue engineering } \\
\text { (cartilage) }\end{array}$ & Aqueous & $\mathrm{H}_{2} \mathrm{O}$ & Nanofibrillated cellulose & $\begin{array}{l}\text { Alginate, cross-linking agent, } \mathrm{D}^{-} \\
\text {Mannitol }\end{array}$ & $10 \div 20 \mathrm{~mm} / \mathrm{sec}$ & [221] \\
\hline $\begin{array}{l}\text { Tissue engineering } \\
\text { (ear / cartilage) }\end{array}$ & Aqueous & Phosphate buffer solution & Alginate hydrogel matrix/chondrocytes & $\begin{array}{l}\text { Antibiotics / antimycotic, silicone, } \\
\text { silver nanoparticles }\end{array}$ & $0.42 \mathrm{~mL} / \mathrm{min}$ & [234] \\
\hline $\begin{array}{l}\text { Tissue engineering } \\
\text { (heart valve) }\end{array}$ & Aqueous & $\begin{array}{l}\text { Acidic or basic aqueous } \\
\text { medium }\end{array}$ & $\begin{array}{l}\text { - Alginate } \\
\text { - Collagen } \\
\text { - Collagen (acidic solution) }\end{array}$ & Dye, photoinitiator, & $3 \div 23 \mathrm{~mm} / \mathrm{s}$ & [211] \\
\hline
\end{tabular}




\section{WILEY-VCH}

Fibrinectin

Methacrilated hyaluronic acid

\begin{tabular}{|c|c|c|c|c|c|c|}
\hline $\begin{array}{l}\text { Tissue engineering } \\
\text { (heart valve) }\end{array}$ & Aqueous & Phosphate buffer solution & Poly(ethylene glycol)-diacrylate & Photoinitiator & Stereolithography & [224] \\
\hline $\begin{array}{l}\text { Tissue engineering } \\
\text { (neural network) }\end{array}$ & Aqueous & Buffered aqueous solution & $\begin{array}{l}\text { Human induced pluripotent stem cells (hiPSCs)/ } \\
\text { alginate/ Chitosan/ fibrin/ genipin }\end{array}$ & I & n.r. & [229] \\
\hline $\begin{array}{l}\text { Tissue engineering } \\
\text { (neural network) }\end{array}$ & Aqueous & Buffered aqueous solution & $\begin{array}{l}\text { Human neural stem cells (hNSCs)/Agarose/ } \\
\text { carboxymethylchitosan/ polysaccharides alginate }\end{array}$ & Cross-linking agent & n.r. & [250] \\
\hline $\begin{array}{l}\text { Tissue engineering } \\
\text { (skin) }\end{array}$ & Aqueous & Human plasma & Human fibroblasts and keratinocytes & Cross-linking agent & $2.85 \mathrm{~cm}^{2} / \mathrm{min}$ & [265] \\
\hline $\begin{array}{l}\text { Tissue engineering } \\
\text { (vascular network) }\end{array}$ & Aqueous & Collagen hydrogel & Human umbilical vein endothelial cells (HUVECs) & I & n.r. & [231] \\
\hline $\begin{array}{l}\text { Tissue engineering } \\
\text { (vascular network) }\end{array}$ & Aqueous & $\begin{array}{l}-\mathrm{H}_{2} \mathrm{O} \\
-\mathrm{H}_{2} \mathrm{O}\end{array}$ & $\begin{array}{l}-10 \% \text { gelatin mixture } \\
\text { - collagen }\end{array}$ & $\begin{array}{l}1 \\
1\end{array}$ & n.r. & [230] \\
\hline $\begin{array}{l}\text { Tissue engineering } \\
\text { (vascular network) }\end{array}$ & Aqueous & Basic buffer solution & Dopamine/ Hydroxylethyl methacrylate & Curing agent, photoiniziators & Stereolithography & [245] \\
\hline $\begin{array}{l}\text { Tissue engineering } \\
\text { (vascular network) }\end{array}$ & Aqueous & Basic buffer solution & Cell-laden silicon ink & Pluronic F127 & $1 \div 50 \mathrm{~mm} / \mathrm{sec}$ & [175] \\
\hline $\begin{array}{l}\text { Tissue engineering } \\
\text { (vascular network) }\end{array}$ & Aqueous & $\mathrm{H}_{2} \mathrm{O}$ & PEGDA & $\begin{array}{l}\text { Dyes, photoinitiator, metal } \\
\text { nanoparticles }\end{array}$ & Stereolithography & [173] \\
\hline $\begin{array}{l}\text { Tissue engineering } \\
\text { (vascular network) }\end{array}$ & Aqueous & Phosphate buffer solution & Gelatin solution & I & Stereolithography & [209] \\
\hline $\begin{array}{l}- \text { Biocompatible scaffolds } \\
-\quad \text { Drug delivery carriers }\end{array}$ & Biphasic & $\mathrm{H}_{2} \mathrm{O} / \mathrm{CH}_{2} \mathrm{Cl}_{2}$ & $\begin{array}{l}\text { Poly( } \varepsilon \text {-caprolactone }) / \text { hydroxyapatite and silica } \\
\text { nanoparticles }\end{array}$ & Nanoparticles surface modifier & $30 \mathrm{~mm} / \mathrm{sec}$ & [235] \\
\hline Tissue engineering & Biphasic & $\begin{array}{l}\mathrm{H}_{2} \mathrm{O} / \text { hexadecane/ } \\
\text { silicone oil }\end{array}$ & 1,2-Diphytanoyl-sn-glycero-3-phosphocholin & Dyes & $200 \mu \mathrm{m} / \mathrm{sec}$ & [202] \\
\hline Biocompatible scaffolds & Organic & $\begin{array}{l}\text { THF / Tripropylene Glycol } \\
\text { Monomethyl Ether }\end{array}$ & $\begin{array}{l}\text { Methyl-silsesquioxane resin/ 3-(trimethoxysilyl) } \\
\text { propyl methacrylate }\end{array}$ & Photoinitiators & Stereolithography & [171] \\
\hline Biocompatible sensors & Organic & $\begin{array}{l}\text { - 1-methyl-2-pyrrolidinone } \\
\text { - m-Xylene }\end{array}$ & $\begin{array}{l}\text { - Poly(methyl methacrylate) } \\
\text { - Silver nanoparticles }\end{array}$ & $\begin{array}{l}-1 \\
-1\end{array}$ & $10 \mathrm{~mm} / \mathrm{sec}$ & [237] \\
\hline Synthetic tissue & Organic & Hexadecane/silicone oil & $\begin{array}{l}\text { diphytanoyl phosphatidylcholine /1,2-dipalmitoyl-sn- } \\
\text { glycero-3-phosphoethanolamine- } \mathrm{N} \text {-[methoxy(poly- } \\
\text { ethylene glycol)-2000] }\end{array}$ & l & n.r. & [204] \\
\hline
\end{tabular}




\section{WILEY-VCH}

\begin{tabular}{|c|c|c|c|c|c|c|}
\hline $\begin{array}{l}\text { Tissue engineering } \\
\text { (bone) }\end{array}$ & Organic & neat & Cyracure $\Theta^{-}$UVR-6105/ hydroxyapatite powder & Photoinitiator & Stereolithography & [167] \\
\hline $\begin{array}{l}\text { Tissue engineering } \\
\text { (bone) }\end{array}$ & Organic & $\begin{array}{l}\mathrm{CH}_{2} \mathrm{Cl}_{2} / \text { 2-butoxyethanol / } \\
\text { dibutyl phthalate }\end{array}$ & $\begin{array}{l}\text { Hydroxyapatite/Polycaprolactone or } \\
\text { Hydroxyapatite/poly(lactic-co-glycolic acid) }\end{array}$ & I & $15 \mathrm{~cm} / \mathrm{sec}$ & [243] \\
\hline $\begin{array}{l}\text { Tissue engineering } \\
\text { (bone) }\end{array}$ & Organic & 1,4-dioxane & Polyurethane/ urea scaffolds & Piperazine & n.r. & [239] \\
\hline $\begin{array}{l}\text { Tissue engineering } \\
\text { (bone) }\end{array}$ & Organic & neat & Poly(propylene fumarate) & $\begin{array}{l}\text { Cross-linking inhibitor, } \\
\text { photoiniziator }\end{array}$ & Stereolithography & {$[168]$} \\
\hline $\begin{array}{l}\text { Tissue engineering } \\
\text { (bone) }\end{array}$ & Organic & neat & Poly(E-caprolactone) & I & $25 \mathrm{~mm} / \mathrm{min}$ & [240] \\
\hline $\begin{array}{l}\text { Tissue engineering } \\
\text { (bone) }\end{array}$ & Organic & $\mathrm{CHCl}_{3} / \mathrm{DMSO}$ & $\begin{array}{l}\text { Mesoporous bioactive glass/ poly(3-hydroxybutyrate- } \\
\text { co-3-hydroxyhexanoate) }\end{array}$ & 1 & $4 \div 10 \mathrm{~mm} / \mathrm{sec}$ & [236] \\
\hline $\begin{array}{c}\text { Tissue engineering } \\
\text { (bone, ear, skelet. muscle) }\end{array}$ & Organic & neat & Poly(ع-caprolactone) & $\begin{array}{l}\text { DMEM, gelatin, fibrinogen, } \\
\text { hyaluronic acid, trombin }\end{array}$ & $0.4 \mu \mathrm{L} / \mathrm{sec}$ & [208] \\
\hline $\begin{array}{l}\text { Tissue engineering } \\
\text { (cartilage) }\end{array}$ & Organic & neat & Acrylonitrile butadiene styrene/ poly(L-lactic acid) & I & n.r. & [222] \\
\hline $\begin{array}{l}\text { Tissue engineering } \\
\text { (eye) }\end{array}$ & Organic & $\begin{array}{l}\text { - Toluene } \\
\text { - Chlorobenzene }\end{array}$ & $\begin{array}{l}\text { - MDMO/PPV } \\
\text { - P3HT/PCBM }\end{array}$ & $\begin{array}{l}1 \\
1\end{array}$ & $0.5 \div 5 \mathrm{~mm} / \mathrm{sec}$ & [242] \\
\hline $\begin{array}{l}\text { Tissue engineering } \\
\text { (heart valve) }\end{array}$ & Organic & $\begin{array}{l}\text { - neat } \\
\text { - neat }\end{array}$ & $\begin{array}{l}\text { - CarboSil }{ }^{\circledR} 80 A \\
\text { - Estane } \AA 58226\end{array}$ & $\begin{array}{l}1 \\
1\end{array}$ & $1000 \mathrm{~mm} / \mathrm{min}$ & [226] \\
\hline $\begin{array}{l}\text { Tissue engineering } \\
\text { (meniscus) }\end{array}$ & Organic & DMSO & $\begin{array}{l}\text { Cellulose nanocrystals/ Phenyl acrylate / Acrylamide } \\
\text { / N,N'-methylenebis(acrylamide) }\end{array}$ & Photoinitiator & $2 \mathrm{~mm} / \mathrm{sec}$ & [166] \\
\hline $\begin{array}{l}\text { Tissue engineering } \\
\text { (meniscus) }\end{array}$ & Organic & neat & Poly(E-caprolactone) & 1 & Stereolithography & [241] \\
\hline
\end{tabular}




\section{WILEY-VCH}

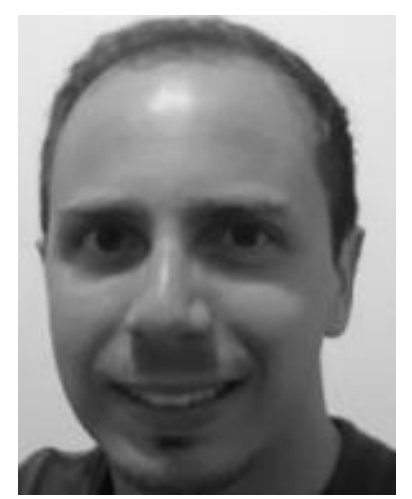

Dr. Giuseppe Arrabito received his B.Sc. in Chemistry and M.Sc. in Biomolecular Chemistry at the Scuola Superiore di Catania. He received his Ph.D. (2012) in Nanoscience from Scuola Superiore di Catania. He was Post-Doctoral fellow in the group of Prof. C.M. Niemeyer at the Technical University of Dortmund and in the group of Dr C. Falconi at the University of Rome Tor Vergata. He is currently a Post-Doctoral Scientist in the group of Prof. B. Pignataro, University of Palermo. His research interests are in the field of Synthetic Biology, Biointerfaces, DNA Nanotechnology, and ZnO-based nanodevices.

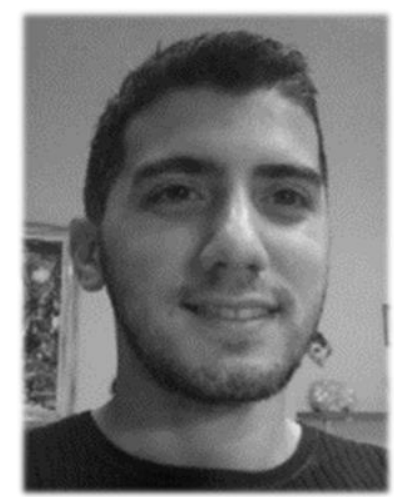

Mr. Vittorio Ferrara received his B.Sc. degree in Chemistry (2013) and M.Sc. degree in Biomolecular Chemistry (2016) from University of Palermo and University of Catania (Italy), respectively. He is currently a Ph.D. student in Materials Science and Nanotechnology under the supervision of Prof. B. Pignataro and of Prof. G. Marletta. His research focuses on the development of new functional interfaces for applications in biotechnology and biosensing.

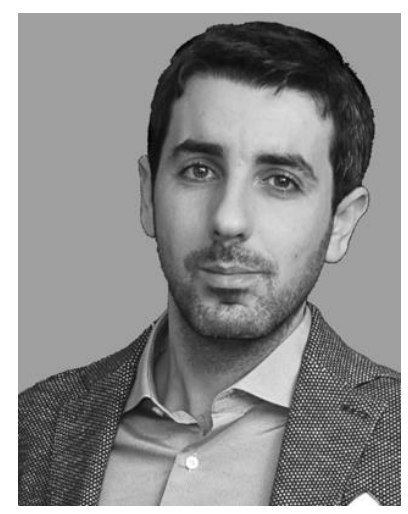




\section{WILEY-VCH}

Dr. Aurelio Bonasera received his B.Sc. and M.Sc. in Chemistry from the University of Messina. He pursued his Ph.D. in Chemistry at the University of Trieste under the supervision of Prof. M. Prato. He was appointed Erasmus-fellow at the University of Mons. He underwent his postdoctoral training as MSCA-fellow at Humboldt-Universität zu Berlin under the supervision of Prof. Stefan Hecht; then, he was Visiting Scientist at University College London and BASF SE. He is currently a Researcher at the University of Palermo. His research interests include dyes, photochromic compounds and supramolecular architectures for light harvesting.

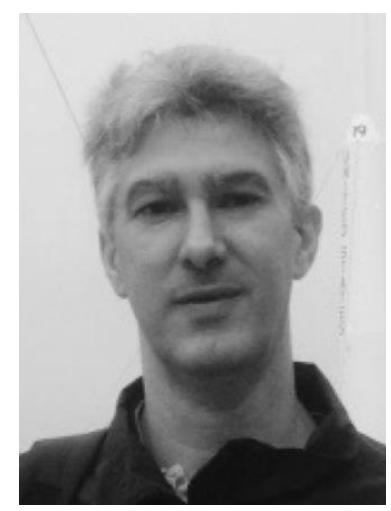

Prof. Bruno Pignataro obtained his Ph.D. degree in Materials Science from the University of Catania. He is a Full Professor of Physical Chemistry at the University of Palermo. He is referee and editorial board member for different international journals and expert evaluator for national and international research proposals. He is the Project Leader of the District of High Technology for innovation in the field of Cultural Heritage in Sicily, and the Delegate for Project Planning at the Department of Physics and Chemistry in Palermo. His research interests are in the topics of nanotechnology, molecular surfaces, plastic electronics, and biotechnology. 


\section{WILEY-VCH}

Printing Biology employs different technologies dispensing molecular inks with tunable composition (molecules, polymers, biomolecules) and drop sizes (from nano- up to macroscale) onto solids or into liquids to develop life-like or life-inspired artificial biosystems (from small condensates, to compartments up to networks, tissues and organs). This work reviews the extraordinary potential of this emerging research field.

\section{Keyword: Printing Artificial Biosystems}

G. Arrabito, V. Ferrara, A. Bonasera, B. Pignataro*

\section{Title: Artificial Biosystems by Printing Biology}

ToC figure

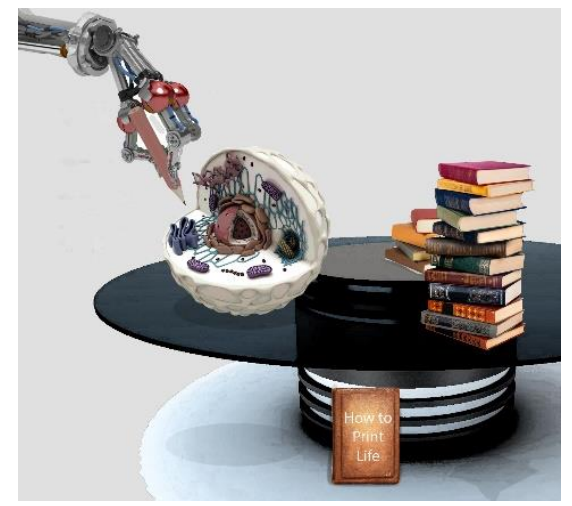

